UNIVERSIDADE DE SÃO PAULO

FACULDADE DE FILOSOFIA, CIÊNCIAS E LETRAS DE RIBEIRÃO PRETO PROGRAMA DE PÓS-GRADUAÇÃO EM PSICOLOGIA

\title{
CARACTERÍSTICAS PSICOLÓGICAS DE CARDIOPATAS CRÔNICOS E EM PRIMEIRO EVENTO CARDÍACO EM CONTEXTO DE EMERGÊNCIA
}

\author{
Aline Cristina Antonechen
}

Orientadora: Profa. Dra. Sonia Regina Pasian

Ribeirão Preto - SP 
FACULDADE DE FILOSOFIA, CIÊNCIAS E LETRAS DE RIBEIRÃO PRETO PROGRAMA DE PÓS-GRADUAÇÃO EM PSICOLOGIA

\title{
CARACTERÍSTICAS PSICOLÓGICAS DE CARDIOPATAS CRÔNICOS E EM PRIMEIRO EVENTO CARDÍACO EM CONTEXTO DE EMERGÊNCIA
}

\begin{abstract}
Aline Cristina Antonechen
Dissertação apresentada ao Programa de Pós-Graduação em Psicologia da Faculdade de Filosofia, Ciências e Letras de Ribeirão Preto da Universidade de São Paulo, como parte das exigências para obtenção do Título de Mestre em Ciências: Área Psicologia (Área de Concentração: Psicologia em Saúde e Desenvolvimento).
\end{abstract}

Orientadora: Profa. Dra. Sonia Regina Pasian

Ribeirão Preto - SP 
Autorizo a reprodução e divulgação total ou parcial deste trabalho, por qualquer meio convencional ou eletrônico, para fins de estudo e pesquisa, desde que citada a fonte.

Antonechen, Aline Cristina

Características Psicológicas de cardiopatas crônicos e em primeiro evento cardíaco em contexto de emergência. Ribeirão Preto, 2019.

$149 \mathrm{f}$.

Dissertação de Mestrado, apresentada à Faculdade de Filosofia, Ciência e Letras de Ribeirão Preto/USP. Área de concentração: Psicologia em Saúde e Desenvolvimento

Orientadora: Pasian, Sonia Regina

1. Avaliação Psicológica. 2. Cardiologia. 3. Medicina de Urgência e Emergência 
Nome: Aline Cristina Antonechen

Título: Características psicológicas de cardiopatas crônicos e em primeiro evento cardíaco em contexto de emergência

\author{
Dissertação apresentada ao Programa de Pós- \\ Graduação em Psicologia da Faculdade de \\ Filosofia, Ciências e Letras de Ribeirão Preto da \\ Universidade de São Paulo, como parte das \\ exigências para obtenção do Título de Mestre em \\ Ciências: Área Psicologia (Área de Concentração: \\ Psicologia em Saúde e Desenvolvimento).
}

Aprovado em:

Banca Examinadora

Prof. Dr.

Instituição:

Assinatura:

Prof. Dr.

Instituição:

Assinatura:

Prof. Dr.

Instituição:

Assinatura: 
À minha família, por todo o amor investido em todos os momentos, Aos meus pacientes, por dividirem seus "tesouros internos" e me ensinarem tanto. 


\section{Agradecimentos}

Primeiramente, a Deus, pela oportunidade de desenvolvimento profissional e pessoal. O amparo e proteção oferecidos pela fé é o que me deram forças para continuar em muitos momentos.

Aos meus pais, Maria das Graças e Ivan (in memorian), por serem meus alicerces e me nutrirem com amor incondicional. Seus investimentos, os ensinamentos transmitidos e o suporte constante é que me permitiram chegar até aqui. Obrigada pela paciência, pelo carinho e por estarem sempre ao meu lado.

Ao meu irmão, Johann, que me incentiva, protege e compartilha comigo o que tem de melhor desde que eu nasci. Ter um irmão é ter um companheiro para toda a vida e sou muito grata por isso. Agradeço a minha cunhada Layla e sobrinha Laura, que também fazem parte da minha amada família.

Ao meu namorado, Maurício, por estar sempre presente, mesmo nos momentos mais difíceis. $\mathrm{O}$ amor e companheirismo construídos na nossa relação foram essenciais nessa jornada, tornaram esse caminho muito mais florido. E aos seus pais, pela torcida e energias positivas.

À Profa. Dra. Sonia Regina Pasian, pela orientação desse trabalho e por todos os ensinamentos transmitidos. Nesse processo, consegui compreender que o papel do docente vai muito além de ensinar os conhecimentos técnicos da área, é também ajudar o aluno a desenvolver o melhor de si. Obrigada por fazer isso de forma tão precisa e com tanto carinho e cuidado. Obrigada!

Aos meus familiares e amigos, pelo amor que dividimos e por compreenderem e me preencherem de afetos mesmo com minhas ausências frequentes, seja pela distância ou pela falta de tempo imposta pela rotina.

Às profissionais que participaram da minha formação profissional. Em especial à minha preceptora de Residência Multiprofissional do HC-UFPR Psicóloga Dra. Maribel Pelaez Dóro, que me acolheu de maneira tão doce em seu serviço e me ensinou a amar a prática da Psicologia e a Psicologia Hospitalar. E à Profa. Dra. Lucia Cecília da Silva, que me orientou em Iniciações Científicas em boa parte da minha graduação e me introduziu aos primeiros passos da pesquisa científica. 
Às minhas principais companheiras de apartamento, Jaíne e Fernanda, por cuidarem de mim e pelo vínculo afetivo que criamos enquanto morávamos juntas. Residindo a tantos quilômetros de distância das nossas famílias, é muito reconfortante ter amigas para dividir as contas, as alegrias, as tristezas, o almoço de final de semana e inclusive nossa maior riqueza, o nosso cachorro Théo. Agradeço a Laís, que também pode morar conosco e dividir seus afetos por um bom período.

Aos colegas do Centro de Pesquisas em Psicodiagnóstico (CPP), por serem uma rede de apoio profissional importante, compartilhando conhecimentos teóricos, oferecendo suporte sempre que necessário e dividindo as alegrias e angústias da pós-graduação. Em especial à Maíra, pela paciência e por me acudir nos momentos em que eu mais precisava.

À Aline Araújo Morais e sua família, pessoas de um coração incrível que me acolheram e ajudaram muito para que eu conseguisse concluir a coleta de dados desse trabalho.

À Unidade de Emergência HCFMRP-USP, onde ingressei há quatro anos e tenho o prazer de exercer minhas atividades profissionais. A ideia e execução desse trabalho foram possíveis graças a essa instituição, que abriu suas portas e me permite desenvolver habilidade e afetos diariamente.

Ao Serviço de Psicologia da Unidade de Emergência HCFMRP-USP, pelo incentivo e suporte durante o meu período e pós-graduação e pelas trocas profissionais valiosas. Em especial, à psicóloga Hellen, minha colega de Sala de Urgência, pela nossa parceria. Aos pacientes da Unidade Coronariana da UE HCFMRP-USP, por aceitarem compartilhar comigo suas histórias de vida e confiar a mim seus afetos, dúvidas e angústias. A experiência de atendê-los me transforma de maneira única. 


\title{
PARADA CARDÍACA
}

\author{
Essa minha secura \\ Essa falta de sentimento \\ Não tem ninguém que segure, \\ Vem de dentro. \\ Vem da zona escura \\ Donde vem o que sinto \\ Sinto muito, \\ Sentir é muito lento. \\ (Paulo Leminski)
}




\section{RESUMO}

As doenças cardíacas estão entre as mais prevalentes no mundo, com elevado índice de morbidade e mortalidade. Essas patologias são atendidas em diversos contextos, inclusive em situações de urgência e emergência médicas, em eventos agudos. Diversas áreas profissionais se propõem a estudar fatores associados ao adoecimento cardíaco, incluindo a Psicologia, que procura compreender componentes psicológicos envolvidos no processo de adoecimento e recuperação desses indivíduos. Este trabalho teve por objetivo caracterizar e comparar indicadores de depressão, ansiedade, vivência de afetos e características psicodinâmicas de pacientes em primeiro evento cardíaco e cardiopatas crônicos atendidos em contexto de emergência em relação a indivíduos não pacientes. A amostra de conveniência foi composta por 80 adultos voluntários distribuídos em dois grupos de 40 participantes, com idade média de 62,7 $( \pm 5,5)$ anos, escolaridade média de $6,6( \pm 4,1)$ anos de estudo, sendo metade pacientes internados (Grupo Clínico=G1, $\mathrm{n}=40$ ) em Unidade Coronariana de Unidade de Emergência de hospital universitário público de referência do interior do Estado de São Paulo, com 28 homens (70\%). Os demais voluntários constituíram o Grupo de Comparação (G2, n=40), pareados em relação a G1 quanto ao sexo e balanceados quanto à idade, escolaridade e nível econômico. Foram examinados individualmente por um conjunto de instrumentos de avaliação psicológica, aplicados e avaliados conforme respectivos padrões técnicos, incluindo Questionário sociodemográfico e clínico, Questionário sobre a Saúde do Paciente (PHQ-9), Inventário Ansiedade de Beck (BAI), Escala de Afetos (EA), Teste de Zulliger e Teste das Pirâmides Coloridas de Pfister (TPC). Os resultados obtidos foram analisados em termos descritivos (medidas de tendência central e variabilidade) e comparativos, recorrendo-se aos testes $t$ de Student, Qui-Quadrado $\left(X^{2}\right)$, ANOVA e Regressão Logística, conforme o tipo de variável e os grupos examinados, com nível de significância de 5\%. Os dados apontaram média significativamente mais elevada de indicadores de depressão (PHQ-9) em G1 $(6,40 \pm 6,60)$ do que em G2 $(2,17 \pm 3,10)$. Os indicadores médios de ansiedade (BAI) também foram estatisticamente mais elevados em G1 $(10,37 \pm 9,40)$ em relação ao G2 $(3,87 \pm 4,80)$. Em relação a vivência de afetos, houve predomínio dos afetos positivos nos dois grupos ( $\mathrm{G} 1=41,4 \pm 7,2$ e $\mathrm{G}=44,3 \pm 5,5)$, contudo verificou-se diferença estatisticamente significativa nos afetos negativos, sendo mais intensa em G1 $(27,6 \pm 9,5)$ do que em G2 $(23,4 \pm 8,7)$. No Teste de Zulliger, foram encontradas algumas particularidades, porém com valor interpretativo reduzido, por serem variáveis isoladas. E no TPC foram encontrados dados semelhantes em G1 e G2,

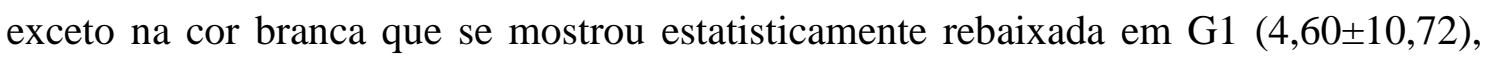
em comparação ao G2 $(6,60 \pm 7,30)$ e ao grupo normativo $(8,3 \pm 7,1)$. Consequentemente, houve rebaixamento na Síndrome Incolor em G1 $(8,5 \pm 6,4)$ em relação a G2 $(13,6 \pm 12,2)$ e ao grupo normativo $(15,8 \pm 10,0)$, sinalizando menos recursos estabilizadores internos. Verificou-se também que o uso do marrom foi elevado em G1 $(6,76 \pm 7,27)$ e em G2 $(7,21 \pm 11,92)$ em relação ao grupo normativo $(4,0 \pm 5,0)$, sendo esta cor associada a mecanismos de defesa mais primitivos. Em síntese, verificou-se que os indicadores de ansiedade, depressão e vivência de afetos negativos foram mais elevados em G1, com sinais de rebaixamento de elementos estabilizadores na dinâmica psíquica entre 
cardiopatas. Não foram identificadas relevantes especificidades de funcionamento psíquico em função do sexo ou da cronicidade da cardiopatia, embora algumas variáveis tenham se mostrado clinicamente importantes para a prática clínica de cuidados com adultos no contexto de emergência cardiológica.

Palavras-chave: Avaliação Psicológica, Cardiopatia, Métodos Projetivos, Medicina de Urgência e Emergência. 


\begin{abstract}
$\underline{\text { ABSTRACT }}$
Cardiac diseases are along the most prevalent health issues in the world, with high incidence of morbidity and mortality associated with them. Diverse health care contexts can provide attention to these pathologies, including emergency and urgency services, during acute events. Many health professionals study the involvement of different factors with cardiopathy, including Psychology, that focus on psychological components associated with illness development and recovery of these patients. This work aims to describe and compare levels of depression, anxiety, affective functioning and psychodynamic functioning of patients in its first cardiac event or with chronic cardiopathy, attended in a emergency health facility, relatively to nonpatients. The convenience sample was comprised of 80 voluntary participants, distributed in two groups of 40, with mean age of 62,7 ( $\mathrm{SD}=5,5)$, mean years of education of 6,6 years $(\mathrm{SD}=4,1)$, with the clinical group (G1) constituted by inpatients at the Coronarian Unity of an school hospital in Brazil, 70\% of them male. The nonclinical group (G2) was paired to G1 in terms of age, and balanced in relation with education and socioeconomical status. All participants were assessed individually through psychological assessment measures, using its standard procedures for administration. Measures included the Patient Health Questionnaire (PHQ-9), Beck Anxiety Inventory (BAI), Scale of Affects (EA), Zulliger Inkblot Method and Pfister's Colored Pyramids Test. Results were analyzed for descriptive and comparative measures, using Student's $\mathrm{t}$ test, chi-square, ANOVA and Logistic Regression analysis, depending on the type of variable and groups examined. Significance level of 5\% were considered for all analysis. Data indicate a higher mean score of depression (PHQ-9) in G1 $(6,40 \pm 6,60)$, when compared to G2 $(2,17 \pm 3,10)$. Difference of mean scores of anxiety (BAI) were also statistically significant, indicating higher levels in clinical group $(10,37 \pm 9,40)$, in comparison with nonclinical sample $(3,87 \pm 4,80)$. The affective functioning showed prevalence of positive affects in both groups $(\mathrm{G} 1=41,4 \pm 7,2$, and $\mathrm{G} 2=44,3 \pm 5,5)$, however, groups varied significantly in the experience of negative affects, that presented higher levels in G1 $(27,6 \pm 9,5)$, comparatively with G2 $(23,4 \pm 8,7)$. In the Zulliger Inkblot Method, a few variables presented particular differences, but the interpretative values were not relevant considering its low frequency. In Pfister's Colored Pyramids Test, similar results were find in both groups, with exception of white color, that was significantly lower in G1 $(4,60 \pm 10,72)$, in relation to $\mathrm{G} 2(6,60 \pm 7,30)$ and normative data $(8,3 \pm 7,1)$. As a consequence, lower indication of uncolored syndrome were found in $\mathrm{G} 1(8,5 \pm 6,4)$ in relation to $\mathrm{G} 2(13,6 \pm 12,2)$ and to normative sample $(15,8 \pm 10,0)$, signaling less internal affective resources for stabilize emotions. The use of the color brown was also elevated in G1 $(6,76 \pm 7,27)$ and $G 2(7,21 \pm 11,92)$, in relation with normativedata $(4,0 \pm 5,0)$. This color is frequently associated with primitive defense mechanisms. In summary, levels of anxiety and depression and negative affective experience were higher in clinical group, with signs of diminished resources for stabilizing psychic dynamics in cardiopathy patients. There were no differences regarding psychological functioning in relation to gender or chronicity of the disease,
\end{abstract}


although some variables were clinically relevant to be considered in clinical practice with patients with acute cardiac events.

Keywords: Psychological Assessment, Cardiopathy, Projective Methods, Emergency and Urgency Medicine. 


\section{LISTA de ABREVIATURAS E SIGLAS UTILIZADAS}

AAS - Ácido Acetilsalicílico

ABEP - Associação Brasileira de Estudos Populacionais

AN - Afetos Negativos

ASDS - Acute Stress Disorder Scale

BAI - Beck Anxiety Inventory

BAVT - Bloqueio Átrio Ventricular

BDI - Beck Depression Inventory

BFP - Bateria Fatorial de Personalidade

Brief-IPQ - Life Orientation Test Revised e Brief Illness Perception Questionnaire

BSI - Brief Symptom Inventory

BVS - Biblioteca Virtual em Saúde

CAg - Conteúdo Agressivo

CBA-H - Cognitive Behavioural Assessment Form Hospital Baterry

CES-D - Center for Epidemiological Studies Depression

CFM - Conselho Federal de Medicina

CID - Classificação Internacional de Doenças

CISS - Coping Inventory for Stressful Situations

CPP - Centro de Pesquisas em Psicodiagnóstico

CSD - Cardiac Depression Scale

CTI - Centro de Terapia Intensiva

DAC - Doença Arterial Coronariana

DCNT - Doença Crônica Não Transmissível

DCV - Doença Cardiovascular

DeCS - Descritores em Ciências da Saúde

DP - Desvio Padrão

DRS XIII - Departamento Regional de Saúde XIII

DS14 - Type-D-Scale-16

DSM IV - Diagnostic and Statistical Manual of Mental Disorders IV

EA - Escala de Afetos

ECR - Experiences in Close Relationships

ESC - Escala de Sensações Corporais 
FFCLRP - Faculdade de Filosofia, Ciência e Letras de Ribeirão Preto

HADS - Hospital Anxiety and Depression Scale

HAI - Health Anxiety Inventory

Ham-D - Hamilton Depression Scale

HC FMRP - Hospital das Clínicas da Faculdade de Medicina de Ribeirão Preto

HC UFPR - Hospital de Clínicas da Universidade Federal do Paraná

HNT - Habits of Nervous Tensions

HPPQ - Social Inhibition Scale of Heart Patients Psychological Questionnaire

IAM - Infarto Agudo do Miocárdio

IAM NE - Infarto Agudo do Miocárdio Não Específico

IC - Insuficiência Cardíaca

ICC - Insuficiência Cardíaca Congestiva

ICFER - Insuficiência Cardíaca com Fração de Ejeção Reduzida

IDS-SR - Inventory of Depressive Symptomatology

IS - Inibição Social

KCCQ - Kansas City Cardiomyopathy Questionnaire

LILACs - Literatura Latino-americana e do Caribe em Ciências da Saúde

MBHI - Millon Behavior Health Inventory

MC - Marlowe-Crowne Scale

MCP - Miocardiopatia

MEEM - Mini Exame de Estado Mental

MG - Minas Gerais

MHLCS - Multidimensional Health Locus of Control Scales

MINI - Mini International Neuropsychiatric Interview

OMS - Organização Mundial da Saúde

OR - Odds Ratio

PAg - Passado Agressivo

PCL-C - Posttraumatic Stress Disorder Checklist-Civilian Version

PECA - Principais Eventos Cardíacos Adversos

PHQ - Patient Health Questionnaire

PSWQ - Penn State Worry Questionnaire

QAC - Questionário de Ansiedade Cardíaca

RJ - Rio de Janeiro

RUE - Rede de Atenção às Urgências e Emergências 
SAMU - Serviço de Atendimento Móvel de Urgência

SCA - Síndrome Coronariana Aguda

SPIN - Social Phobia Inventory

SP - São Paulo

SPSS - Statistical Package for Social Sciences

SQ - Symptom Questionnaire

STAI - State Trait Anxiety Inventory

SST - Supra desnivelamento do Segmento T

SUS - Sistema Único de Saúde

TABP - Type A Behavior Pattern

TAS-20 - 20-item Toronto Alexithymia Scale

TCLE - Termo de Consentimento Livre e Esclarecido

TEPT - Transtorno de Estresse Pós-Traumático

UCo - Unidade Coronariana

UE - Unidade de Emergência

UEM - Universidade Estadual de Maringá

UPA - Unidade de Pronto-Atendimento

USP - Universidade de São Paulo

VCF - Variabilidade de Frequência Cardíaca 


\section{LISTA de FIGURAS}

Figura 1. Percurso amostral do Grupo Clínico $(\mathrm{G} 1, \mathrm{n}=40)$.........................................64

Figura 2. Percurso amostral do Grupo de Comparação $(\mathrm{G} 2, \mathrm{n}=40)$...........................66 


\section{LISTA de TABELAS}

Tabela 1. Caracterização sociodemográfica da amostra e sua comparação estatística em função dos grupos. .67

Tabela 2. Caracterização da amostra em função dos hábitos de vida...........................79

Tabela 3. Caracterização da amostra em função de patologias......................................8

Tabela 4. Caracterização da amostra em relação ao uso de medicamentos..................81

Tabela 5. Distribuição dos sintomas relatados pelo grupo clínico $(G 1, n=40) \ldots \ldots \ldots . . .83$

Tabela 6. Frequência e análise estatística do diagnóstico principal do grupo clínico $(G 1, n=40)$ em função do perfil da patologia (primeiro evento ou crônico) .84

Tabela 7. Diagnóstico da internação atual do grupo clínico $(G 1, n=40)$ subdivido entre pacientes de primeiro evento cardíaco $(n=22)$ e cardiopatas crônicos $(n=18)$

Tabela 8. Indicadores de depressão (PHQ-9) e ansiedade (BAI) e sua comparação estatística entre os grupos

Tabela 9. Níveis de ansiedade (BAI) e sua comparação estatística entre os grupos.....87

Tabela 10. Níveis de depressão (PHQ-9) e de ansiedade (BAI) e sua comparação estatística entre os grupos.

Tabela 11. Níveis de depressão (PHQ-9) e de ansiedade (BAI) e sua comparação estatística em função do sexo dos participantes dos grupos.

Tabela 12. Níveis de depressão (PHQ-9) e de ansiedade (BAI) e sua comparação estatística em função da cronicidade (ou não) da cardiopatia entre os grupos.....

Tabela 13. Indicadores da Escala de Afetos (EA) e sua comparação estatística em função dos grupos.

Tabela 14. Indicadores da Escala de Afetos (EA) e sua comparação estatística em função do sexo dos participantes dos grupos.

Tabela 15. Indicadores da Escala de Afetos (EA) e sua comparação estatística em função da cronicidade (ou não) da cardiopatia entre os grupos.

Tabela 16. Índices de produtividade e ritmo no Teste de Zulliger em função dos grupos .93

Tabela 17. Modos de apreensão no Teste de Zulliger em função dos grupos...... .94

Tabela 18. Determinantes das respostas no Teste de Zulliger em função dos grupos...95

Tabela 19. Conteúdos das respostas no Teste de Zulliger em função dos grupos..........96 
Tabela 20. Tipos Vivenciais e Fórmula da Angústia no Teste de Zulliger em função dos grupos.

.98

Tabela 21. Principais variáveis do Teste de Zulliger e sua comparação estatística em função do sexo dos participantes dos grupos.

Tabela 22. Principais indicadores do Teste de Zulliger e sua comparação estatística em função da cronicidade (ou não) da cardiopatia entre os grupos. 100

Tabela 23. Cores e síndromes cromáticas no Teste de Pfister e sua comparação estatística em função dos grupos.

Tabela 24. Fórmula Cromática do Teste Pfister e sua comparação estatística em função dos grupos.

Tabela 25. Indicadores da execução, colocação e aspecto formal das pirâmides do Teste de Pfister e sua comparação em função dos grupos.

Tabela 26. Cores e Síndromes Cromáticas do Teste de Pfister e sua comparação estatística em função do sexo dos participantes 106

Tabela 27. Fórmula Cromática do Teste de Pfister e sua comparação estatística em função do sexo dos participantes.

Tabela 28. Execução, colocação e aspecto formal das pirâmides no Teste de Pfister e sua comparação estatística em função do sexo dos participantes. 109

Tabela 29. Cores e Síndromes Cromáticas no Teste de Pfister e sua comparação estatística em função da cronicidade (ou não) da cardiopatia entre os grupos. 110

Tabela 30. Fórmula Cromática do Teste de Pfister e sua comparação estatística em função da cronicidade (ou não) da cardiopatia

Tabela 31. Execução, colocação e aspecto formal das pirâmides no Teste de Pfister e sua comparação estatística em função da cronicidade (ou não) da cardiopatia 


\section{SUMÁRIO}

1. Apresentação. .28

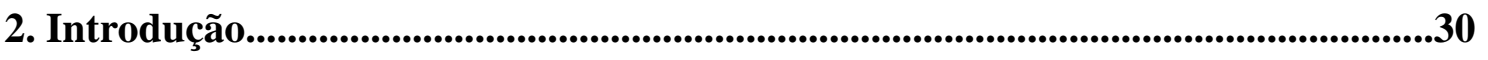

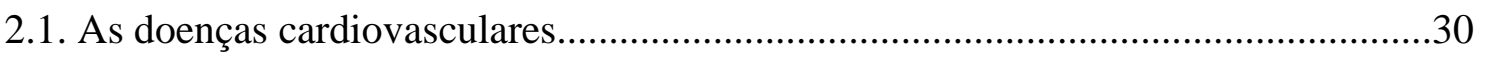

2.2. Atenção hospitalar em Urgência e Emergência em Cardiologia...............................32

2.3. Avaliação Psicológica na área da Cardiologia...........................................................35

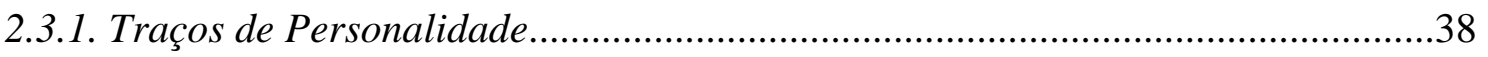

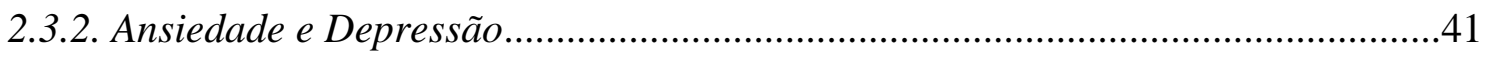

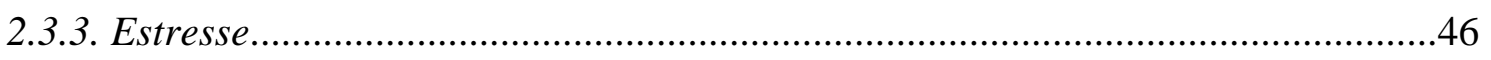

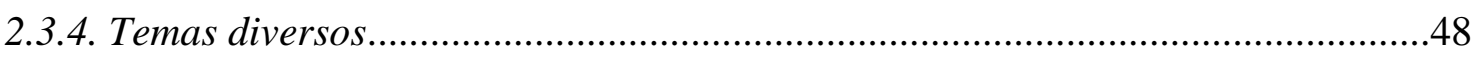

2.3.5. Pesquisas realizadas no contexto brasileiro ......................................................50

2.4. Métodos projetivos de avaliação psicológica na área da Cardiologia......................52

2.5. Síntese dos fundamentos sobre avaliação psicológica em Cardiopatia....................55

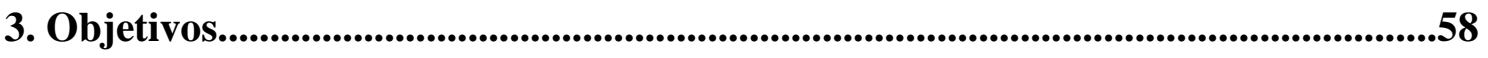

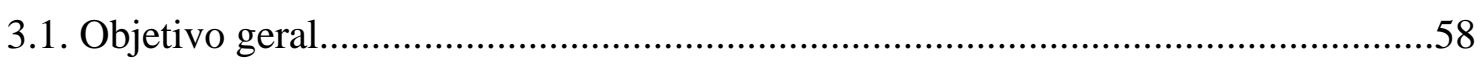

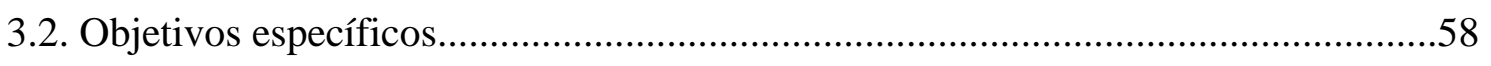

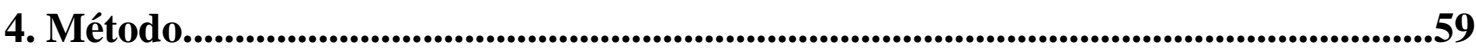

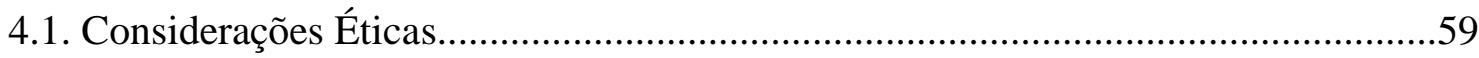

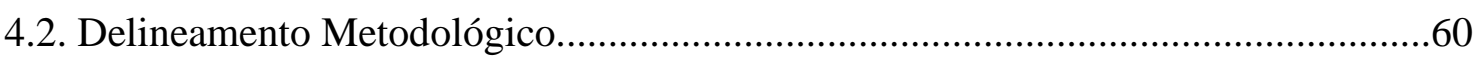

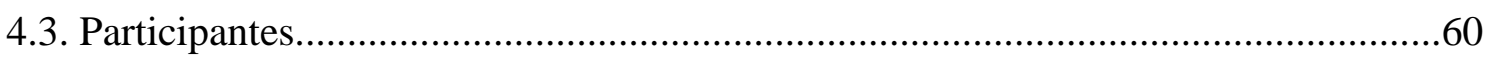

4.3.1. Contexto Institucional e Percurso amostral do Grupo Clínico (G1) ....................62

4.3.2. Percurso amostral do grupo de Comparação (G2) .............................................65

4.3.3. Caracterização dos participantes.......................................................................66

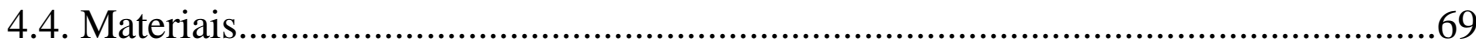

4.4.1. Termo de Consentimento Livre e Esclarecimento (TCLE) .................................69

4.4.2. Questionário sociodemográfico e clínico ..............................................................69

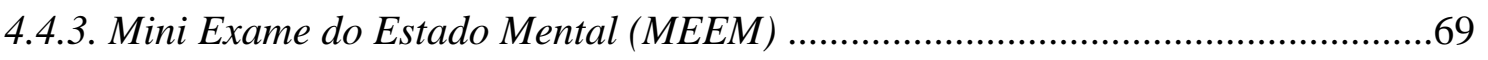

4.4.4. Questionário sobre Saúde do Paciente (Patient Health Questionnaire-9 - PHQ-9)

4.4.5. Inventário de Ansiedade de Beck (Beck Anxiety Inventory - BAI) .......................70 


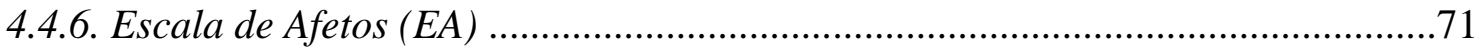

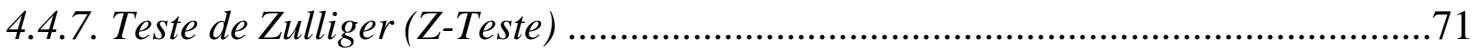

4.4.8. Teste das Pirâmides Coloridas de Pfister...........................................................73

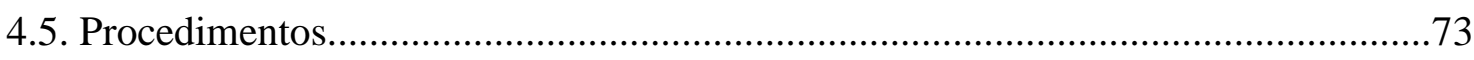

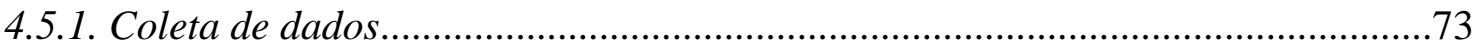

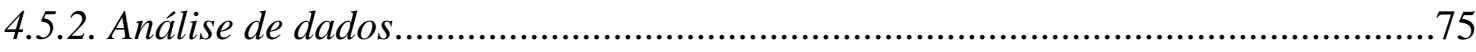

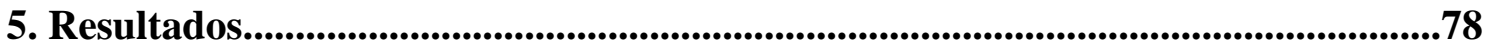

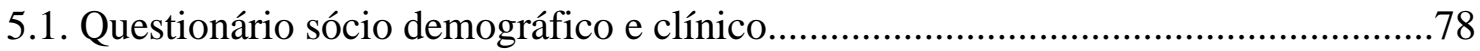

5.2. Patient Health Questionnaire-9 (PHQ-9) e Beck Anxiety Inventory (BAI).........86

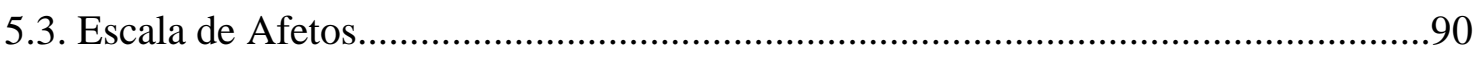

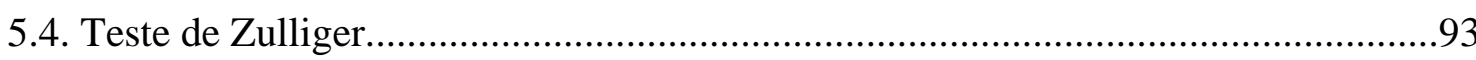

5.5. Teste das Pirâmides Coloridas de Pfister..................................................................102

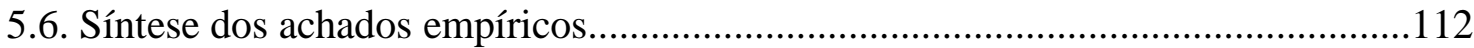

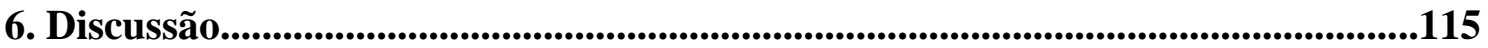

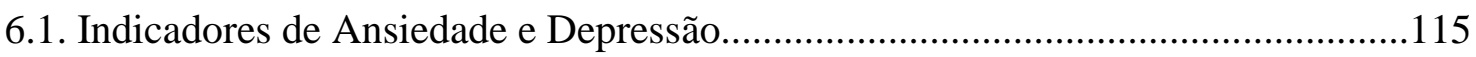

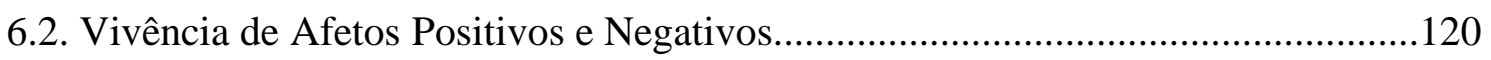

6.3. Funcionamento cognitivo e afetivo avaliado por métodos projetivos....................122

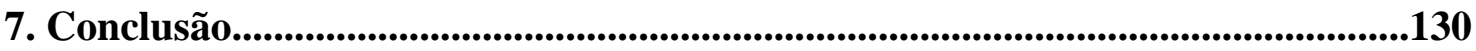

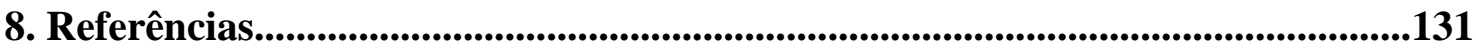

9. Anexos e Apêndices.......................................................................................139 


\section{APRESENTACÃO}

Ao iniciar esse trabalho faz sentido descrever, em poucas palavras, o percurso até a ele chegar. Realizei graduação em Psicologia pela Universidade Estadual de Maringá (UEM) no período de 2008 a 2013e logo em seguida fiz a Residência Multiprofissional em Atenção Hospitalar, na Área de Concentração Oncologia e Hematologia, no Hospital de Clínicas da Universidade Federal do Paraná (HC UFPR) nos anos 2014 e 2015. Nesse período, tive intensa vivência na área hospitalar, na pesquisa em Psicologia no contexto hospitalar e em experiências do processo de adoecimento de pacientes acometidos por patologias crônicas não transmissíveis.

Em 2014, prestei concurso para Agente Técnico em Saúde (psicólogo) no Hospital das Clínicas da Faculdade de Medicina de Ribeirão Preto (HC FMRP - USP), ao qual fui convocada no ano de 2015. Ao ingressar, fui alocada na Unidade de Emergência (UE), local em que permaneço até o momento, atuando como psicóloga de referência da Clínica Médica e da Unidade Coronariana (UCo), de onde surgiu meu interesse no presente trabalho.

Em minha experiência na assistência aos pacientes cardiológicos atendidos na UCo, sempre foi forte a impressão de existirem componentes psicológicos específicos na maneira daqueles indivíduos lidarem com o adoecimento e a hospitalização, com similaridades entre os usuários do serviço, mesmo sendo tão distintos em suas histórias. Fiz algumas investigações na literatura científica da área, supri muitas dúvidas, mas ainda restavam alguns questionamentos. Assim, surgiu o interesse em identificar e compreender elementos da psicodinâmica desses pacientes, utilizando a avaliação psicológica como processo para alcançar esse objetivo. A proposta seria identificar variáveis do funcionamento psíquico dos pacientes cardiológicos que pudessem influenciar no processo de saúde e doença, desde o diagnóstico da patologia, ao enfrentamento da hospitalização e posterior adesão ao tratamento. Assim, seria possível pensar em futuras intervenções para auxiliar esses pacientes em processo de préreabilitação cardíaca no campo da Psicologia.

O presente trabalho foi organizado de forma didática, a fim de contextualizar o leitor sobre a pesquisa realizada. Neste primeiro capítulo apresentei minha trajetória enquanto pesquisadora e meu interesse no estudo. No segundo capítulo, tem-se um panorama geral da literatura científica da área, onde são definidos os principais 
conceitos utilizados, com achados na área da Psicologia em interface com a Cardiologia, acompanhada da justificativa do trabalho.

O terceiro capítulo expõe o objetivo geral do estudo e seus objetivos específicos, ou seja, o que se espera com a pesquisa. No quarto capítulo é apresentado o método, descrevendo o delineamento do estudo, seu planejamento e execução, incluindo os cuidados éticos realizados.

No quinto capítulo são apresentados os resultados, procurando-se acompanhar a ordem dos objetivos propostos para essa investigação científica. O sexto capítulo, por sua vez, procurar discutir esses achados empíricos à luz da literatura científica da área, oferecendo suporte para a conclusão do trabalho. Na sequência são listadas as referências utilizadas nessa pesquisa, seguindo-se apêndices e anexos citados durante esse material. 


\section{INTRODUCÃO}

\subsection{As doenças cardiovasculares}

A Organização Mundial de Saúde (OMS - World Health Organization, 2017a) define as doenças cardiovasculares como aquelas que acometem coração e vasos sanguíneos, ou seja, doenças arteriais coronarianas, doenças cerebrovasculares, doenças reumáticas, dentre outras. As doenças cardiovasculares são as principais causas de morte em todo o mundo, com estimativa de 17,7 milhões de óbito em 2015, representando $31 \%$ das mortes globais. Deste conjunto 7,4 milhões de mortes são atribuídas especificamente às doenças cardíacas, aquelas que acometem exclusivamente o coração (American Heart Association Statistics Committee and Stroke Statistics Subcommittee, 2014).

O Brasil apresenta números elevados em relação a mortes por doenças cardíacas. Em 2017 foram contabilizados 191.895 óbitos por doenças cardíacas sendo 49\% (94.114 casos) registrados na Região Sudeste. Dentre as Unidades Federativas, São Paulo corresponde a 55\% (51.953 óbitos) desse total, sendo o estado com a maior taxa de mortalidade por essa causa (DATASUS, 2019). Além disso, as doenças cardíacas também estão fortemente associadas às morbidades. No ano de 2018, foram registradas 572.981 internações por complicações cardíacas, as quais se concentram na faixa etária entre 50 a 79 anos, que conta com 70,6\% dos registros, correspondendo a 404.848 internações. Em relação ao sexo, os homens apresentaram maior prevalência de internação por doenças cardíacas, atingindo a cifra de 56\% (322.617 registros) (DATASUS, 2019). De acordo com dados divulgados pelo Ministério da Saúde, no Brasil cerca de 300 mil pessoas sofrem infarto por ano e 30\% (90 mil casos) desses ataques cardíacos são fatais (Brasil, 2017). Outras 210 mil pessoas passam a serem considerados cardiopatas crônicos e necessitam de acompanhamento médico durante toda a vida.

As doenças cardíacas podem ser congênitas, em que a pessoa nasce com alguma má formação específica, ou desenvolver-se ao longo da vida. Alguns fatores podem aumentar o risco de desenvolvimento dessas patologias, dentre eles tabagismo, inatividade física, alimentação rica em gorduras, sobrepeso e obesidade, histórico familiar, colesterol alto, pressão alta e diabetes mellitus (American Heart Association, 2017; Sociedade Brasileira de Cardiologia, 2013). Algumas patologias também podem 
aumentar a predisposição a doenças cardíacas, como a Síndrome de Marfan e Síndrome de Down (Almeida \& Ribeiro, 2008).

Há inúmeras doenças cardíacas e entre as mais comuns estão as Síndromes Coronarianas Agudas (SCA), a Valvulopatia, a Insuficiência Cardíaca, a Doença Arterial Coronariana e o Bloqueio Atrioventricular (American Heart Association, 2017). A manifestação das cardiopatias pode se dar tanto pelo seu perfil crônico como por meio de um evento agudo.

A cardiopatia de perfil crônico está associada ao diagnóstico prévio dessa patologia. Uma vez diagnosticada, a cardiopatia acometerá o indivíduo por toda sua vida, exigindo acompanhamento clínico constante e cuidados específicos. A Portaria $\mathrm{n}^{\circ}$ 483 de $1^{\circ}$ de abril de 2014, que discorre acerca da Atenção à Saúde das Pessoas com Doenças Crônicas no Sistema Único de Saúde (SUS), define como doenças crônicas “(...) as doenças que apresentam início gradual, com duração longa ou incerta, que, em geral, apresentam múltiplas causas e cujo tratamento envolve mudanças no estilo de vida, em um processo de cuidado contínuo que, usualmente, não leva à cura" (Brasil, 2014). As doenças cardíacas são classificadas como Doenças Crônicas Não Transmissíveis (DCNT). Tais patologias podem causar impacto significativo na qualidade de vida e bem-estar subjetivo dos indivíduos, pelo impacto físico (cansaço, fadiga) e necessidade de mudanças de hábito de vida (American Heart Association, 2017; Andrade, 2009).

Já a manifestação aguda da cardiopatia pode ocorrer em dois contextos: a) em primeiro evento, em que o indivíduo manifesta sintomas característicos e ao procurar o serviço de saúde é diagnosticado com uma doença cardíaca; b) na alteração ou piora de quadro clínico prévio de cardiopatia. As principais doenças relacionadas aos eventos agudos são as Síndromes Coronarianas Agudas (SCA), caracterizadas pelo bloqueio súbito do sangue fornecido ao músculo cardíaco. Esse perfil é considerado uma emergência médica, uma vez que cada minuto que o coração passa sem ser suprido de sangue de maneira ideal causa danos irreversíveis e morte de células cardíacas. As SCA mais conhecidas são o Infarto Agudo do Miocárdio (IAM) e a Angina Instável, as quais atingem os maiores índices de mortalidade e morbidade entre as doenças cardíacas. Tais eventos agudos podem ocorrer tanto em indivíduos sem cardiopatia prévia como naqueles que já tem um diagnóstico cardíaco (American Heart Association, 2015).

A classificação das doenças cardíacas em perfil crônico ou agudo se dará mais pela forma como ela se manifesta do que pelo seu diagnóstico, como pode ser visto pela 
Diretriz Brasileira de Insuficiência Cardíaca Crônica e Aguda, elaborada pela Sociedade Brasileira de Cardiologia (2018). Nessa diretriz, a Insuficiência Cardíaca (IC) é definida como uma síndrome complexa em que o coração se torna incapaz de bombear sangue de forma adequada. Utiliza-se o termo Insuficiência Cardíaca Crônica para descrever o caráter persistente e progressivo dessa doença e a terminologia Insuficiência Cardíaca Aguda para se referir a alterações e sintomas que necessitam de intervenção de urgência (Sociedade Brasileira de Cardiologia, 2018).

O atendimento clínico voltado ao paciente com cardiopatia ocorre em diversas instâncias da rede de atenção à saúde. Há cuidados voltados à prevenção dos fatores de risco, em consultas periódicas para detecção precoce da doença, em atendimento ambulatorial para acompanhamento e controle da doença diagnosticada, em internações para compensação de quadro clínico ou em casos de agravos agudos, em contexto de emergência. Em função do foco do presente trabalho passa-se, a seguir, a elucidar essa última modalidade de assistência.

\subsection{Atenção hospitalar em Urgência e Emergência na Cardiopatia}

O atendimento em Urgência e Emergência no Sistema Único de Saúde (SUS) é caracterizado pela assistência a doenças e agravos agudos, com a finalidade de socorrer o sofrimento de pessoas acometidas por acidentes, violências e doenças cardiovasculares (Brasil, 2011a). Segundo o Conselho Federal de Medicina (CFM, 1995), "define-se por urgência a ocorrência imprevista de agravo à saúde com ou sem risco potencial de vida, cujo portador necessita de assistência médica imediata" e “define-se como emergência a constatação médica de condições de agravo à saúde que impliquem em risco iminente de vida ou sofrimento intenso exigindo, portanto, tratamento médico imediato" (Conselho Federal de Medicina, 1995, p. 1).

Há uma gama de serviços em saúde que atendem a esses agravos agudos, de acordo com a necessidade apresentada pelo paciente. Visando a organizar e qualificar a assistência oferecida, o Ministério da Saúde instaurou em julho de 2011 a Portaria $\mathrm{n}^{\circ}$ 1.600, na qual institui a Rede de Atenção às Urgências e Emergências (RUE) no SUS. Os componentes de assistência da RUE são: (I) Promoção, Prevenção e Vigilância em Saúde; (II) Atenção Básica em Saúde; (III) Serviço de Atendimento Móvel de Urgência (SAMU) e suas Centrais de Regulação Médica de Urgência; (IV) Sala de Estabilização; (V) Força Nacional de Saúde do SUS; (VI) Unidade de Pronto-Atendimento (UPA 24h) 
e o conjunto de serviços de urgência 24 horas; (VII) Hospitalar; (VIII) Atenção Domiciliar (Brasil, 2011a). Cada uma dessas esferas presta atendimento em Urgência e Emergência em situações distintas e em diferentes níveis de atenção, de acordo com a complexidade exigida.

Especificamente no que diz respeito à Atenção Hospitalar, a RUE preconiza que existam hospitais para atendimento ininterrupto de demandas espontâneas e referenciadas de urgências e emergências clínicas, pediátricas, cirúrgicas e/ou traumatológicas, obstétricas e em saúde mental. Tais hospitais devem atender a alguns critérios, estando entre eles oferecer ao menos uma das linhas de cuidado prioritária da RUE: (1) Linha de Cuidado Cardiovascular: Foco na Atenção ao Infarto do Miocárdio; (2) Linha de Cuidado Cerebrovascular: Foco na Atenção ao Acidente Vascular Cerebral; (3) Linha de Cuidado do Trauma: Foco de Atenção ao Politrauma; (4) Pediatria (Brasil, 2013). Sendo assim, os hospitais credenciados da RUE devem ter equipamentos e equipes em saúde para atendimento a essas demandas de alta complexidade. Os atendimentos em atenção hospitalar da RUE devem ser priorizados de acordo com a Classificação de Risco, que avalia o grau de sofrimento, agravo à saúde e risco iminente de óbito do paciente. A avaliação é realizada por equipe de médicos ou enfermeiros capacitados, mas o cuidado deve ser ofertado por equipe multiprofissional, capacitada para ouvir e averiguar as necessidades do paciente, suprindo-a na medida do possível (Brasil, 2011b; Conselho Federal de Medicina, 2014).

Ao focalizar especificamente o número de hospitalizações no Brasil nota-se que a proporção derivada de doenças cardíacas é considerada elevada. Segundo dados do DATASUS, em 2018 houve 579.590 internações em decorrência de complicações cardíacas, sendo 86,7\% (502.832 casos) em caráter de urgência. Na Região Sudeste do país, concentrou-se 44\% (254.302 internações) das hospitalizações por eventos cardíacos e os números mais expressivos foram do Estado de São Paulo, que corresponderam a 51,6\% (131.448 casos) dessas internações. Nessa Região, registrou-se 43\% (219.567 casos) das internações de urgência cardiológica, sendo metade dessas (110.849 internações) no Estado de São Paulo (DATASUS, 2019).

As internações de urgência e emergência devido a doenças cardíacas são relacionadas aos eventos agudos, sejam eles primeiro evento ou agudização de quadros crônicos. Nessas hospitalizações, principalmente por se tratar de eventos inesperados, os traços de personalidade do paciente poderão influenciar de maneira significativa em suas reações e na maneira como enfrentará o processo de adoecimento. Os recursos 
internos podem estar mais mobilizados, bem como os pacientes podem ficar mais regredidos emocionalmente, sendo necessário compreender o funcionamento psíquico para intervir de maneira eficaz (Almeida \& Ribeiro, 2008; Simonetti, 2016).

Ao pensar no cuidado integral a esses pacientes, diversas profissões dedicam-se ao estudo dos fatores associados às doenças cardíacas. No que concerne à Psicologia, há uma linha de estudos voltada para a investigação de características de personalidade e possível influência de fatores como ansiedade, depressão, estresse e demais transtornos de ordem psíquica no desenvolvimento da cardiopatia.

Nesse contexto, o psicólogo é inserido como um dos profissionais que pode oferecer técnicas e recursos exclusivos de sua profissão na assistência em Urgência e Emergência. Franco (2015) conceitua situações de emergência como:

\footnotetext{
"Um fenômeno ou acontecimento inesperado e desagradável por causar danos ou alterações na pessoa, nos bens, nos serviços ou no meio, que, apesar de ocasionar uma ruptura na normalidade do sistema, não excede a capacidade de resposta da comunidade afetada" (Franco, 2015, p. 31).
}

O olhar psicológico sobre as situações de emergência tende a priorizar o momento de crise vivenciado pelo paciente e seu núcleo social/familiar, no qual há brusca ruptura da rotina de vida em curso até então (Franco, 2015). No atendimento hospitalar em Urgência e Emergência ao paciente com cardiopatia, é importante considerar o momento de crise suscitado pelo adoecimento e a dor vivenciada pelo indivíduo ao sentir-se fragilizado. Esse processo se associa à repentina quebra da rotina de vida do sujeito, favorecendo dor emocional que necessita ser ouvida.

Nesse contexto, o psicólogo busca ter um olhar sobre os aspectos psicológicos associados à doença, ou seja, quais as manifestações da subjetividade diante desse adoecimento. Esses componentes podem exercer influência de diversas formas, podendo atuar como desencadeante da doença, agravante do quadro clínico, fator de manutenção da patologia ou mesmo consequência do adoecer. Compreender a subjetividade do indivíduo e favorecer processo de elaboração simbólica do adoecimento torna-se essencial para o cuidado em saúde. Assim, cabe ao profissional de Psicologia auxiliar o paciente a encontrar formas adaptativas mais adequadas ao novo contexto de saúde e doença e, assim, conseguir integrar novamente o seu corpo físico e 
psíquico (Almeida \& Ribeiro, 2008; Simonetti, 2016). Para identificar e compreender variáveis psicológicas envolvidas nesse processo, o psicólogo pode realizar uma investigação sistemática a partir de recursos da avaliação psicológica, tópico a seguir detalhado.

\subsection{Avaliação Psicológica na área da Cardiologia}

A relação entre a Psicologia e o coração humano era percebida desde a Antiguidade, quando Aristócrates (384-322 a.C.) afirmava que o órgão era fonte das emoções e sensações, portanto seria o último a morrer. A primeira pesquisa científica que associa fatores emocionais a problemas cardíacos foi publicada apenas em 1910 e descrevia a propensão de pacientes mais ambiciosos e ansiosos a desenvolverem doença cardíaca isquêmica (Almeida \& Ribeiro, 2008).

No entanto, apenas na década de 1950 houve ascensão dos estudos voltados para a relevância dos fatores emocionais no adoecimento, quando os trabalhos de Freud, Jung e Lacan apresentavam a interação entre corpo, mente e meio ambiente, propondo o modelo biopsicossocial em detrimento do modelo biomédico (Almeida \& Ribeiro, 2008). Desde então, foram realizados diversos estudos nessa área procurando identificar características psicológicas presentes entre indivíduos com patologias, incluindo as cardiopatias.

Um dos achados clássicos no campo da Psicologia na cardiologia foi publicado por Meyer Friedman, em 1958, ao descrever os cardiopatas com um padrão específico de comportamento, denominado como "tipo A" (Type A Behavior Pattern - TABP). Os traços principais do TABP seriam hostilidade, competitividade, impaciência e senso de urgência. Segundo o autor, tais características estariam mais presentes em indivíduos que apresentam doenças cardíacas do que na população em geral. Posteriormente, Meyer escreveu outro artigo onde expõe a relação dos componentes fisiopatológicos da cardiopatia com o TABP (Friedman, 1977).

Essa hipótese foi amplamente discutida pela comunidade científica até a década de 1980, quando pesquisadores da área passaram a apontar divergências entre os métodos avaliativos utilizados nas pesquisas. Questionaram a relevância do contexto cultural e sua interferência no perfil de personalidade, identificando que o TABP não se enquadrava em sociedades não ocidentais. A partir de então diminuiu o interesse em encontrar um perfil de personalidade específico para as pessoas com cardiopatia, 
passando-se a estudar características isoladas. Esses estudos permitiram refletir acerca das implicações de componentes psicológicos para as doenças cardíacas, principalmente aquelas relacionadas a vivências afetivas negativas, como depressão, ansiedade, hostilidade, raiva, dentre outros (Braunwald, 2006; Suguihura, 2014).

Com base nesse tipo de delineamento faz-se relevante ilustrar os achados empíricos relativos à hipótese da Personalidade Tipo D. A pesquisa foi iniciada por Denollet, Sys e Brutsaert (1995) ao estudaram a relação do distresse com a mortalidade após Infarto Agudo do Miocárdio (IAM). O estudo foi realizado em um centro de reabilitação cardíaca na cidade de Antuérpia, na Bélgica, onde foram selecionados 105 homens com idade entre 45 e 60 anos $(53,6 \pm 4,4)$ que sofreram IAM e que foram acompanhados por período de dois a cinco anos (média 3,8 anos) após esse evento. No primeiro semestre após o infarto, os indivíduos foram avaliados em suas características de personalidade por meio dos instrumentos: Social Inhibition Scale of Heart Patients Psychological Questionnaire (HPPQ), State Trait Anxiety Inventory (STAI) e MarloweCrowne Scale (MC). Os riscos biomédicos foram mensurados por meio da baixa tolerância a exercícios, fração da injeção do ventrículo esquerdo, IAM prévios e local atingido, tabagismo após o IAM, idade, hiperglicemia, e terapia com betabloqueadores. Os riscos psicossociais foram examinados pelo instrumento Millon Behavior Health Inventory (MBHI). Após o tempo de acompanhamento, 15 (14\%) dos casos haviam evoluído a óbito. Foram comparados os quatro perfis de personalidade desses casos (distress, introvertido, contido e excitável), verificando-se que $73 \%(\mathrm{n}=11)$ dos óbitos foram de pacientes que apresentavam algumas características específicas, como a vivência de afetos negativos (AN) e a inibição social (IS). A junção desses dois fatores ficou conhecida como "personalidade tipo D”, visto que as tensões internas vivenciadas pelo indivíduo ocasionavam quadro de distress (angústia, aflição) (Denollet, Sys \& Brutsaert, 1995).

No intuito de padronizar a mensuração desses traços de personalidade, Denollet (1998) desenvolveu a Type-D-Scale-16 (DS16). Essa escala ficou composta por 16 itens dimensionados em cinco pontos (tipo Likert), com respostas que variando entre zero (False) e quatro (True). Os itens foram subdivididos em duas subescalas que mensuram Inibição Social (IS) e Afetos Negativos (AN), construtos que constituem a Personalidade tipo D (Denollet, 1998). Posteriormente, essa escala foi aprimorada pelo autor e passou a ter 14 itens, sendo denominada Type-D-Scale-14 (DS14) (Denollet, 2005). Essa última foi adaptada para o Brasil por Suguihura (2014). 
Em seu estudo, Suguihura (2014) teve por objetivo adaptar a Escala DS-14 para o contexto do Brasil e verificar a incidência de personalidade tipo D entre pessoas com e sem doenças cardiovasculares. Para tanto, dividiu o estudo em duas fases, sendo que na primeira a pesquisadora avaliou 40 pessoas $(60 \%$ do sexo feminino e idade média de $45,2 \pm 14,9$ anos) para estudo metodológico de tradução e adaptação cultural do $D S-14$. $\mathrm{Na}$ segunda fase, foram entrevistados 184 participantes, sendo 80 pessoas com doenças cardiovasculares (DCV) e outras 104 sem a patologia, a fim de avaliar características psicométricas (evidências de precisão e validade) da escala e comparar a prevalência de personalidade tipo $\mathrm{D}$ nesses dois grupos. Dos participantes, 54,3\% $(\mathrm{n}=100)$ eram mulheres, idade média de 47,5 $\pm 13,5$ anos e predomínio de baixa escolaridade $(44,6 \%$ não completou Ensino Fundamental). Para as avaliações nas duas fases, foram utilizados os seguintes instrumentos: a versão original, elaborada em inglês, da escala DS-14; roteiro de tradução da escala; roteiro de retrotradução da escala; escala DS-14 (versões semifinal e final da escala traduzida para o português) e Bateria Fatorial de Personalidade (BFP). Na análise comparativa entre os grupos, verificou-se que o grupo com DCV era composto 51,3\% de homens, com idade média de 53,2 $\pm 13,5$ anos e $6,5 \pm 4,1$ anos de estudo. Já o grupo sem a patologia foi composto de $61 \%$ de mulheres,

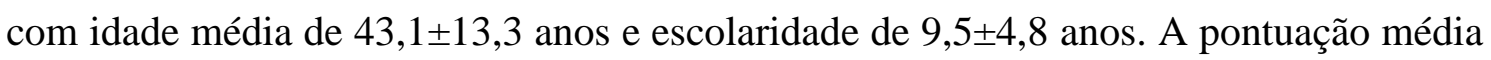
na DS-14 foi de 24,99 $\pm 11,6$ pontos, não havendo diferença estatisticamente significativa entre os grupos. Nas subescalas, os participantes com DCV apresentaram

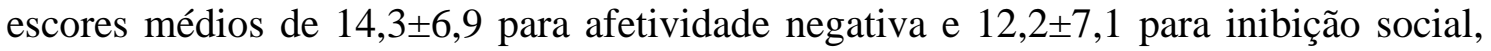
enquanto os pacientes sem DCV obtiveram $11,9 \pm 6,7$ pontos na afetividade negativa e $11,9 \pm 7,1$ pontos em inibição social. Segundo os escores, $50 \%(n=40)$ dos participantes com DCV e 42,3\% ( $n=44)$ sem DCV apresentaram personalidade tipo D (Suguihura, 2014).

A fim de verificar pesquisas atuais na interface entre os recursos da avaliação psicológica e a área da Cardiologia foi realizada, em abril de 2019, revisão de literatura científica sobre a temática nos últimos sete anos, ou seja, de 2013 a 2019, envolvendo apenas artigos em periódicos. Foram utilizadas duas bases de dados para a busca dos artigos, PsycINFO e LILACs, sendo a primeira uma base de dados internacional que integra artigos na área de psicologia, psiquiatria, educação e ciências sociais e a LILACs (Literatura Latino-americana e do Caribe em Ciências da Saúde) uma base de dados com material científico na área da saúde da América Latina e Caribe. Essas bases foram selecionadas para que a revisão contemplasse a literatura internacional e latino- 
americana, contribuindo para conhecimento mais amplo nessa área de investigação. Para a revisão foram utilizados os unitermos: cardiopatia e avaliação psicológica e métodos projetivos. $\mathrm{Na}$ base de dados estrangeira foram utilizados os termos equivalentes em inglês. Primeiramente, os termos foram procurados nos descritores das bases de dados e quando não encontrados, foram utilizados como palavras-chave.

Na base de dados PsycINFO, foram encontrado 387 resultados utilizando-se os seguintes termos: "Heart Disorders" OR "Cardiovascular Disorders" OR "Angina Pectoris" OR "Arrhythmias (Heart)" OR "Coronary Thromboses" OR "Myocardial Infarctions" como termos indexados e "Psychological Assessment" OR "Psychometrics" OR "Projective Techniques" em qualquer campo do artigo. Destes, foram selecionados 75 artigos, sendo o restante excluído por envolver outras patologias, não estar diretamente relacionado à área de conhecimento da Psicologia, artigos serem anteriores a 2013, ou os participantes serem animais, crianças e adolescentes, o que difere do público-alvo desse estudo.

$\mathrm{Na}$ base de dados LILACs foram encontrados 41 resultados utilizando os Descritores em Ciências da Saúde (DeCS): C14.280\$ (“doenças do coração") AND F04.711\$ (“testes psicológicos”), na Categoria DeCS explodida, ou seja, busca por todos os artigos que tivessem esses descritores ou outros relacionados. Destes, foram selecionados apenas cinco artigos, excluindo-se as repetições da base de dados anterior, manuscritos que não tratavam de doenças cardíacas ou não correspondiam à área de conhecimento da Psicologia.

Ao integrar as duas bases de dados pesquisadas, o material encontrado no atual levantamento de literatura cientifica totalizou 80 artigos. As temáticas avaliadas foram divididas em traços de personalidade (16 artigos), ansiedade e depressão (38 estudos), estresse (11 trabalhos) e temas diversos (15 artigos). A seguir, serão descritos alguns desses artigos, com intuito de apresentar um panorama geral das investigações. Serão selecionados cerca de três artigos de cada temática em ordem cronológica, priorizando as revisões de literatura científica e os artigos que apresentaram resultados discordantes entre si, a fim de demonstrar diferentes perspectivas analíticas do tema e favorecer o debate científico.

\subsubsection{Traços de personalidade}

Dos 16 estudos que tem como tema principal a investigação da personalidade, 11 estudavam a personalidade tipo $\mathrm{D}$, quatro investigavam a personalidade tipo A (Type A 
Behavior Pattern - TABP), e um artigo focou na relação entre os dois tipos de personalidade e a cardiopatia. Nesse subtópico, será apresentado um artigo sobre personalidade tipo A, um estudo sobre personalidade tipo $\mathrm{D}$ e o trabalho que expõe a relação entre os dois tipos de personalidade.

Apesar dos estudos com TABP terem diminuído com o passar dos anos, há autores que investem nessa linha de investigação e encontram resultados significativos. Um dos estudos encontrados compara prevalência de personalidade tipo A, exposição a eventos estressores em cinco anos anteriores ao evento cardíaco, ansiedade como estado e traço, além de locus de controle saudável. O estudo foi realizado na Croácia por Milicic et al. (2016) e contou com a participação de 118 pacientes (80,5\% homens) que sofreram Infarto Agudo do Miocárdio (IAM) (idade média 65,3 $\pm 3,8$ nos) e 103 homens sem patologia (idade média 60,8 $\pm 2,9$ anos). Foram utilizados os instrumentos HolmesRahe Life Stress Inventory, Bortner Type A Scale, Spielberger State-Trait Anxiety Inventory (STAI), Coping Inventory for Stressful Situations (CISS) e Multidimensional Health Locus of Control Scales (MHLCS). Verificou-se que os homens com cardiopatia, em relação aos homens saudáveis, apresentaram maior prevalência de personalidade tipo A, eram mais afetados pelos eventos estressores, expressavam mais ansiedade estado e traço e locus de controle externo (Milicic et al., 2016).

Steca et al. (2016) propuseram-se a investigar a relação entre a personalidade tipo A e tipo D em 711 pacientes da Itália, sendo 70,7\% ( $n=503)$ homens, com idade

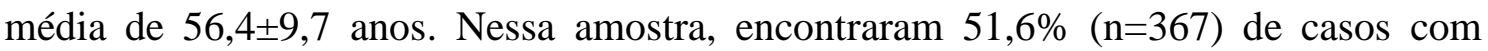
episódio de Síndrome Coronariana Aguda (SCA) e o restante era hipertenso. Para avaliação da personalidade tipo A, foi aplicado Cognitive Behavioural Assessment Form Hospital Baterry (CBA-H) e para avaliação da personalidade tipo D foi utilizada a Type-D-Scale-14 (DS14). Demais variáveis psicológicas foram mensuradas pela Hospital Anxiety and Depression Scale (HADS), Rosenberg Self-Esteem Scale, Life Orientation Test Revised e Brief Illness Perception Questionnaire (Brief-IPQ). Além disso, foram coletadas informações sóciodemográficas, percepção da saúde, hábitos de vida e evolução clínica. A partir dos resultados encontrados, os participantes foram divididos em seis subtipos: 17,2\% (122 participantes) com personalidade tipo D; $16,8 \%$ (119 pacientes) com personalidade tipo A e escore elevado de vivências de afetos negativos; 15,9\% (113 casos) com altos escores de vivências de afetos negativos e sem personalidade tipo A; 20,1\% (143 pessoas) com altos escores de inibição social e baixo escore de vivências de afetos negativos; 16,8\% (119 participantes) com baixo escore de 
inibição social e escore moderado de vivência de afetos negativos e personalidade tipo A; 13,2\% (94 casos) com baixos escores para indicadores de personalidade tipo A e tipo D. As correlações realizadas apontaram que a personalidade tipo A estava fortemente relacionada à vivência de afetos negativos e fracamente relacionada a outras variáveis como inibição social, ansiedade e depressão. Os afetos negativos apareceram fortemente relacionados à ansiedade e, por sua vez, a inibição social esteve fracamente relacionada à depressão (Steca et al., 2016).

Quanto à personalidade tipo $\mathrm{D}$, alguns dos artigos encontrados no atual levantamento da literatura científica tiveram por objetivo a validação da escala DS-14 em pacientes cardiopatas de diversos países. Assim, houve esse tipo de estudo na Espanha, Bélgica, Grécia, Malásia, Taiwan e Turquia (Batselé et al., 2017; Christodoulou et al., 2013; Annagur, Demir, Avci \& Uygur, 2017; Montero, Bermudez \& Rueda, 2017; Weng et al., 2013;Kaur, Zainal, Low, Ramasamy \& Sidhu, 2014).

Um trabalho a destacar foi o realizado por Condén, Rosenblad, Ekselius e Aslund (2014), que investigou a estabilidade temporal da personalidade tipo D em pacientes que sofreram Infarto Agudo do Miocárcio (IAM), na Suíça. Os autores realizaram estudo longitudinal com 946 pacientes, com idade entre 38 a 97 anos (idade média de 70,1 $\pm 11,8$ anos), sendo 66,9\% $(\mathrm{n}=633)$ homens. Mensuraram a personalidade tipo D em três momentos diferentes: durante a hospitalização, um mês após o evento cardíaco e 12 meses após a primeira avaliação. Recorreram a um questionário sóciodemográfico e às escalas DS14 e HADS. Os resultados apontaram prevalência de personalidade tipo $\mathrm{D}$ em $14 \%(\mathrm{n}=132)$ dos pacientes durante a hospitalização, $25,1 \%$ $(\mathrm{n}=104)$ depois de um mês e 19,2\% ( $\mathrm{n}=95)$ após 12 meses. Dos 313 pacientes que conseguiram participar das três etapas da avaliação, 214 (68\%) não apresentaram indicadores positivos para personalidade tipo D em nenhuma das avaliações, $80(25,6 \%)$ participantes tiveram alteração na avaliação da personalidade no período estimado de tempo e apenas $19(6,1 \%)$ dos pacientes apresentaram personalidade tipo $\mathrm{D}$ em todas as etapas. Esses estudos comprovaram que a Escala DS14 apresenta evidências de validade de construto, avaliando o que se propõe (afetos negativos e inibição social), porém com baixa estabilidade temporal, não sendo recomendado seu uso durante momentos críticos (Condén, Rosenblad, Ekselius e Aslund, 2014). 


\subsubsection{Ansiedade e Depressão}

A maior parte dos artigos dessa revisão da literatura científica investigou a relação entre a cardiopatia e a depressão e a ansiedade. Foram 38 estudos sobre o tema, sendo 23 destes especificamente sobre a depressão, cinco sobre a ansiedade e 10 sobre ambos os transtornos. Destes, serão descritos dez artigos selecionados por sua relevância, sendo cinco sobre a depressão, três voltados à ansiedade/depressão e dois sobre ansiedade.

No que concerne aos estudos sobre depressão nas cardiopatias, destaca-se o uso frequente de instrumentos avaliativos de rápida aplicação e com adequados indicadores psicométricos, como o Questionário sobre a Saúde do Paciente (Patient Health Questionnaire - PHQ) e a Escala Hospitalar de Ansiedade e Depressão (Hospital Anxiety and Depression Scale - HADS). Em estudos que investigaram apenas grupo clínico, também foi frequente o uso da Escala de Depressão Cardíaca (Cardiac Depression Scale - CDS), possivelmente por ser um instrumento validado e específico para esses indivíduos. Para representar os estudos dessa área, foram selecionados artigos sobre a depressão no contexto de hospitalização, a diferença de manifestação entre os sexos, a presença de cardiopatia em pacientes com depressão e revisão de literatura científica sobre o tema.

McGuire, Eastwood, Macabasco-O'Cornnell, Hays e Doering (2013) avaliaram 100 pacientes com Síndrome Coronariana Aguda (SCA), em Unidade de Cuidados Cardíacos nos Estados Unidos, pelos instrumentos PHQ-2, 9 e 10 e a Escala de Classificação de Depressão de Hamilton (The Depression Interwiew and Structured Hamilton). Utilizando esta última escala como critério, 77 dos participantes $(75 \%$ homens e idade média de 65,5 $\pm 11,2$ anos) não apresentaram sinais de depressão e 23 pacientes (52\% mulheres e idade média de 56,6 $\pm 13,4$ anos) pontuaram positivamente para sintomas depressivos. Ao realizar as análises estatísticas devidas, concluiu-se que todas as formas da escala PHQ foram apropriadas para avaliação de pacientes, tendo a escala PHQ-2 maior acurácia (McGuire, Eastwood, Macabasco-O’Cornnell, Hays \& Doering, 2013).

Outro estudo relevante na área foi realizado no Canadá (Grace, Yee, Reid \& Stewart, 2013) com 2.657 pacientes um ano após hospitalização por problema cardíaco. Destes, 829 casos foram considerados inelegíveis $(n=386)$ ou declinaram $(n=443)$ do

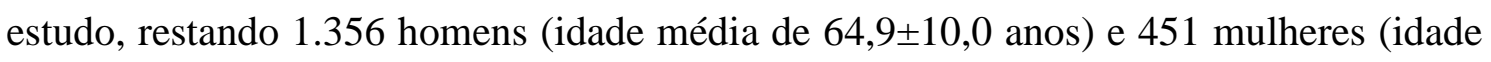

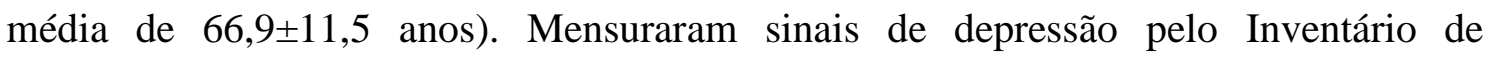


Depressão de Beck-II (Beck Depression Inventory-II - BDI-II) e pelo Gotland Scale of Male Depression, examinando possíveis especificidades em função do sexo. Identificaram correlação positiva estatisticamente significativa entre as escalas, sendo que o BDI-II evidenciou maior sensibilidade para identificar depressão nesses indivíduos, sendo classificados 156 pacientes (113 homens e 46 mulheres) com esse quadro. A incidência dos sintomas depressivos em função do sexo foi estatisticamente diferente somente no que diz respeito à fadiga, sendo que as mulheres referiram maior prevalência desse sintoma.

Em contrapartida a esse estudo anterior, foi possível identificar trabalhos que questionaram a relação positiva entre depressão e cardiopatia. Exemplo disso foi a pesquisa desenvolvida por Almeida, Alfonso, Yeap, Hankey e Flicker (2013) na Austrália. Acompanharam, por seis anos, 431 homens diagnosticados com depressão vascular, com idade inicial entre 69 e 89 anos, verificando que 212 casos $(49,2 \%)$ desenvolveram doenças cardiovasculares (DCV). Em posterior análise, os grupos com DCV (idade média 76,5 $\pm 4,4$ ) e sem DCV (idade média 76,2 $\pm 4,3$ ) foram submetidos ao PHQ-9 para avaliar sintomas depressivos. Constataram inexistência de diferenças estatisticamente significativas na frequência de sintomas recorrentes da depressão entre os dois grupos.

Em 2014 foi publicada uma revisão de literatura científica acercada relação entre variabilidade da frequência cardíaca (VFC) e depressão em pacientes com Síndromes Coronarianas Agudas (SCA). Os autores buscaram os artigos nas bases de dados PubMed e Web of Science, utilizando como palavras-chave: "variabilidade da frequência cardíaca", "depressão" e "síndrome coronariana aguda", considerando os resultados por período de dez anos (2003 a 2013), chegando a nove artigos. Tiveram por base o conceito de depressão segundo Manual Diagnóstico e Estatístico de Transtornos Mentais IV (Diagnostic and Statistical Manual of Mental Disorders IV - DSM IV). Utilizaram como instrumentos de mensuração da depressão a Escala de Depressão de Hamilton (Hamilton Depression Scale - Ham-D), o Inventário de Depressão de Beck (Beck Depression Inventory - BDI) e entrevistas para determinar a gravidade da depressão. Os resultados indicaram relação entre a VFC e a depressão na SCA, mas sem consenso na área, sendo necessários mais estudos para comprovação dessa associação e seus potenciais efeitos (Harris, Sommargren, Stein, Fung \& Drew, 2014).

Faller, Stork, Gelbrich, Schowalter, Ertl e Angermann (2015) estudaram o impacto dos sintomas depressivos e o estado funcional no prognóstico de pacientes com 
Insuficiência Cardíaca (IC). Participaram do estudo 863 pacientes (72\% homens e com idade média de $67 \pm 12,4$ anos) de um centro especializado na Alemanha. Para avaliação do estado funcional dos pacientes foi utilizado Kansas City Cardiomyopathy Questionnaire (KCCQ), alcançando-se escore médio de 60,0 25,0 pontos. Para verificar indicadores de depressão foi usado o PHQ-9 e o escore médio da amostra foi

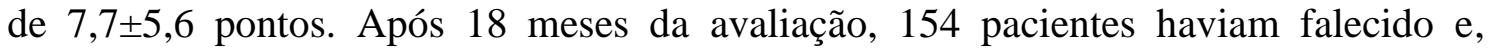
através de análise de regressão logística, verificou-se que prejuízos no estado funcional associados a sintomas depressivos aumentavam em 1,04 (com intervalo de confiança de 95\%) o risco de mortalidade. Nesses casos, cada ponto adicional no PHQ-9 aumentava em $7 \%$ o risco de mortalidade entre os pacientes (Faller, Stork, Gelbrich, Schowalter, Ertl e Angermann, 2015).

Em relação aos estudos que investigaram sinais conjuntos de ansiedade e depressão associados às cardiopatias, serão apresentados artigos relevantes para a compreensão do impacto desses transtornos, a associação em função de idade e como preditores de mortalidade. Um desses estudos (Seldenrijk, Vogelzangs, Batelaan, Wieman, Schaik \& Penninx, 2014) foi realizado na Holanda e avaliou a ansiedade e depressão de 2.541 pessoas (67,7\% mulheres e idade média de 41,2 anos) saudáveis e as reavaliou seis anos depois. Os sintomas de ansiedade e depressão foram mensurados pelo Inventário de Sintomatologia Depressiva (Inventory of Depressive Symptomatology - IDS-SR), Inventário de Ansiedade de Beck (Beck Anxiety Inventory - BAI), Questionário do Medo e Questionário de Estado de Preocupação de Penn (Penn State Worry Questionnaire - PSWQ). Destas 4,2\% (n=106) desenvolveram disfunção cardiovascular (DCV), verificando-se correlação positiva e estatisticamente significativa entre o aumento da incidência dessa patologia e a depressão $(5,4 \%)$ e a ansiedade e depressão $(6,3 \%)$ no momento do estudo. Houve ainda associação positiva entre ansiedade e incidência de DCV (3,8\%), porém não estatisticamente significativa. Concluíram que a depressão apresentou maior impacto do que os sinais de ansiedade no desenvolvimento dessas patologias cardiológicas.

Outro artigo investigou a relação entre ansiedade e depressão e as rehospitalizações e mortalidade entre pacientes com Insuficiência Cardíaca (Alhurani et al., 2015). Nesse estudo, realizado nos Estados Unidos, foram avaliados 1.260 pacientes de um centro especializado, sendo 63,8\% (n=804) do sexo masculino e a idade média foi de 63,57士13 anos. Após 12 meses, foi verificado o número de reinternações e óbitos ocorridos no grupo total de casos. Para investigação dos sintomas depressivos, foi 
utilizado o instrumento PHQ-9 e, para mensuração da ansiedade, a subescala de ansiedade do Inventário Breve de Sintomas (Brief Symptom Inventory - BSI). Como

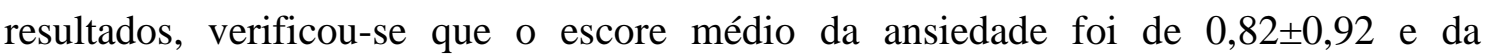

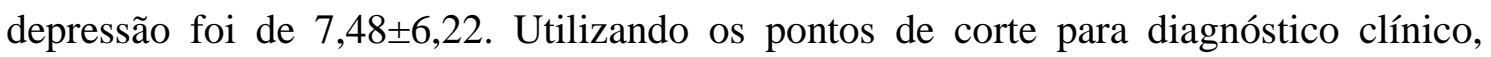
26,8\% (n=338) dos participantes obtiveram pontuação positiva para ansiedade e depressão, 5,7\% (n=72) pontuaram apenas para indicadores de depressão, 26,1\% $(n=329)$ obtiveram apenas indicadores de ansiedade e 41,3\% (n=521) não manifestaram indicadores clínicos de depressão e nem ansiedade. Após um ano da primeira internação, 14,4\% $(n=182)$ dos pacientes foram re-hospitalizados e 6,5\% $(n=82)$ faleceram, sendo a ansiedade e depressão preditores desse último evento, com odds ratio de 1,02 (Alhurani et al., 2015).

Em perspectiva complementar a esse tipo de investigação, Annagur, Avci, Demir e Uygur (2015) examinaram possíveis manifestações psiquiátricas em pacientes que sofrem Infarto Agudo do Miocárdio (IAM) em diferentes idades. Participaram do estudo 116 pacientes da Turquia, divididos em dois grupos: aqueles que tiveram IAM com menos de 45 anos (24 participantes, 91,7\% homens e idade média de 40,6 45,5 anos) e aqueles que tiveram IAM após 45 anos (92 participantes, sendo 88\% homens e idade média de 58,9 $\pm 8,5$ anos). Para mensurar as morbidades psiquiátricas, foi utilizado BDI, Inventário Spielberger de Ansiedade Estado-Traço 1 e 2 (Spielberger State-Trait Anxiety Inventory - STAI 1 e 2) e Inventário de Ansiedade e Saúde (Health Anxiety Inventory - HAI). Os escores médios encontrados entre pacientes mais jovens e mais

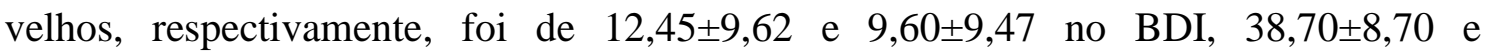
$36,89 \pm 9,22$ no STAI-1, 47,0 $\pm 11,08$ e 41,64 $\pm 9,08$ no STAI- 2 e $18,62 \pm 9,34$ e $14,25 \pm 8,90$ no HAI. Os pacientes mais jovens apresentaram mais transtornos psiquiátricos do que os mais velhos $(45,8 \%$ e $23,9 \%$, respectivamente), bem como maior período da vida com diagnóstico psiquiátrico e transtorno de humor (principalmente Transtorno Depressivo Maior). Outra diferença percebida em função da idade é que os pacientes mais jovens tenderam a apresentar sintomas depressivos antes do evento cardíaco, enquanto em pacientes mais velhos a depressão foi mais prevalente após o IAM (Annagur, Avci, Demir \& Uygur, 2015).

Em relação à temática da ansiedade, foram encontrados apenas cinco artigos no atual levantamento de literatura científica. Selecionou-se, para atual descrição, dois trabalhos de revisão de literatura científica sobre o tema, ambas sobre associação dos transtornos de ansiedade e as doenças coronarianas e cardiovasculares. A revisão de 
literatura científica realizada por Tully, Cosh e Baumeister (2014) teve por objetivo verificar a associação entre transtornos de ansiedade e as doenças coronarianas. Os autores pesquisaram o tema nas bases de dados Medline, Embase, SCOPUS e PsycInfo, em novembro de 2013. Foram eleitos artigos cujos participantes fossem maiores que 18 anos, com $70 \%$ ou mais da população estudada com diagnóstico de doenças coronárias e com diagnóstico confirmado por exames cardiológicos. Os estudos necessitavam ter mais de 30 participantes e o diagnóstico de ansiedade deveria seguir o Manual Diagnóstico e Estatístico de Transtornos Mentais (DSM) ou Classificação Internacional de Doenças (CID). A partir de tais critérios, os autores selecionaram 43 artigos para análise e meta-análise, subdividindo-os em três grupos: (1) aqueles que relatavam associação entre os transtornos de ansiedade e as cardiopatias; (2) aqueles que expunham relação prognóstica entre a ansiedade e os principais eventos cardíacos adversos (PECA); (3) aqueles que reportavam a eficácia do tratamento dos transtornos de ansiedade na cardiopatia. Como resultados mais relevantes foram encontrados cinco artigos que falavam sobre a relação entre transtorno de ansiedade generalizada e o PECA, contudo sem expor associação estatisticamente significativa entre esses eventos. No entanto, o tamanho do efeito dessa associação foi maior em amostras de pacientes ambulatoriais. Nenhum outro transtorno de ansiedade foi associado ao PECA. A depressão apareceu como comorbidade associada à ansiedade em 49,1\% dos estudos. Notou-se também que o avaliador ser psicólogo ou psiquiatra aumentava a frequência de transtorno de pânico $(9,9 \%$ versus $4,7 \%)$ e transtorno de ansiedade generalizada $(18,5 \%$ versus $13,0 \%)$ entre os participantes. Destacou-se a ausência de artigos randomizados controlados que poderiam contribuir para o campo de conhecimento, devendo-se ainda investir em estudos que considerassem também a depressão (Tully, Cosh \& Baumeister, 2014).

Outra revisão de literatura científica encontrada foi a de Batelaan, Seldenrijk, Bot, Balkom e Penninx (2016), que também se propôs a estudar a associação entre ansiedade e doenças cardiovasculares (DCV). Para investigação foram utilizadas as bases de dados PubMed, EMBASE E PsycINFO em outubro de 2013, utilizando combinação de palavras associadas a ansiedade, DCV e estudos prospectivos. Dois juízes independentes selecionaram artigos pela leitura do título e resumo e os critérios de inclusão selecionados foram: estudos longitudinais, com avaliação da ansiedade antes do início da DCV, recente avaliação da DCV e com análise comparativa entre indivíduos com e sem ansiedade. A avaliação da ansiedade poderia ser por autorrelato, 
avaliação diagnóstica ou acessada em banco de dados. Foram encontrados 2.489 artigos inicialmente, sendo selecionados no final, 37 manuscritos publicados de 1991 a 2013 . O número de participantes por estudo foi de 506 a 404.643 casos e o período de seguimento foi de um a 24 anos. De acordo com os dados encontrados em meta-análise, o transtorno de ansiedade aumentava em 52\% o risco de incidência de DCV, independente de outros fatores de risco e a depressão. Os autores ressaltaram que os participantes dos artigos selecionados apresentavam risco em entupimento nas três artérias principais: cérebro, coração e periférica, não sendo possível inferir se a ansiedade interfere em uma delas em específico. Outro ponto levantado pelos autores é que os artigos tinham como foco principal o estudo da ansiedade, sendo necessários mais estudos para investigação da relação com outros transtornos de humor, como a depressão.

\subsubsection{Estresse}

Outra temática considerada relevante pela literatura científica acessada foram as vivências de estresse em pacientes cardiopatas. Para apresentar essa área de investigação, serão expostos quatro artigos, sendo um artigo teórico-técnico, uma revisão de literatura científica, um estudo sobre estresse pós-traumático e uma pesquisa sobre o estresse no ambiente hospitalar.

No artigo escrito por Lagraauw, Kuiper e Bot (2015), é fornecida uma explicação sobre os mecanismos do estresse agudo e crônico associado às doenças cardiovasculares. Os autores compilam materiais de diversos artigos e descrevem os mecanismos fisiológicos e metabólicos associados ao estresse, demonstrando seu efeito nocivo, principalmente do estresse crônico, na arterosclerose (acúmulo de placas de gordura nas paredes das artérias - causa frequente das doenças cardiovasculares). Os autores evidenciaram que o tipo de estresse vivenciado (agudo, transtornos afetivos, baixo status econômico, estresse do cuidador, dentre outros) pode estar relacionado a marcadores inflamatórios específicos. Concluíram que o estresse pode ser considerado um fator de risco para diversas patologias, inclusive para as doenças cardiovasculares e que entender seu mecanismo de funcionamento é fundamental para planejamento de intervenções e prevenção de doenças. No entanto, os achados na área ainda não conseguem elucidar totalmente o funcionamento e os efeitos do estresse, sendo necessários mais estudos para a compreensão dos mecanismos biológicos e mentais desse campo, na análise dos pesquisadores. 
Um tipo específico de vivência de estresse é o Transtorno de Estresse PósTraumático (TEPT). Este pode ser considerado tanto fator de risco como consequência do evento cardíaco. O artigo mais relevante sobre o tema foi realizado na China por Gao, Zhao, Li e Cao (2015). Foram entrevistados 97 pacientes que haviam sofrido primeiro Infarto Agudo do Miocário (IAM), procurando verificar a prevalência e relação do TEPT, alexitimia e apego nesses indivíduos. Havia $76 \%$ de homens no estudo, com idade média de 56,2 $\pm 8,8$ anos. Os sintomas de TEPT foram mensurados pelo questionário Posttraumatic Stress Disorder Checklist-Civilian Version (PCL-C), as manifestações de apego pela escala ExperiencesinCloseRelationships(ECR) e a alexitimia pelo instrumento 20-item Toronto Alexithymia Scale (TAS-20). Verificou-se que $25,8 \%(n=25)$ dos entrevistados preencheram critérios para sintomas de TEPT e que manifestações de apego configuradas por ansiedade e evitação estavam mais presentes nesse grupo. Quanto à alexitimia, identificou-se correlação positiva entre TEPT e os itens de dificuldade em identificar e descrever sentimentos. Concluiu-se, portanto, que o IAM pode ser fator de risco para o desenvolvimento de TEPT e que o mesmo se mostrou diretamente associado ao apego evitativo e a fatores da alexitimia.

O ambiente hospitalar também pode ser favorecedor de estresse para o paciente. Meister et al. (2016) estudaram como o ambiente hospitalar agitado pode favorecer o desenvolvimento de estresse em indivíduos que acabaram de sofrer IAM. Os autores investigaram 102 pacientes hospitalizados há 48 horas em um hospital na Suíça, sendo $80,4 \%$ homens $(n=82)$ e a média de idade foi de 59,4 410,3 anos. A percepção de agitação no ambiente hospitalar foi mensurada por autorrelato do paciente e para mensuração do estresse utilizou-se a Escala de Transtorno de Estresse Agudo (Acute Stress Disorder Scale - ASDS). Dos participantes, 12\% acharam o ambiente hospitalar agitado e $4 \%$ consideraram o ambiente muito agitado. Nenhum dos participantes avaliados obteve pontuações para critério de Transtorno de Estresse Agudo segundo o Manual Diagnóstico e Estatístico de Transtornos Mentais (Diagnostic and Statistical Manual of Mental Disorders - DSM-IV), embora 17,6\% tenham pontuado para sintomas dissociativos. O escore médio obtido na ASDS foi $16,26 \pm 9,80$ e nas

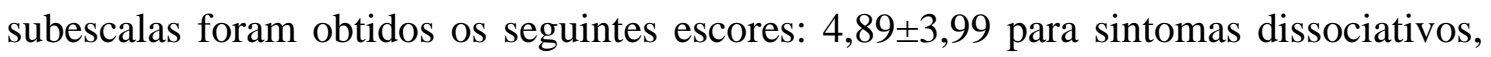

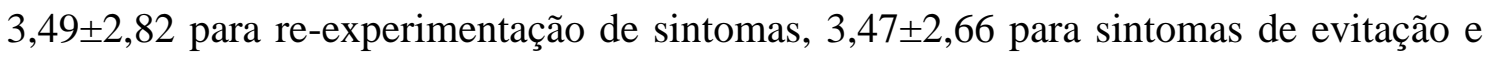

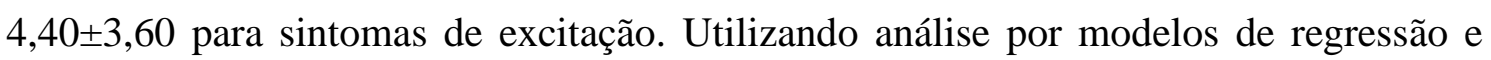
comparação entre respostas, observou-se que pacientes que percebiam o ambiente 
hospitalar como mais agitado tinham mais predisposição para desenvolvimento de transtorno de estresse agudo, independente de outras variáveis.

Uma revisão de literatura científica sobre a temática do estresse pós-traumático verificou publicações relacionadas aos eventos cardíacos, desde 1970 até 2015 (Vilchinsky, Ginzburg, Fait \& Foa, 2017). Os autores investigaram as bases de dados PsycInfo, Pubmed/Medline e CINAHL com termos específicos do estresse póstraumático e das doenças cardiológicas. Foram identificados 3.202 artigos, sendo selecionadas 150 publicações para análise. Verificou-se que a prevalência de estresse pós-traumático variou de zero a $38 \%$, com média de $12 \%$ nos casos de doença cardiológica. Os artigos associavam a prevalência do estresse pós-traumático a fatores psicológicos, como a angústia de morte, e verificavam consequências como a má adesão ao tratamento ou maior risco de mortalidade. Foram encontradas muitas inconsistências no campo que tornaram inviável associação de causalidade entre cardiopatia e estresse pós-traumático. Apesar disso, verificou-se que o estresse pós-traumático se configurou como relevante hipótese a ser investigada na área da cardiologia, principalmente na forma aguda da doença.

\subsubsection{Temas diversos}

Neste subtópico foram agrupados os artigos identificados na revisão da literatura científica que investigaram construtos mais específicos. Foram contabilizados 15 artigos sobre os temas diversos, porém três serão descritos por serem considerados mais relevantes, tendo como temática central os afetos positivos e negativos, a hostilidade e a exaustão vital. Os demais trabalhos abordam questões sobre fatores sociais, jogo patológico, hostilidade, fadiga, gratidão, concepção da doença e construtos psicológicos diversos, sendo cada tema trabalhado em um artigo.

Em contrapartida aos estudos de personalidade tipo D (que enfatizam a influência dos afetos negativos em pacientes cardiovasculares), Freak-Poli, Mirza, Franco, Ikram, Hofman e Tiemeier (2015) estudaram a influência dos afetos positivos no desenvolvimento dessas patologias. Para tanto, avaliaram 6.349 adultos saudáveis, $39,7 \%(\mathrm{n}=2.519)$ homens com idade superior a 55 anos $(68,3 \pm 8,1)$ utilizando-se os itens da escala de depressão (Center for Epidemiological Studies Depression - CES-D) e da escala de ansiedade e depressão (Hospital Anxiety and Depression Scale - HADS). Verificaram que 1.480 participantes tiveram um primeiro episódio de doença cardiovascular e, ao comparar os resultados destes com aqueles que não desenvolveram 
patologia cardíaca, não foram encontradas diferenças estatisticamente significativas nos itens relacionados a afetos positivos (Freak-Poli, Mirza, Franco, Ikram, Hofman \& Tiemeier, 2015).

Outro estudo relevante foi o de Rafanelli, Gostoli, Tully e Roncuzzi (2016), que teve por objetivo investigar o impacto da hostilidade e outros fatores psicológicos no curso da patologia (re-hospitalização e óbito) de paciente com Insuficiência Cardíaca Congestiva (ICC). Foram avaliados 68 pacientes (72\% homens e idade média de $75,4 \pm 10,8$ anos) em um hospital na Itália. Após quatro anos, esses pacientes foram procurados para saber se haviam passado por evento cardíaco. Para investigação de quadro depressivo menor/maior e desmoralização, foi realizada uma entrevista estruturada de acordo com os critérios do DSM-IV e para avaliação do distress e do bem-estar, foram utilizados o Questionário de Sintomas (Symptom Questionnaire - SQ) e a escala PWB (escala de avaliação do bem-estar, que investiga seis áreas: autonomia, meio ambiente, crescimento pessoal, relações positivas, propósito de vida e autoaceitação). Na primeira avaliação, 32,4\% dos participantes preenchiam critério para depressão maior, $10,3 \%$ para depressão menor e 20,6\% para desmoralização. Sobre o distress e bem-estar, destacou-se média elevada em relação a somatização $(10,2 \pm 5,8$ pontos) e média abaixo do esperado em relação ao crescimento pessoal $(48,5 \pm 14,4$ pontos) e propósito de vida (48,1 $\pm 11,2$ pontos). Após quatro anos, apenas $88,2 \%$ da amostra total conseguiu ser reavaliada e destes 14 haviam necessitado de reinternação nesse período, 13 haviam evoluído a óbito pela doença cardíaca e quatro haviam falecido por causas adversas. Ao realizar regressão logística, verificou-se que a hostilidade foi o único construto que apresentava correlação estatisticamente significativa com os eventos cardíacos. Apresentar indicador de hostilidade aumentava em 2,38 vezes a possibilidade de desfecho desfavorável, apontando para a importância de intervenção aos sinais desse tipo de vivência afetiva.

Por fim, destaca-se uma revisão de literatura científica realizada por Frestad e Prescott (2017) sobre a Exaustão Vital e o risco de Doença Arterial Coronariana (DAC). A Exaustão Vital é definida como sentimento de fadiga excessiva, aumento da irritabilidade e sentimentos de desmoralização. Foram procurados artigos acerca dessa temática nas bases de dados PubMed e PsycInfo, publicados entre os anos de 1980 e 2015. Os critérios de seleção dos artigos foram: estudos prospectivos ou caso-controle, participantes não terem cardiopatia prévia, voltados ao tema da Exaustão Vital ou Burnout não relatado, envolvendo doenças cardíacas e metodologia de análise de risco 
ou regressão logística. Na primeira investigação, foram encontrados 332 artigos, porém ao serem aplicados os critérios de elegibilidade, restaram apenas 16 artigos, sendo 13 trabalhos prospectivos e três estudos tipo caso-controle. Em síntese, verificaram que o risco de cardiopatia em pessoas saudáveis com Exaustão Vital foi de 1,50 em estudos prospectivos e 2,61 em estudos de caso-controle, sendo que o risco de recorrência do evento cardíaco foi de 2,06. Diante dos achados, concluíram que a Exaustão Vital está relacionada ao aumento e incidência das cardiopatias.

\subsubsection{Pesquisas realizadas no contexto brasileiro}

Nessa atual revisão de literatura científica, foram encontradas apenas quatro pesquisas realizadas com a população brasileira. Os quatro artigos serão descritos, para contextualizar as pesquisas mais recentes realizadas no país, de acordo com as publicações atingidas pelas bases de dados selecionadas.

Sardinha, Nardi, Araújo, Ferreira e Eifert (2013) examinaram evidências de validade do Questionário de Ansiedade Cardíaca (QAC), uma escala de mensuração de ansiedade específica para pacientes cardíacos. Foram avaliados 98 pacientes com Doença Arterial Coronariana (DAC) em um ambulatório de cardiologia no Rio de Janeiro (RJ). Desses, 62,2\% (n=61) eram homens e os participantes apresentavam idade entre 34 e 89 anos, com média de 64,2ะ10,64 anos. Numa primeira fase, de análise da estrutura fatorial e confiabilidade, foi aplicado o QAC e a Mini Entrevista Neuropsiquiátrica Internacional (Mini International Neuropsychiatric Interview MINI). Numa segunda fase, na verificação de sinais de validade convergente e divergente, foram avaliados 56 pacientes $(62,2 \%$ do sexo masculino e idade média de 71,1 7,90 anos), utilizando QAC, a Escala de Sensações Corporais (ESC) e o Inventário de Fobia Social (Social Phobia Inventory - SPIN). Na terceira e última fase, os 98 pacientes foram divididos em dois grupos, de "cardíacos com pânico" e "cardíacos sem pânico", e comparados entre si, a fim de verificar se havia diferenças significativas entre os escores do QAC. Verificou-se que, conforme esperado, o grupo de "cardíacos com pânico" (que compôs 37,75\% da amostra) obteve maiores indicadores de ansiedade do que o grupo "cardíacos sem pânico". A partir de analises estatísticas pertinentes, averiguou-se que a escala QAC evidenciou propriedades psicométricas adequadas para uso clínico e em pesquisa no Brasil.

Outra pesquisa dedicou-se a avaliação psicológica de pacientes que passariam por transplante cardíaco. Foram avaliados 60 pacientes com idade média de 
45,18 $\pm 11,91$ anos, no pré-operatório para transplante cardíaco, tendo a amostra 71,3\% $(n=43)$ de homens. Os pacientes estavam hospitalizados em hospital do interior do Estado de São Paulo e foram avaliados pelos psicólogos integrantes da equipe multidisciplinar de Cardiologia. O protocolo de avaliação foi constituído do Inventário Beck de Depressão, Questionário de Qualidade de Vida SF-36 e roteiro de entrevista. Os resultados obtidos foram que as mulheres apresentaram escores de depressão mais elevados do que o dos homens (respectivamente $21,41 \pm 12,82$ versus $14,61 \pm 9,43$ ). Em relação à qualidade de vida, mulheres e homens mostraram-se estatisticamente diferentes nos domínios de funcionalidade física $(20,08 \pm 12,09$ versus $32,73 \pm 20,19)$, vitalidade $(34,18 \pm 18,06$ versus $53,47 \pm 26,35)$, aspectos emocionais $(35,68 \pm 36,58$ versus $57,53 \pm 37,98)$ e saúde mental $(46,56 \pm 21,05$ versus $62,13 \pm 27,60)$, sugerindo prejuízo na qualidade de vida das mulheres. Os autores ressaltaram a importância do atendimento psicológico aos pacientes, principalmente aqueles que apresentaram vulnerabilidades psicossociais (Cunha, Miyazaki, Villafanha, Junior \& Domingos, 2014).

Outro estudo realizado no Brasil (Kemp et al., 2015) avaliou 15.105 funcionários públicos de seis capitais brasileiras distintas (Belo Horizonte, Porto Alegre, Rio de Janeiro, Salvador, São Paulo e Vitória), a fim de verificar a relação entre doença cardíaca e diabetes, determinantes sociais e fatores de risco. Verificou-se que $7 \%$ da amostra $(n=721)$ tinham diagnóstico de doença cardíaca, sendo 45,5\% mulheres

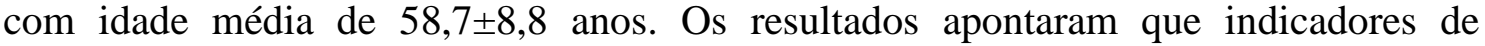
ansiedade e de depressão estavam três vezes mais aumentados em grupos com cardiopatia $(n=434)$ do que naqueles que não apresentavam a patologia $(n=1.844)$. Os achados sugeriram a necessidade de cuidado a essas comorbidades psiquiátricas no tratamento das doenças cardiovasculares.

Por fim, Lemos, Moraes e Pellanda (2016) publicaram artigo sobre a resiliência em pacientes portadores de Cardiopatia Isquêmica. Foram investigados 133 pacientes (51,1\% homens e idade média de 53,7 $\pm 8,4$ anos) em um instituto cardiológico no Rio Grande do Sul, avaliados pela Escala de Resiliência adaptada por Pesce et al. (2005) e questionário sociodemográfico. De acordo com o instrumento empregado, $81 \%$ ( $\mathrm{n}=108)$ dos pacientes foram considerados resilientes, índice considerado como alta incidência desse construto na amostra. Os autores sugeriram novos estudos para verificar a relação da resiliência com o desfecho dos pacientes cardiopatas.

Percebe-se que a maior parte das investigações científicas, seja em âmbito internacional ou nacional, enfatiza a percepção consciente dos pacientes em relação a 
sua condição psicológica, sendo utilizados instrumentos de autorrelato para essa avaliação. Foram encontradas poucas investigações que buscam apreender aspectos globais da psicodinâmica desses indivíduos, incluindo uso de técnicas psicológicas diversificadas, praticamente inexistindo pesquisas com os métodos projetivos de avaliação psicológica, dentro do alcance do atual levantamento realizado na literatura científica. Diante desse contexto, procurou-se ativamente buscar trabalhos voltados à exploração de componentes psicodinâmicos associados aos quadros de cardiopatia, o que será explorado no tópico a seguir.

\subsection{Métodos projetivos de avaliação psicológica na área da Cardiologia}

Instrumentos de autorrelato e métodos projetivos de avaliação psicológica constituem recursos investigativos sobre componentes psicológicos do indivíduo, cada qual com sua área de alcance informativo em função da teoria que os embasa. Uma das peculiaridades dos métodos projetivos é seu objetivo de buscar componentes inconscientes (além dos disponíveis à razão) de comportamentos humanos, ou seja, a acessar aquilo que o indivíduo não quer ou não consegue expressar (Anzieu, 1986; Cohen, Swerdlik \& Sturman, 2014).

Os métodos projetivos caracterizam-se por ofertar ao indivíduo estímulos poucos estruturados, solicitando-se construção de respostas relacionadas a essa estimulação, no geral envolvendo percepções e registros verbais ou gráficos. A maneira como o indivíduo executa essas tarefas e as respostas oferecidas fornecerão evidências acerca de suas necessidades, medos, desejos, impulsos e conflitos, sejam eles conscientes ou inconscientes (Cohen, Swerdlik \& Sturman, 2014). Dessa maneira, os métodos projetivos permitem o estudo do funcionamento psíquico em uma perspectiva psicodinâmica, considerando as condutas do indivíduo, suas possíveis articulações e potencialidades para mudança (Chabert, 2004).

Diante dessa possibilidade informativa ofertada pela metodologia projetiva de avaliação psicológica, considerou-se relevante identificar trabalhos científicos que utilizaram métodos projetivos para investigação de personalidade de cardiopatas. A partir dessa busca faz-se possível destacar alguns estudos realizados com o Método de Rorschach.

A investigação realizada por Abduch (1990) examinou indicadores do funcionamento psíquico de pacientes com Doença Arterial Coronariana, avaliando 40 
pacientes com diagnóstico médico, sendo 20 participantes de cada sexo, com maior concentração em escolaridade de nível fundamental $(n=35)$. Os participantes tinham idade entre 30 e 50 anos, sendo $27,5 \%(n=11)$ de 30 a 40 anos e 72,5\% (n=29) de 41 a 50 anos e os fatores de risco investigados foram colesterol elevado $(n=31)$, tabagismo $(n=33)$ e histórico familiar $(n=21)$. Os instrumentos utilizados foram uma entrevista semidirigida e o Método de Rorschach (Escola Francesa), destacando as variáveis: Fórmulas Vivenciais, mecanismos de Controle e Adaptação Intelectual e Afetiva. Seus resultados apontaram predomínio de tipos afetivo coartado, coartativo e introversivo no Tipo de Ressonância Íntima (TRI) e na Fórmula Complementar do TRI. Não houve alteração da produtividade frente às pranchas coloridas, evidenciando a tendência desse grupo em apresentar bloqueio ou inibição na manifestação e vivência de seus afetos. Em relação ao Controle e Adaptação Intelectual, também foram observados aspectos sugestivos de restrição afetiva, com utilização de pensamento estereotipado e diminuição da produtividade como tentativa de menor envolvimento com o teste. No tocante ao Controle e Adaptação Afetiva, houve sinais de instabilidade emocional, sentimentos de angústia reprimidos e dificuldade no contato humano, tornando-o distante e formal. Em síntese, constatou-se que os pacientes com Doença Arterial Coronariana tenderam a relacionar-se de maneira mais formal, utilizando a racionalização e a função lógica como mecanismos de defesa recorrentes para bloqueio e inibição afetiva (Abduch, 1990).

Em revisão da literatura científica sobre o tema do psicodinamismo e cardiopatia, Bertran (1996) focalizou o uso do Método de Rorschach para o estudo de doenças coronárias. Segundo o pesquisador, os primeiros trabalhos encontrados utilizando métodos projetivos para avaliar pacientes cardiopatas foram escritos por Arlow (1945 apud Bertran, 1996) e Kemple (1945 apud Bertran, 1996). Detalha que Arlow (1945) estudou 13 pacientes com doença coronária, descrevendo-os com sinais de fuga das neuroses pela deformação do caráter e conflito de identificação com a figura paterna, apresentando ao mesmo tempo medo e admiração. No entanto, Arlow (195) teria excluído dois casos que não corroboravam a sua hipótese, enfraquecendo seus achados. Já Kemple (1945) fez estudos com quatro grupos diferentes de pacientes hospitalizados e encontrou que aqueles que apresentavam doenças coronarianas se revelavam mais agressivos, ambiciosos e lutavam de forma mais compulsiva para conseguir poder e prestígio (Bertran, 1996). 
Dentre os artigos encontrados, Bertran (1996) destacou algumas semelhanças diante do Método de Rorschach: diminuição no número de respostas, diminuição nas respostas de movimento humano e diminuição nas respostas associadas a determinantes cromáticos (resposta cor). No entanto, a autora destaca a dificuldade em comparar os estudos em função dos diferentes sistemas avaliativos utilizados no Rorschach. Suas sugestões para estudos futuros incluíam maior controle da definição da doença e dos fatores de risco associados à patologia; controle sobre o tempo entre a crise coronária e a administração do método projetivo; empenho em sistematizar as variáveis do Rorschach nesse campo de estudo de modo a permitir análises comparativas entre sistemas avaliativos, unificando-os.

Praticamente duas décadas mais tarde, Dritto et al. (2015) procuraram mensurar características da personalidade tipo D (inibição social e afetos negativos) por meio do Método de Rorschach. Para tanto, foram avaliados 40 pacientes cardíacos, sendo $32 \%$ $(n=13)$ mulheres e idade média de $64,0 \pm 8,9$ anos. $O$ autor informa que utilizou abordagem psicanalítica para aplicação e análise do Rorschach, conhecida na atualidade como Escola de Paris. Como resultados, obteve-se prevalência de conteúdos Animal (63\%), Humano (14\%) e Anatomia (13\%). Quanto aos determinantes, verificou-se maior frequência das respostas de movimento humano (63\%), seguidas de movimento animal $(35 \%)$ e de objetos inanimados $(1 \%)$. Houve predomínio do tipo vivencial introversivo, além de $42 \%$ de respostas banais, principalmente nos cartões I, III, V, VIII e X. A partir das respostas fornecidas, os autores associaram o número acima do esperado de respostas anatômicas como excessiva preocupação somática que estaria relacionada a preocupação com saúde física. O baixo número de respostas de cor em comparação com as respostas de movimento, em particular de movimento animal foi interpretado pelos autores como sinais de inibição social, enquanto o aumento no número de banalidades foi considerado como sinal da necessidade de aceitação social, embora não seja marcador patológico. Dessa forma, o estudo concluiu que por meio de métodos projetivos foi possível ter acesso a traços de inibição social, como os caracterizados pela personalidade tipo D, comumente associada a quadros de cardiopatia.

Em um artigo mais recente, Meyer, Katko, Mihura, Klag e Meoni (2017) investigaram indicadores de validade de métodos de autorrelato e métodos baseados em desempenho para avaliar a hostilidade como fator de predisposição a doenças cardiovasculares em médicos. Para tanto, foram utilizados dados obtidos da avaliação 
de 416 estudantes homens que cursaram a faculdade de medicina na Universidade John Hopkins entre os anos de 1948 e 1964. A aplicação foi realizada de modo individual e a partir das normativas do Rorschach no sistema Beck, porém Meyer, Katko, Mihura, Klag e Meoni (2017) codificaram os protocolos a partir do Sistema Compreensivo de Exner. Os estudantes foram avaliados na graduação e seu estado de saúde foi acompanhado anualmente, até 2003. Para avaliação da hostilidade e agressividade nos protocolos de Rorschach foram utilizadas duas variáveis: conteúdo agressivo (CAg) e passado agressivo (PAg). O CAg foi avaliado pelas respostas que continham comportamento hostil, armas e instrumentos agressivos. Já o PAg foi avaliado a partir das consequências da agressão, caracterizada pelas respostas que continham estrago, prejuízo ou objetos estragados. A hostilidade autorrelatada foi avaliada a partir do questionário Habits of Nervous Tensions (HNT), que conta com 27 itens que mensuram as respostas de raiva associadas ao estresse ou à pressão. Como covariáveis foram avaliados outros fatores potenciais de risco: pressão sanguínea diastólica e sistólica, níveis de colesterol, frequência cardíaca, índice de massa corporal, número de cigarros consumidos diariamente e uso de álcool. Considerou-se também se os pais sofriam de doenças cardiovasculares prematuras (55 anos para os pais e 65 anos para as mães) e qual o status profissional dos pais. Como a pesquisa foi constituída apenas de homens, considerou-se como ponto de corte para definir doença cardiovascular prematura a idade de 55 anos. Identificaram que 9\% (n=37) dos casos desenvolveram doença cardiovascular precoce, com idade média de 48,4 46,5 anos e 5,5\% $(\mathrm{n}=23)$ apresentaram especificamente doença cardíaca prematura, com idade de $48,7 \pm 4,8$ anos. Os dados apontaram que altos níveis de raiva e hostilidade implícita e explícita foram estatisticamente relacionados com desenvolvimento precoce de doenças cardiovasculares e cardíacas, mesmo após controle das covariáveis tabagismo (para ambas as patologias) e colesterol elevado (para doenças cardíacas). Os achados deste trabalho, bastante robusto em termos metodológicos, ilustram com clareza as relevantes informações advindas das características de personalidade (examinadas pelo Método de Rorschach em especial) para compreensão dos quadros de doenças cardiovasculares.

\subsection{Síntese dos fundamentos sobre avaliação psicológica em Cardiopatia}

Na literatura científica no campo da Medicina e da Psicologia é possível verificar que os aspectos psicológicos dos pacientes com cardiopatia vêm sendo 
estudados desde tempos mais remotos até os dias atuais, demonstrando a relevância do tema. A partir da contextualização da inserção da Psicologia no campo da cardiopatia e da revisão de literatura realizada, foi possível perceber investimentos científicos que buscam compreender esse fenômeno a partir de diferentes pontos de vista.

A maior parte dos estudos encontrados evidenciaram a investigação de construtos específicos e que são acessados pelo relato dos pacientes. Foi possível notar que muitas das investigações realizadas na interface entre Avaliação Psicológica/Psicologia e Cardiologia concentram-se em verificar construtos específicos, como indicadores de ansiedade, depressão e tipos específicos de personalidade, como o tipo D (inibição social e afetos negativos). Poucos trabalhos se propõem a examinar aspectos mais amplos do psiquismo, como características psicodinâmicas de indivíduos com cardiopatia. Pelo atual levantamento da literatura científica dessa área apenas poucos trabalhos recorreram a métodos projetivos para investigação, deixando em aberto as possíveis contribuições desses recursos técnicos para compreensão dos impactos da dinâmica psíquica dos indivíduos no campo das doenças cardiológicas.

Nesse contexto, os processos de avaliação psicológica pautados em multimétodos, integrando instrumentos de autorrelato e métodos projetivos, tendem a ampliar os conhecimentos na área, permitindo acesso a conteúdos que não são expressos de maneira direta pelo indivíduo. Sendo assim, o presente estudo se propõe a examinar características de personalidade de pacientes com cardiopatia, atendidos em contexto de emergência (momento de crise, segundo Almeida \& Ribeiro, 2008), a partir de informações obtidas por avaliação sistemática de recursos psicológicos, por meio de métodos de autorrelato e métodos projetivos. Nesse campo foi encontrado número restrito de artigos publicados, bem como achados contraditórios, justificando-se o atual investimento científico. Pondera-se que este estudo poderá contribuir para compreensão de variáveis relevantes desse contexto e posteriores planos de intervenção diante de quadros de cardiopatia atendidos em urgência e emergência, numa diretriz relacionada a vivências afetivas e sua influência no desenvolvimento de sintomas ou processos adaptativos dos indivíduos.

A proposta do atual trabalho é somar evidências aos estudos já realizados, procurando ampliar o acesso ao indivíduo por meio de avaliação psicológica numa perspectiva multimétodos, incluindo instrumentos de autorrelato e projetivos. Além disso, será focalizado o contexto de atendimento clínico em momento de crise, em situação de internação hospitalar por emergência médica, seja em primeiro evento 
cardíaco ou em agudização da doença cardíaca crônica. Espera-se que os achados proporcionem elementos elucidativos das necessidades psicológicas desses pacientes e de seu funcionamento psicodinâmico, de modo a facilitar a futura elaboração de propostas de intervenção psicológica em contexto de emergência cardiológica. 


\section{OBJETIVOS}

\subsection{Objetivo Geral}

Este estudo teve o objetivo geral de identificar e comparar indicadores de características psicológicas de pacientes adultos com cardiopatia, atendidos em um contexto de emergência, em relação a adultos não pacientes.

\subsection{Objetivos Específicos}

Pretendeu-se neste estudo, em termos específicos, alcançar os seguintes objetivos:

3.2.1. Caracterizar e comparar vivências de depressão e de ansiedade em adultos cardiopatas atendidos em situação de emergência em relação a adultos não pacientes.

3.2.2. Descrever e comparar indicadores de afetos positivos e afetos negativos em adultos cardiopatas atendidos em situação de emergência em relação a adultos não pacientes.

3.2.3. Identificar e comparar características de personalidade (por meio de métodos projetivos) de adultos cardiopatas atendidos em situação de emergência em relação a adultos não pacientes.

3.2.4. Examinar possíveis especificidades de indicadores psicológicos relativos a ansiedade, depressão, afetos positivos e negativos e características de personalidade em função do primeiro evento cardíaco ou quadro crônico de cardiopatia em contexto de emergência.

3.2.5. Examinar eventual especificidade de características psicológicas de pacientes cardiopatas em situação de emergência em função do sexo. 


\section{MÉTODO}

\subsection{Considerações Éticas}

O projeto de pesquisa foi submetido para análise do Comitê de Ética em Pesquisa com Seres Humanos da Faculdade de Filosofia, Ciências e Letras de Ribeirão Preto (FFCLRP/USP), sendo aprovado em 28 de novembro de 2017 (Certificado de Apresentação para Apreciação Ética $=$ CAAE no 74133317.0.0000.5407) (ANEXO 1). Para realização da coleta de dados no Serviço de Emergência contou-se com autorização da Unidade de Emergência do Hospital das Clínicas da Faculdade de Medicina de Ribeirão Preto (UE - HCFMRP/USP) através do Centro de Estudos de Emergência em Saúde desse hospital (ANEXO 2). Somente após a regularização dessas formalidades institucionais, os possíveis voluntários foram selecionados e convidados para o estudo.

Antes de iniciar aplicação dos instrumentos do estudo, a pesquisadora esclareceu as informações básicas e os objetivos da pesquisa e ofereceu o Termo de Consentimento Livre e Esclarecido (TCLE - APÊNDICE A) a todos os eventuais participantes. Foi ressaltado o caráter voluntário da participação na pesquisa, a possibilidade de desistência a qualquer momento e a garantia do sigilo, respeitando os princípios de bioética em pesquisa envolvendo seres humanos. Havia também a identificação e o contato da pesquisadora responsável pelo trabalho, bem como do Comitê de Ética em Pesquisa, para eventuais dúvidas e sugestões. O documento TCLE foi apresentado e lido no momento do convite ao estudo, sendo as dúvidas sanadas pela pesquisadora. Quando o voluntário concordava em participar do estudo, concedia sua autorização mediante assinatura do TCLE. Foram disponibilizadas duas vias do documento, sendo uma entregue ao participante e outra arquivada com o restante dos materiais de pesquisa. Durante todo o processo, ratificou-se o sigilo e preservação da identidade do participante, bem como demais cuidados éticos.

Aos participantes interessados em receber informações (devolutiva) do processo avaliativo realizado, foi disponibilizada a possibilidade de agendamento de uma entrevista individual. Mediante solicitação do voluntário, as entrevistas devolutivas foram agendadas em dia, horário e local convenientes para a pesquisadora e entrevistado, expondo-se os principais resultados e esclarecendo eventuais dúvidas. Por fim, realizava-se um fechamento sobre a participação do voluntário na pesquisa por 
meio de formal agradecimento. Nesse estudo houve demanda por devolutivas em cinco casos avaliados, processo positivamente valorizado pelos participantes.

\subsection{Delineamento Metodológico}

Trata-se de pesquisa de natureza quantitativa, com delineamento transversal, observacional, descritivo-comparativo e interpretativo a partir de instrumentos de avaliação psicológica (Cozby, 2006). No enfoque quantitativo, é realizada coleta de dados por meio de instrumentos mensuráveis e, posteriormente, as informações são analisadas estatisticamente para comprovação ou não da hipótese de pesquisa. Essa modalidade de estudo contempla o desenho transversal descritivo, que tem por objetivo averiguar a prevalência de determinadas variáveis em um ou mais grupos, podendo-se comparar os achados desses grupos (Sampieri, Collado \& Lucio, 2013).

Esse delineamento de estudo demonstrou-se adequado para o objetivo da pesquisa, voltado à caracterização de variáveis psicológicas de grupos distintos de indivíduos adultos, sendo um deles com a cardiopatia e em situação de emergência (Grupo Clínico = G1) e outro sem autorrelato de patologia cardíaca (Grupo de Comparação = G2). O foco do estudo voltou-se ao tema da cardiopatia e suas possíveis associações com indicadores de depressão, ansiedade, afetos positivos e negativos, funcionamento cognitivo e afetivo dos cardiopatas em contexto de emergência comparativamente a adultos não pacientes.

\subsection{Participantes}

Diante dos objetivos propostos, foram convidados indivíduos adultos, de ambos os sexos, com idade entre 55 e 75 anos (faixa etária de maior prevalência de cardiopatias segundo DATASUS, 2019), qualquer escolaridade, voluntários, a comporem dois grupos: grupo clínico=G1 (pacientes cardiopatas em situação de emergência) e grupo de comparação=G2 (indivíduos não pacientes). Para definir o número de participantes que cada grupo deveria conter, foi realizado cálculo amostral, utilizando o programa GPower 3.1.9.4 e considerando a existência de dois grupos independentes. Verificou-se que, com um alfa de 0,5, um tamanho de efeito de 0,7 e um poder estatístico de 0,8 , seria necessária amostra de 34 participantes por grupo. Dessa forma, amostra selecionada nesse trabalho permite avaliar a diferença desses grupos 
com tamanho de efeito de moderado a alto. Os indivíduos foram selecionados por viabilidade prática, compondo amostra de conveniência, a partir dos critérios expostos a seguir.

(a) Grupo clínico $(\mathrm{G} 1, \mathrm{n}=40)$ : pacientes com primeiro evento cardíaco (primeiro episódio de Síndrome Coronariana Aguda - SCA ou primeiro diagnóstico de demais cardiopatias) ou cardiopatia crônica agudizada (doenças cardíacas já instauradas) internados na Unidade Coronariana da Unidade de Emergência do Hospital das Clínicas da Faculdade de Medicina de Ribeirão Preto da Universidade de São Paulo (UE HCFMRP/USP). Os critérios de inclusão foram: o paciente estar consciente, em boas condições mentais (segundo informações do Mini Exame de Estado Mental - MEEM, aceitando-se no estudo somente aqueles com pontuação compatível ao esperado para sua escolaridade), demonstrar compreensão sobre o estudo proposto e para as instruções dos instrumentos a serem aplicados. Dentre esses casos foram inclusos aqueles cujo período de internação atingiu até cinco dias, tendo em vista que o tempo médio de hospitalização esperado para pacientes cardiopatas e idosos é de seis dias (Pagotto, Silveira \& Velasco, 2012; Kaufman, Azevedo, Xavier, Geller, Chaves, \& Castier, 2015; DATASUS, 2019). Pacientes com período prolongado de hospitalização não foram selecionados, a fim de diminuir a possibilidade de inclusão de casos com complicações, que poderiam inserir variáveis confundidoras e vieses para a pesquisa. Os critérios de exclusão foram: o paciente não estar em condições clínicas, mentais ou emocionais para responder aos instrumentos, ser portador de cardiopatia congênita, presidiário (por ficar algemado no setor), deficiências sensoriais, comunicar-se por meio de recurso alternativo ao oral e estar entubado e/ou sob o efeito de substâncias psicoativas que pudessem alterar sua percepção da realidade.

(b) Grupo de comparação ( $\mathrm{G} 2, \mathrm{n}=40)$ : foram convidados indivíduos da comunidade, selecionados por indicação da rede de contatos da pesquisadora. A seleção de indivíduos que estavam inseridos em seu contexto e sem aparente limitação em saúde no momento permitiu caracterização mais próxima do esperado para essa população. Os participantes convidados eram residentes de Ribeirão Preto (SP) ou região, que contemplassem os critérios de inclusão e tivessem sexo, idade e escolaridade balanceados aos participantes do grupo clínico, coletado previamente. Os critérios de inclusão foram semelhantes aos do grupo clínico: estar consciente, em boas condições mentais (segundo informações do Mini Exame de Estado Mental - MEEM, aceitandose no estudo somente aqueles com pontuação compatível ao esperado para sua 
escolaridade), demonstrar compreensão sobre o estudo proposto e para as instruções dos instrumentos a serem aplicados, aceitando participar do estudo. Os critérios de exclusão foram: não estar em condições mentais ou emocionais para responder os instrumentos, deficiências sensoriais, estar sob o efeito de substâncias psicoativas que pudessem alterar sua percepção da realidade, relatar ter alguma cardiopatia e estar hospitalizado.

Cabe comentar que os principais fatores de risco para cardiopatia (hipertensão arterial, diabetes e colesterol alto) não foram considerados fatores de exclusão nesse estudo pela alta prevalência na população em geral, principalmente na faixa etária selecionada. Em estudos com idosos no Brasil, verificou-se que a hipertensão arterial ocorreu em 60\% a 85\% dos casos (Zattar, Boing, Giehl \&D’Orsi, 2013; Mendes, Moraes \& Gomes, 2014) e a diabetes atingiu quase $25 \%$ dessa população (Silva, Engroff, Sgnaolin, Ely \& Gomes, 2016; Vitoi, Fogal, Nascimento, Franceschini \& Ribeiro, 2015). Em estudo com a população geral do município de São Paulo (SP), encontrou-se taxa de 59,74\% de alteração no colesterol entre os participantes (Garcez, Pereira, Fontanelli, Marchioni \& Fisberg, 2014).

Procurou-se balancear o número de casos dos dois grupos em termos etários, em função do sexo e da escolaridade. Esse cuidado metodológico teve a finalidade de constituir grupos homogêneos nessas características demográficas, de modo que pudessem ser comparados nas demais variáveis psicológicas de interesse no estudo.

A seguir será exposto o percurso amostral para constituição de ambos os grupos. Também será descrito e contextualizado o local de coleta dos casos internados em contexto de emergência, na Unidade Coronariana (UCo) da UE - HCFMRP/USP.

\subsubsection{Contexto Institucional e Percurso amostral do Grupo Clínico (G1)}

Os participantes do grupo clínico foram selecionados na Unidade Coronariana (UCo) da Unidade de Emergência do Hospital das Clínicas da Faculdade de Medicina de Ribeirão Preto da Universidade de São Paulo (UE - HCFMRP/USP). O HCFMRP/USP foi inaugurado em 1955, sendo que o prédio ficava localizado no centro da cidade e era composto de 150 leitos para atendimento da população em geral. Com o aumento expressivo da demanda, surgiu necessidade de sua ampliação do HC, para fornecer a devida assistência e contemplar especialidades. Em 1979 foi inaugurada a sede do HC no campus universitário da USP, contando com prédio maior e, consequentemente, mais leitos. $\mathrm{O}$ antigo prédio continuou fazendo parte do complexo 
HC e passou por devidas reformas, inaugurando-se em 1987 sua Unidade de Emergência (UE - HCFMRP/USP), vigente desde então.

Como uma das clínicas que constituem a UE, a UCo foi fundada em 2008 e está localizada no segundo andar do anexo B dessa instituição. Trata-se de um Centro de Terapia Intensiva (CTI) especializado nos agravos cardiológicos, por isso sua disposição física conta com um grande espaço sem divisórias para que a equipe de enfermagem possa ter acesso rápido e constante aos pacientes. É constituída de 10 leitos, sendo um desses reservados para isolamento respiratório. Nos leitos da UCo todos os pacientes ficam monitorados para aferição constante de seus sinais vitais. Ao lado de cada leito há uma mesa para alimentação, quando o paciente consegue alimentar-se por via oral, e um criado-mudo em que o paciente consegue deixar seus pertences pessoais. Quando o paciente consegue sentar-se, a equipe de enfermagem e fisioterapia posiciona uma poltrona ao lado do leito, de modo que possa permanecer sentado e monitorizado.

A equipe mínima que compõe a UCo é constituída de um enfermeiro, quatro a cinco auxiliares e técnicos de enfermagem, um médico contratado (responsável pela UCo) e uma fisioterapeuta. A nutricionista avalia os pacientes diariamente e a terapeuta ocupacional e a fonoaudióloga atendem os casos mediante pedido formal de interconsulta. A psicóloga e a assistente social fazem contato diário com a equipe e realizam atendimentos rotineiros de acordo com a necessidade do setor, focalizando prioritariamente intervenções de apoio (aos pacientes e a seus familiares) e enfrentamento da situação de crise iniciada com a internação hospitalar.

Além dos profissionais contratados, atuam na UCo os residentes multiprofissionais e os residentes médicos da cardiologia, clínica médica, emergência e CTI. Trata-se, portanto, de um serviço clínico especializado, considerado como de alto risco à vida, com grande rotatividade de pacientes, de acompanhantes e de equipes profissionais. As demandas atendidas no setor são os pacientes com doenças cardiológicas, no geral encaminhadas pelo Departamento Regional de Saúde XIII (DRS XIII) para atendimento em CTI especializado.

A UCo conta com uma rotina específica de atividades, embora no momento se encontre em revisão de alguns de seus procedimentos. Na rotina da Unidade, os pacientes ficam o dia acamados ou sentados na poltrona próxima ao leito para permanecerem monitorados. No período da manhã se concentram grande parte das atividades, como banhos, trocas de curativos, exames médicos e consulta com equipe 
médica. No período da tarde, os pacientes recebem visita de seus familiares em horário estipulado pela equipe (das $15 \mathrm{~h} 00$ às $17 \mathrm{~h} 00$ ) e os visitantes poderão retornar novamente em um horário no período noturno (das $20 \mathrm{~h} 00$ às $21 \mathrm{~h} 00$ ). Recentemente, a UCo foi inserida em projeto de visita estendida, no qual os familiares podem permanecer com paciente por horário prolongado (das $09 \mathrm{~h} 00$ às 21h00), mediante treinamento com membros da equipe multiprofissional. São servidas quatro alimentações aos pacientes, caso não haja necessidade de jejum: café da manhã, almoço, jantar e ceia.

A coleta de dados nesse serviço de emergência médica (UCo - UE HCFMRP/USP) permitiu a constituição do Grupo Clínico (G1) e ocorreu entre janeiro e julho de 2018. Nesse período foram hospitalizados 259 pacientes na UCo, sendo que 53 casos $(20,4 \%)$ foram convidados a fazerem parte do estudo.

Os demais pacientes (em um total de 206 casos) não foram inclusos pelos seguintes motivos: não estar entre a faixa etária estudada (55 a 75 anos) (n=117), receber alta hospitalar ou ser transferido da UCo antes de ser abordado pela pesquisadora $(n=37)$, estar confuso ou em estado grave de saúde $(n=18)$, estar entubado $(n=5)$, hospitalização sem apresentar doença cardíaca, configurando "leito emprestado" na rotina hospitalar $(n=2)$, ter ultrapassado o tempo de internação estipulado (mais de uma semana) $(n=1)$, já ter participado do estudo por ser reinternação $(n=2)$, estar inserido no sistema prisional $(n=1)$, ter dificuldade visual $(n=1)$, estar em isolamento de contato $(n=1)$. Além desses motivos, não foram contatados outros 21 casos, visto que a pesquisadora já havia atingido o número de casos planejado para G1. Esse percurso amostral pode ser visualizado na Figura 1.

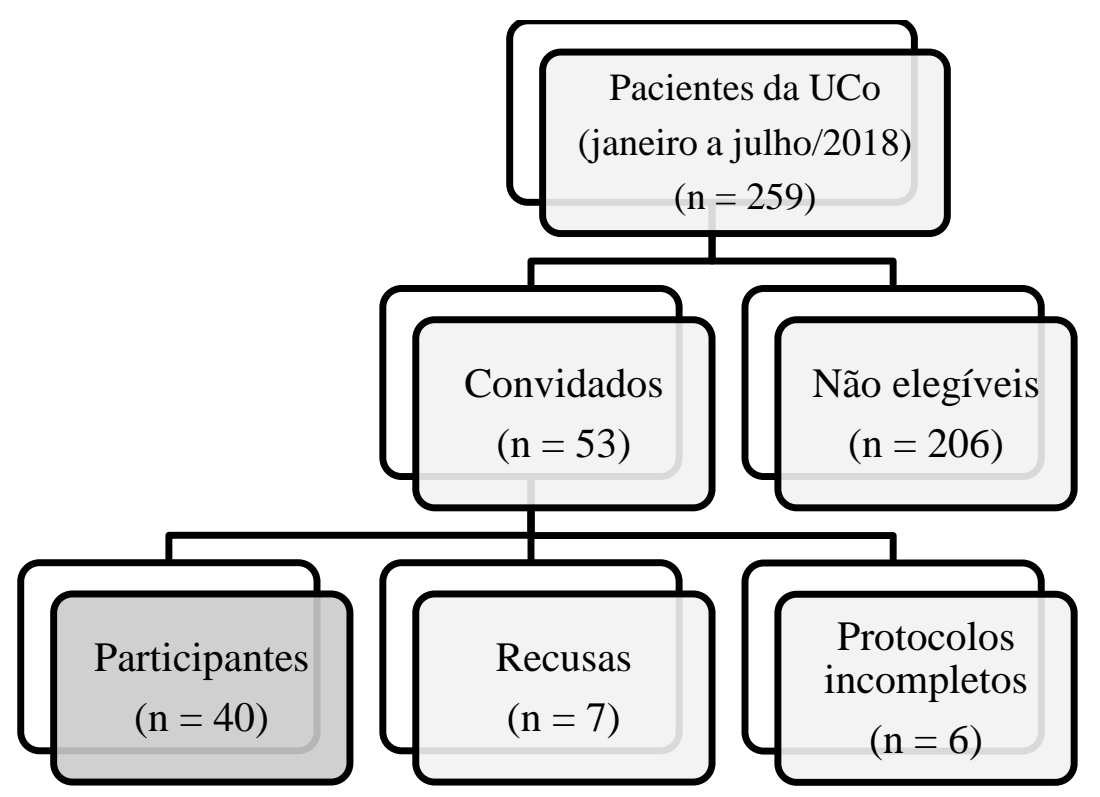

Figura 1. Percurso amostral do grupo clínico $(\mathrm{G} 1, \mathrm{n}=40)$. 
Percebe-se que dos 53 participantes convidados, sete recusaram a pesquisa e seis não conseguiram completar o protocolo, devido mal-estar físico durante a aplicação ou transferência para outro hospital/unidade hospitalar. Restaram, portanto, 40 pacientes, que foram avaliados de modo completo, compondo os participantes de G1.

\subsubsection{Percurso amostral do Grupo de Comparação (G2)}

Para compor o grupo de comparação (G2), foram selecionados participantes com sexo, idade e escolaridade similares aos participantes do grupo clínico (G1), a fim de tornar os grupos balanceados para posterior comparação dos resultados. Os participantes do G2 foram convidados a partir de abordagem direta da pesquisadora ou indicação de pessoas de seu círculo social e de outros participantes do estudo, sendo esta estratégia conhecida como "bola de neve" (Dewes, 2013).

No total foram convidadas ao estudo 84 pessoas, sendo que 44 desses indivíduos $(52,4 \%)$ não participaram do estudo. Os motivos pelos quais esses 44 voluntários não puderam ser incluídos na pesquisa foram variados: 12 casos recusaram participação; 15 adultos não possuíam similaridade em termos escolares com os casos de G1; nove indivíduos não eram compatíveis com a idade dos participantes de G1; um voluntário não era do sexo necessário para balancear o grupo em relação a G1; sete voluntários referiram ter cardiopata.

A pesquisadora realizou abordagem direta de 21 adultos em seu ambiente de trabalho (funcionários da UE - HCFMP/USP), em pontos de ônibus, igrejas e estabelecimentos comerciais. Os demais 63 convidados chegaram à pesquisadora por sua rede de contatos sociais: familiares e vizinhos de colegas de trabalho, indicações de amigos e de pós-graduandos do Campus USP de Ribeirão Preto. A grande maioria dos indivíduos que compuseram o grupo de comparação $(n=34)$ foi proveniente de indicações recebidas pela pesquisadora, sendo, portanto, a estratégia "bola de neve" considerada a mais eficiente para constituir o grupo de comparação desse estudo.

O percurso amostral do grupo de comparação encontra-se esquematizado na Figura 2. 


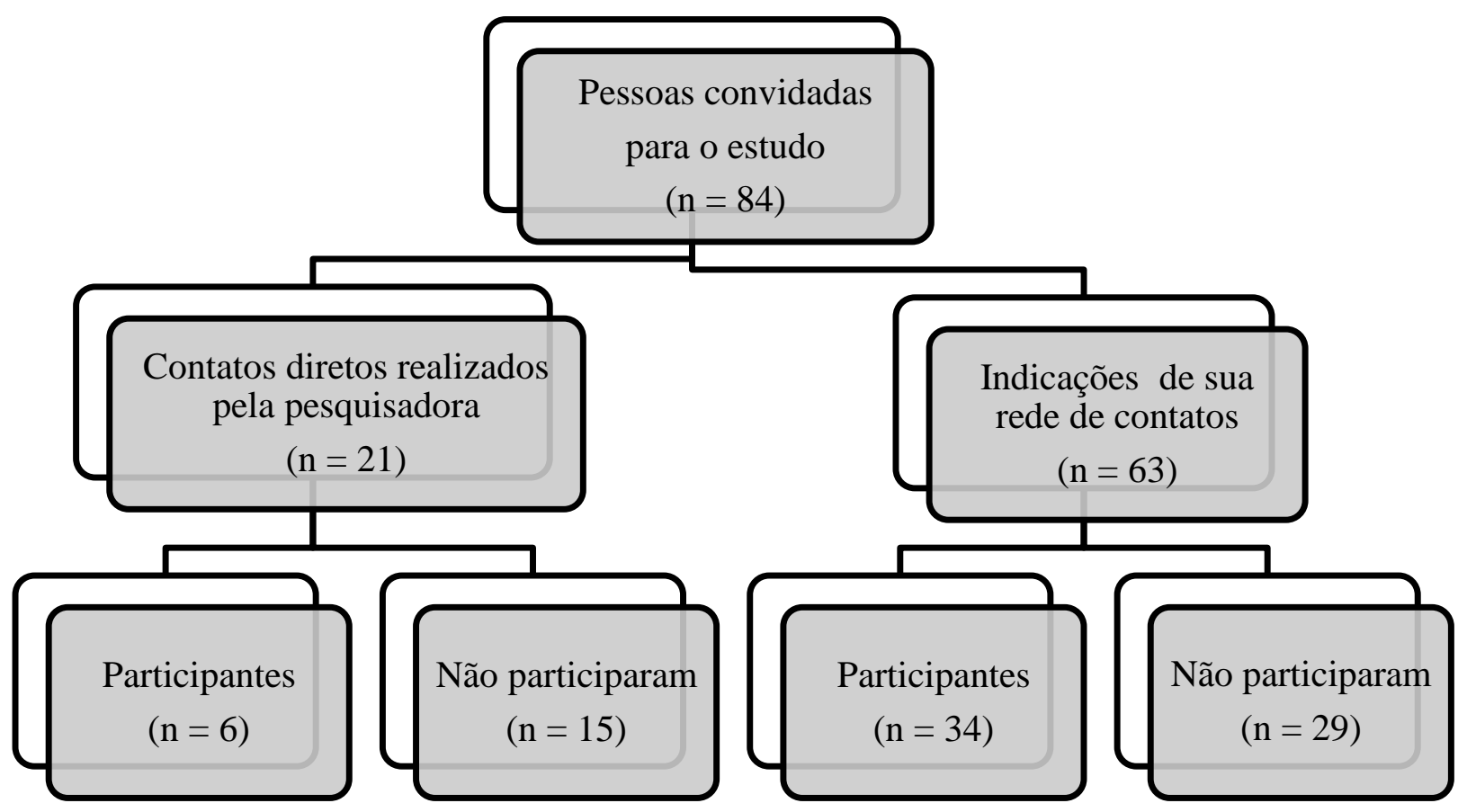

Figura 2.Percurso amostral do Grupo de Comparação $(\mathrm{G} 2, \mathrm{n}=40)$.

\subsubsection{Caracterização dos participantes}

Foi possível constituir dois grupos balanceados de voluntários, cada qual com 40 participantes, como inicialmente delineado em função dos objetivos da pesquisa. As informações sociodemográficas de ambos os grupos serão apresentados na Tabela 1.

Tabela 1.Caracterização sociodemográfica da amostra e sua comparação estatística em função dos grupos. 


\begin{tabular}{|c|c|c|c|c|c|c|c|}
\hline \multirow{3}{*}{ Variável } & \multirow{2}{*}{\multicolumn{2}{|c|}{$\begin{array}{l}\text { Grupo clínico } \\
\text { G1 }(\mathrm{n}=40)\end{array}$}} & \multirow{2}{*}{\multicolumn{2}{|c|}{$\begin{array}{l}\text { Grupo comparação } \\
\qquad \text { G2 }(\mathrm{n}=40)\end{array}$}} & \multicolumn{3}{|c|}{ Comparação estatística } \\
\hline & & & & & \multirow[b]{2}{*}{$t$} & \multirow[b]{2}{*}{$p$} & \multirow[b]{2}{*}{$d$} \\
\hline & Média $(D P)$ & $\operatorname{Min} / \operatorname{Max}$ & Média $(D P)$ & $\operatorname{Min} / \operatorname{Max}$ & & & \\
\hline Idade & $62,7(5,5)$ & $56 / 74$ & $62,4(5,3)$ & $54 / 74$ & 0,246 & 0,806 & $-0,055$ \\
\hline \multirow[t]{2}{*}{ Escolaridade (anos) } & $6,6(4,1)$ & $1 / 16$ & $8,6(3,4)$ & $1 / 15$ & $-2,364$ & 0,021 & 0,529 \\
\hline & $f$ & $\%$ & $f$ & $\%$ & $X^{2}$ & $p$ & $\boldsymbol{V}$ \\
\hline \multicolumn{8}{|l|}{ Sexo } \\
\hline Masculino & 28 & 70 & 28 & 70 & \multirow{2}{*}{$\leq 0,001$} & \multirow{2}{*}{1,000} & \multirow{2}{*}{$\leq 0,001$} \\
\hline Feminino & 12 & 30 & 12 & 30 & & & \\
\hline \multicolumn{8}{|l|}{ Estado Civil } \\
\hline Casado & 31 & 77,5 & 33 & 82,5 & \multirow{4}{*}{3,205} & \multirow{4}{*}{0,361} & \multirow{4}{*}{0,200} \\
\hline Divorciado & 3 & 7,5 & 4 & 10,0 & & & \\
\hline Viúvo & 5 & 12,5 & 1 & 2,5 & & & \\
\hline Solteiro & 1 & 2,5 & 2 & 5,0 & & & \\
\hline \multicolumn{8}{|l|}{ Estado Profissional } \\
\hline Trabalha & 17 & 42,5 & 20 & 50,0 & \multirow{4}{*}{0,554} & \multirow{4}{*}{0,907} & \multirow{4}{*}{0,144} \\
\hline Do lar & 5 & 12,5 & 5 & 12,5 & & & \\
\hline Aposentado & 16 & 40,0 & 13 & 32,5 & & & \\
\hline Desempregado & 2 & 5,0 & 2 & 5,0 & & & \\
\hline \multicolumn{8}{|l|}{ Nível Econômico* } \\
\hline $\mathrm{A}$ & 5 & 12,5 & 5 & 12,5 & \multirow{6}{*}{6,351} & \multirow{6}{*}{0,274} & \multirow{6}{*}{0,296} \\
\hline B1 & 6 & 15,0 & 9 & 22,5 & & & \\
\hline B2 & 12 & 30,0 & 17 & 42,5 & & & \\
\hline $\mathrm{C} 1$ & 10 & 25,0 & 8 & 20,0 & & & \\
\hline $\mathrm{C} 2$ & 5 & 12,5 & 1 & 2,5 & & & \\
\hline$D-E$ & 2 & 5,0 & - & - & & & \\
\hline
\end{tabular}

Nota: Min = Mínimo; Max = Máximo; DP = Desvio Padrão; $f=$ Frequência; $\%=$ Porcentagem; $t=$ Teste $t$ de Student; $X^{2}=$ Teste Qui-Quadrado; $p=$ Nível de Significância; $d=\mathrm{D}$ de Cohen; $v=\mathrm{V}$ de Cramer.

*Segundo Critério de Classificação Econômica Brasil (ABEP, 2015). 
Para comparação das médias entre os dois grupos em relação a idade e escolaridade, utilizou-se o Teste $t$ de Student para amostras independentes $(p \leq 0,05)$ e o $d$ de Cohen para verificar o tamanho do efeito. Para as variáveis sexo, estado civil, estado profissional e nível econômico, contabilizadas em escalas ordinais, utilizou-se o Teste Qui-Quadrado, usando-se o mesmo nível de significância estatística e o $V$ de Cramer para investigar o tamanho do efeito. Esses dados permitiram compreender o perfil sociodemográfico dos grupos estudados.

No tocante ao sexo os grupos foram pareados, sendo predominantemente constituídos por participantes do sexo masculino (28 casos, $70 \%$ de cada grupo). Esse dado retrata a maior frequência de homens internados na UCo, replicando informações da literatura científica da área. A análise comparativa das características etárias de G1 e G2 não evidenciou diferenças estatisticamente significativas entre os grupos, alcançando-se homogeneidade nessa variável.

Quanto à escolaridade, G1 apresentou média menor de anos de estudo $(6,6 \pm 4,1$

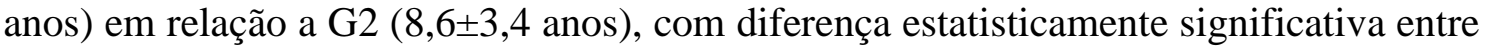
os grupos. Apesar dessa diferença se mostrar estatisticamente significativa, devendo ser considerada na análise dos resultados, ressalta-se que a média de anos de estudo de ambos os grupos é compatível com o ensino fundamental (até a $8^{\mathrm{a}}$ série do ensino regular). Em outras palavras, os participantes de G1 e G2 possuem, na prática, vivência acadêmica semelhante.

Em ambos os grupos prevaleceu o estado civil casado, que constituiu mais de 77\% em G1 e em G2. Em relação ao estado profissional, a maioria dos participantes dos dois grupos encontrava-se em atividade regular de trabalho, embora com atividades diversificadas. Houve grande frequência de indivíduos aposentados, compatível com a idade dos participantes.

O nível econômico mostrou distribuição similar entre os grupos, conforme classificação das faixas do Critério de Classificação Econômica Brasil (ABEP, 2015). Mais da metade dos indivíduos de G1 e de G2 se posicionaram entre as faixas econômicas A até B2, ou seja, com adequadas condições materiais de subexistência. Os grupos não se diferenciaram, em termos estatísticos, nessa variável representativa do nível econômico. 


\subsection{Materiais}

Para avaliação dos participantes foram selecionados instrumentos de autorrelato e métodos projetivos de avaliação psicológica, a fim de contemplar os componentes psíquicos selecionados para este trabalho. Apesar da existência de questionários específicos para mensuração de construtos psicológicos em cardiopatas, estes não foram utilizados neste estudo em função do objetivo de análise comparativa de resultados diante de grupo de indivíduos não cardiopatas (grupo de comparação). Assim, optou-se por utilizar instrumentos de avaliação psicológica não específicos para pacientes cardiopatas. Foram utilizados os seguintes materiais e instrumentos de avaliação psicológica nesse estudo:

\subsubsection{Termo de Consentimento Livre e Esclarecido (TCLE) (APÊNDICE A)}

Esse termo contém a apresentação do estudo e as explicações necessárias aos possíveis participantes: título, objetivos, benefícios, possíveis riscos e benefícios, critérios para participação, caráter voluntário da pesquisa, local de realização, além de dados da pesquisadora responsável e da instituição promotora do estudo. Durante apresentação e leitura do termo, foram ressaltados os aspectos éticos, incluindo sigilo das informações fornecidas e possibilidade de desistência em qualquer etapa do estudo. Esse documento foi apresentado em duas vias, sendo que, após assinatura, uma cópia permaneceu com o participante e a outra com a pesquisadora.

\subsubsection{Questionário sociodemográfico e clínico (APÊNDICE B)}

Questionário elaborado pela pesquisadora para apurar dados demográficos, sociais, hábitos de vida e antecedentes pessoais dos participantes. Para levantamento do nível econômico foram inseridos indicadores do Critério de Classificação Econômica Brasil (ABEP, 2015). Para os voluntários a compor o grupo clínico (G1), foram inclusas questões referentes ao adoecimento e tratamentos, além de informações gerais sobre estado de saúde atual do indivíduo.

\subsubsection{Mini Exame de Estado Mental (MEEM) (ANEXO 3)}

Instrumento constituído de 19 itens com objetivo de examinar orientação temporal e espacial, memória de curto prazo e evocação, cálculo, linguagem-nomeação, repetição, compreensão, escrita e cópia de desenho, servindo como material de triagem 
dos casos a serem incluídos na pesquisa, visto que deveriam ser eliminados voluntários com alterações neurológicas, detectáveis pelo MEEM.

A versão utilizada foi a disponível na Biblioteca Virtual em Saúde (BVS), atualizada por Brucki, Nitrini, Caramelli, Bertolucci e Okamoto (2003), com escore máximo de 30 pontos. Os escores medianos apontados pelos autores de acordo com a escolaridade são: 20 pontos para analfabetos; 25 pontos para indivíduos com um a quatro anos de estudo; 26,5 pontos para aqueles com cinco a oito anos de estudo; 28 pontos para indivíduos com nove a 11 anos de estudo; 29 pontos para ensino superior.

\subsubsection{Questionário sobre Saúde do Paciente (Patient Health Questionnaire-9 - PHQ-9)}

Trata-se de questionário constituído por nove itens para rastreio de indicadores de depressão, baseado nos sintomas descritos no Manual Diagnóstico e Estatístico de Transtornos Mentais IV (Diagnostic and Statistical Manual of Mental Disorders IV DSM IV). Os itens estão dispostos em uma escala do tipo Likert de quatro pontos, com valores de pontuação entre zero e três pontos. Esse questionário foi adaptado para o Brasil por Osório, Mendes, Crippa e Loureiro (2009), a partir de amostra de mulheres, no contexto de atenção primária à saúde. Desse estudo tem-se a seguinte classificação dos resultados no PHQ-9: escores iguais ou acima de 10 pontos = depressão moderada; de 15 a 19 pontos = depressão grave; escore igual ou acima de 20 pontos $=$ depressão muito grave (Osório et al., 2009).

No entanto, neste trabalho foi utilizado como referência o estudo mais atual realizado por Santos et al. (2013), por envolver participantes masculinos e femininos em sua amostra. De acordo com estes autores, considera-se como indicador de depressão um resultado no PHQ-9 igual a nove ou mais pontos.

\subsubsection{Inventário de Ansiedade de Beck (Beck Anxiety Inventory - BAI)}

Inventário de referencial teórico de base cognitiva, utilizado para identificar sintomas de ansiedade. É constituído de 21 itens, em formato do tipo Likert de quatro pontos, com escores variando entre zero e três. O Inventário de Ansiedade de Beck foi validado no Brasil por Cunha (2001), sendo esta a referência utilizada neste trabalho.

Os resultados, segundo Cunha (2001), são assim interpretados: 0 a 10 pontos = ansiedade mínima; 11 a 19 pontos = ansiedade leve; 20 a 30 pontos = ansiedade moderada; 31 a 63 pontos $=$ ansiedade grave. No presente trabalho, optou-se por considerar a presença de ansiedade clínica (ansiedade moderada e grave) ou ausência de 
indicadores de ansiedade clínica (ansiedade mínima e leve), conforme exposto por Cunha (2001).

\subsubsection{Escala de Afetos (EA)}

Trata-se de escala de autorrelato constituída de 20 itens que mensuram a vivência de afetos positivos (10 itens) e negativos (10 itens), organizados em formato do tipo Likert com cinco pontos, variando entre um e cinco. Segue referencial teórico da Psicologia Positiva, sendo adaptada para o Brasil por Zanon, Batianello, Paccio e Hutz (2013), com adequados indicadores psicométricos nessa realidade. Para sua adaptação foram avaliados 853 universitários de duas cidades gaúchas, encontrando-se resultados médios de $39,8( \pm 6,1)$ pontos para afetos positivos e $27,8( \pm 7,3)$ pontos para afetos negativos, dentre os 50 pontos possíveis (máximo) para cada subescala. Não estão disponíveis, até o momento, outros referenciais normativos para interpretação dos resultados da EA no contexto do Brasil.

\subsubsection{Teste de Zulliger (Z-Teste)}

O Teste de Zulliger ou Z-Teste caracteriza-se como método projetivo de avaliação psicológica, utilizado para avaliar componentes estruturais e funcionais da

personalidade. É constituído por três pranchas com manchas de tintas, diante das quais o indivíduo é convidado a emitir suas interpretações por meio de associações livres. A instrução básica do teste é: “Com o que isso se parece?", apresentada diante de cada cartão, não havendo resposta certa ou errada. Após aplicação das três pranchas, é realizado o inquérito das respostas, onde são solicitados esclarecimentos sobre a localização da área interpretada e quais elementos do estímulo favoreceram as interpretações oferecidas. Para aplicação do Z-Teste são necessários: os três cartões do Zulliger, uma folha de localização, três folhas para registro das respostas, cronômetro e canetas de cores diversas para localização das diferentes respostas na folha de localização.

Há diversos sistemas avaliativos para sistematizar e fundamentar a interpretação das variáveis do Teste de Zulliger (Grazziotin \& Scortegagna, 2016; Resende, 2016; Vaz \& Alchieri, 2016). Nesse trabalho, foram utilizadas as diretrizes da Escola de Paris, apresentadas na Tese de Doutorado de Resende (2016).

A Escola de Paris (ou Escola Francesa) tem como referencial teórico pressupostos psicanalíticos para análise e interpretação dos dados. As variáveis 
fornecidas pelos métodos projetivos com manchas de tintas são analisadas em conjunto, uma vez que variáveis isoladas não oferecem informações conclusivas sobre qualquer aspecto. A partir da interpretação dessas variáveis, espera-se verificar aspectos referentes ao funcionamento cognitivo e das vivências afetivas, constituindo uma avaliação psicodinâmica do indivíduo (Pasian \& Amparo, 2018).

O esquema interpretativo e referencial teórico utilizado pela Escola de Paris para o Método de Rorschach (10 cartões) são análogos aos utilizados para o Teste de Zulliger (três cartões), ambos pautados na interpretação de cartões com manchas imprecisas de tintas. As codificações, determinantes e conteúdos explorados são semelhantes, no entanto com localizações específicas, sendo necessário um atlas formulado diretamente para os cartões do Teste de Zulliger. No Brasil, a Tese de Doutorado de Resende (2016) abarcou essa diretriz, sendo utilizada como referencial básico neste trabalho.

Resende (2016) avaliou amostra de 650 adultos residentes na região metropolitana de Belo Horizonte (MG). No atual trabalho foi necessário, no entanto, recorrer ao uso do Atlas de Localizações bem como a lista das Banalidades descritas por Vaz e Alchieri (2016), uma vez que não constava, nessa época, no trabalho de Resende (2016). Foram acrescidas informações do esquema interpretativo da Escola de Paris para o Método de Rorschach, presentes em Pasian e Amparo (2018), de modo a favorecer a análise das variáveis e a possível correspondência entre achados desses dois métodos projetivos, com bases técnicas similares.

De acordo com as diretrizes de Resende (2016), foram mensurados: o tempo que a pessoa leva entre observar o cartão e emitir a primeira resposta (tempo de latência), o tempo gasto para fornecer todas as respostas em todos os cartões (tempo total), o número total de repostas e se houve recusas (a pessoa não oferecer respostas em algum dos cartões), denegações (quando a pessoa emite a resposta durante a aplicação, mas a retira no momento do inquérito) e as respostas adicionais (fornecidas apenas durante o inquérito). Além disso, as respostas foram classificadas quanto a quatro grupos de variáveis: a localização em que foi vista (global, grande detalhe, pequeno detalhe, detalhe branco), os determinantes (forma, cor, sombreado, movimento), os conteúdos e as banalidades e as possíveis tendências das respostas. A partir desse conjunto, tornouse possível a análise de recursos subjetivos projetados pelo indivíduo no Teste de Zulliger.

Durante a finalização deste trabalho foi publicado um novo atlas de localização das respostas ao Teste de Zulliger pelo próprio pesquisador Resende e Nascimento 
(2019). No entanto, não foi possível realizar a classificação dos dados com base nesse material, tendo em vista sua recente publicação, posterior à classificação e análise dos resultados desse estudo.

\subsubsection{Teste das Pirâmides Coloridas de Pfister}

Método projetivo de avaliação psicológica que tem como intuito verificar indicadores do funcionamento da personalidade por meio da construção de pirâmides coloridas. $\mathrm{O}$ instrumento conta com quadrículos de 10 diferentes cores, subdivididas em 24 tonalidades. Sete das cores são subdivididas em tonalidades: quatro tipos de azul, quatro de vermelho, quatro de verde, três de violeta, dois de laranja, dois de amarelo e dois de marrom. As cores restantes são preto, branco e cinza.

A fundamentação teórica do Pfister contempla uma abordagem teórica psicodinâmica de personalidade, portanto, leva em consideração os elementos inconscientes, complementando informações dos instrumentos de autorrelato. Para análise dos dados, foram utilizadas orientações fornecidas no manual do instrumento (Villemor-Amaral, 2012), onde constam adequadas evidências psicométricas desse teste no Brasil, bem como orientações técnicas para análise de seus indicadores. As variáveis do Teste de Pfister permitem avaliação de aspectos relativos ao funcionamento afetivo e ao funcionamento lógico dos indivíduos de diferentes faixas etárias.

\subsection{Procedimentos}

\subsubsection{Coleta de dados}

Os voluntários do grupo clínico (G1) foram convidados para a pesquisa por contato direto da pesquisadora, na beira do leito na UCo, após estabilização clínica de seu quadro clínico. Os participantes de G1 foram avaliados entre o segundo e o quinto dia de sua internação nessa unidade, conforme previsto inicialmente no delineamento do estudo. A coleta de dados foi realizada com paciente sentado em poltrona ao lado de seu leito, pois como a UCo é considerada um Centro de Tratamento Intensivo (CTI), os participantes necessitam de monitoramento constante e não podem sair do leito hospitalar. Para preservar o conteúdo da entrevista e em respeito ao sigilo necessário da identidade do participante, as cortinas ao redor do leito foram fechadas, de modo a manter um espaço privado para o voluntário e a pesquisadora. 
A pesquisadora permaneceu sentada à direita do paciente, em ângulo de 90 graus e com uma mesa para auxiliar na aplicação dos instrumentos. Essa mesa fica ao lado de cada leito e é usualmente utilizada para alimentação dos pacientes. Antes da abordagem, a pesquisadora verificou a agenda do paciente e solicitou à equipe que não houvesse interrupções durante o período de aplicação, exceto em casos de urgência. A equipe respeitou o acordo firmado, interrompendo apenas quando extremamente necessário, como em medicações com horário controlado. A coleta de dados não foi realizada em horário próximo ao período de visitas da unidade, a fim de evitar maior fluxo de pessoas e interrupções nas atividades. Evitou-se também a aplicação no dia em que o paciente havia realizado procedimento de cateterismo, uma vez que os movimentos da mão direita ficam prejudicados por um período.

No caso do grupo de comparação (G2), o processo de coleta de dados foi também realizado integralmente pela pesquisadora, em ambiente adequado, sem riscos de interrupções e com o mínimo de interferência externa possível. Grande parte dos participantes foi examinada em sua própria residência (em acordo com os voluntários), sendo poucos casos avaliados no Centro de Pesquisas em Psicodiagnóstico (CPP) da FFCLRP/USP ou em sala multiprofissional na Unidade de Emergência do HCFMRP/USP.

Após convite e aceitação da proposta do estudo, houve a assinatura do TCLE em duas vias, deixando-se uma com o voluntário e outra com a pesquisadora. A ordem de aplicação dos instrumentos foi a seguinte em todos os casos: (1) Mini Exame de Estado Mental (MEEM); (2) Questionário sociodemográfico e clínico; (3) Questionário sobre a Saúde do Paciente (Patient Health Questionnaire-9 - PHQ-9); (4) Inventário Ansiedade de Beck (Beck Anxiety Inventory - BAI); (5) Escala de Afetos (EA); (6) Teste de Zulliger; (7) Teste das Pirâmides Coloridas de Pfister.

O tempo médio para explicações iniciais sobre o estudo, entrevista e aplicação dos instrumentos foi de uma hora, em apenas uma sessão individual. Após término da coleta de dados foi realizado o devido fechamento formal desse contato com o voluntário, ressaltando possibilidades para acessar a pesquisadora caso tivesse dúvidas ou necessidades de esclarecimentos adicionais.

Aos que desejaram saber sobre os seus resultados foram agendados horários específicos para entrevista devolutiva. Apenas cinco indivíduos solicitaram informações sobre seus resultados (um participante do grupo clínico e quatro do grupo de comparação), que foram devidamente orientados em momento oportuno, posterior à 
análise dos achados. Apesar de poucos casos, esse processo de devolutivas foi positivamente valorizado pelos participantes.

\subsubsection{Análise de dados}

Os dados individuais coletados foram sistematizados de acordo com as normas técnicas de cada instrumento, tabulados e arquivados no Programa Microsoft Excel para posterior análise. Inicialmente os achados de cada instrumento foram sistematizados em um arquivo específico, sendo posteriormente transpostos para um arquivo final onde foram condensadas todas as informações referentes a cada caso avaliado, de modo a facilitar a transferência dos dados para outros softwares de análise.

Os dados do questionário sociodemográfico foram tabulados em variáveis numéricas, ordinais e categóricas, de acordo com o seu conteúdo específico. A pontuação referente ao Critério de Classificação Econômica Brasil foi classificada de acordo com as normas definidas pela ABEP (2015). As escalas PHQ-9 e BAI foram tabuladas e a soma de todos os itens constituiu um resultado final, que foi classificado a partir dos dados normativos dos referenciais teóricos considerados nesse trabalho. Para o PHQ-9, considerou-se o estudo de Santos et al. (2013) e, para o BAI, foram utilizados os padrões normativos expostos no manual de Cunha (2001). Em relação à Escala de Afetos, os dados foram tabulados e os itens da escala foram somados de acordo com sua categorização, compondo pontos para afetos positivos e para afetos negativos (num total de 50 pontos possíveis para cada subescala desse instrumento).

O Teste de Zulliger foi analisado de acordo com as orientações presentes em Resende (2016) e Vaz e Alchieri (2016). As variáveis para codificação da produção individual estão apresentadas de forma sintética no Apêndice C. As respostas oferecidas durante a aplicação do Z-Teste foram codificadas pela aplicadora e por um avaliador independente, para acordo da codificação entre os pares. Foi verificada a concordância entre as codificações realizadas por cada profissional, sendo esse processo denominado como acordo entre examinadores independentes. Recorreu-se ao cálculo do índice Kappa (Fonseca, Silva \& Silva, 2007; Matos, 2014).

Essas avaliadoras constituíram colaboradoras dessa pesquisa, sendo psicólogas devidamente treinadas e que assumiram compromisso ético de sigilo com as informações dos participantes. Nos casos em que não havia acordo entre as codificações dos dois juízes, um terceiro avaliador (orientadora desse trabalho) realizou análise das 
codificações para resolver as eventuais discordâncias, chegando-se a uma classificação final para a resposta.

No Teste de Zulliger foram sistematizados os dados referentes aos indicadores de produtividade (número total de respostas, respostas adicionais, recusas, denegações), ritmo (tempo médio de latência e tempo total médio para as respostas), modos de localização, determinantes, conteúdos e banalidades, Fórmulas Vivenciais e Fórmula da Angústia. A partir desse conjunto de variáveis, foi possível realizar algumas inferências interpretativas sobre as características do funcionamento psíquico de ambos os grupos avaliados.

Por fim, os dados obtidos pelo Teste das Pirâmides Coloridas de Pfister foram sistematizados conforme as diretrizes do manual de Villemor-Amaral (2012). Foram consideradas as variáveis relativas às frequências do uso das cores e das síndromes cromáticas, fórmulas cromáticas, modo de colocação e execução das pirâmides, bem como seu aspecto formal.

Após o devido registro do conjunto dos achados em um único arquivo no Microsoft Excel, os dados foram transferidos para o software Statistical Package for Social Sciences (IBM SPSS, versão 23.0) e para o software estatístico de livre acesso JASP (versão 0.8.6, Universidade de Amsterdam, https://jasp-stats.org/). Para descrição das características dos grupos foi utilizada estatística descritiva, na qual se obteve a média, o mínimo, máximo e o desvio-padrão de variáveis numéricas ou a contagem (frequência e porcentagem) de variáveis categóricas.

Para análise comparativa das variáveis de interesse entre G1 e G2 foram utilizados diferentes recursos técnicos e estatísticos. A escolha dos testes estatísticos a serem utilizados foi realizada após testagem da normalidade dos resultados obtidos nos diferentes instrumentos avaliativos. Ao realizar análise de normalidade dos dados, pelo cálculo da assimetria e curtose, verificou-se que não violaram os pressupostos de distribuição normal, segundo literatura (Kim, 2013). Dessa forma, foram escolhidos testes paramétricos para análise estatística comparativa dos dados coletados.

Para comparar resultados médios (portanto, no caso de variáveis numéricas) recorreu-se ao Teste $t$ de Student para amostras independentes. No caso de variáveis categóricas utilizou-se o Teste Qui-quadrado para comparar a distribuição dos participantes dos grupos avaliados. Quando realizada comparação entre três ou mais subgrupos (por exemplo, comparação de achados do subgrupo clínico agudo, clínico crônico e de comparação), recorreu-se a ANOVA para amostras independentes. Em 
caso de identificação de diferenças estatisticamente significativas entre subgrupo, recorreu-se ao Teste de Bonferroni para examinar e embasar a interpretação dessas especificidades de resultados.

Para cada teste estatístico foi calculado o tamanho de efeito correspondente. Para o Teste $t$ de Student foi utilizado o $d$ de Cohen $(d)$, para o Teste Qui-Quadrado foi calculado o Vde Cramer $(V)$ e, no caso da ANOVA, foi calculado o eta $\left(\eta^{2}\right)$. Para analisar a magnitude do tamanho de efeito, considerou-se o estipulado por Field (2009), a saber: tamanho igual ou inferior a $0,10=$ efeito de tamanho pequeno; entre 0,20 a $0,40=$ efeito de tamanho médio; igual ou superior a $0,50=$ efeito de tamanho grande.

Por fim, foi realizada Análise de Regressão Logística das variáveis categóricas na comparação entre o grupo de cardiopatas e o grupo de não pacientes. As variáveis focalizadas nessa análise foram: hábitos de vida, patologias prévias, medicamentos utilizados, indicadores de depressão e ansiedade, Fórmulas Vivenciais e Fórmula da Angústia do Teste de Zulliger, Fórmula Cromática e processo de execução das pirâmides do Teste de Pfister. Foi utilizado Teste de Regressão Logística Binária, calculado no programa JASP. Em todas as análises utilizou-se o nível de significância de $5 \%(p \leq 0,05)$, com intervalo de confiança de $95 \%$. 


\section{RESULTADOS}

Os resultados apresentados nesse trabalho são fruto da coleta de dados realizada de fevereiro a outubro de 2018. Nesse período foi possível entrar em contato com 137 possíveis participantes e destes 80 aceitaram fazer parte do estudo. O projeto inicial previa a avaliação psicológica de 80 casos, sendo 40 do grupo clínico e 40 do grupo de comparação, sendo concluída essa etapa com sucesso.

Os resultados estão apresentados em função dos instrumentos utilizados no estudo, a saber: características da amostra (questionário sócio demográfico e clínico), indicadores de depressão (PHQ-9), de ansiedade (BAI), de afetos positivos e negativos (EA), Teste de Zulliger e Teste de Pfister (para avaliação das vivências afetivas).

Como anteriormente descrito, em termos gerais este estudo pretende examinar e comparar características psicológicas de pacientes cardiopatas atendidos em contexto de emergência, por meio de instrumentos de avaliação psicológica. Pretende-se verificar se os pacientes cardiopatas internados em serviço de emergência diferem de pessoas sem cardiopatia prévia e não hospitalizadas (grupo de comparação) em relação a sinais indicativos de depressão, ansiedade, vivência de afetos positivos e negativos, bem como em termos de seu funcionamento lógico e afetivo global. Pela literatura científica disponível na área, tem-se a hipótese de mais indicadores de depressão, de ansiedade e de afetos negativos no grupo clínico (G1). O estudo também se propôs a verificar eventuais diferenças nas variáveis psicológicas avaliadas em função do sexo e do tipo de cardiopatia (primeiro evento ou crônico).

Dessa forma, optou-se pelo uso de métodos de autorrelato e métodos projetivos para avaliação psicológica dos indivíduos, a fim de ampliar conhecimento na área. $\mathrm{O}$ uso de métodos variados permite verificar a expressão das características psicológicas a partir de diferentes ângulos, sendo possível ratificá-las ou verificar possíveis contradições. Os resultados são apresentados na ordem supracitada, pelos indicadores centrais dos instrumentos utilizados, com posterior discussão a respeito do conteúdo abordado.

\subsection{Questionário sócio demográfico e clínico}

No levantamento de informações sociodemográficas e clínicas, foram inseridas questões referentes a hábitos de vida, doenças pregressas e patologia atual, no caso do 
grupo clínico (G1). Sobre os hábitos de vida, foram investigados aqueles comumente associados às doenças cardíacas, a saber: tabagismo, etilismo e a prática de atividade física. O etilismo foi mensurado segundo critério da Organização Mundial da Saúde, que preconiza como consumo de risco doses diárias acima de $20 \mathrm{~g}$ de álcool puro ou não deixar de beber pelo menos dois dias da semana (World Health Organzation, 2010). Os dois primeiros são considerados, pela literatura científica da área, fatores de risco (tabagismo e etilismo) e o último (atividade física) fator de proteção para as doenças coronárias. Essas informações estão expostas na Tabela 2.

Tabela 2. Caracterização da amostra em função dos hábitos de vida.

\begin{tabular}{|c|c|c|c|c|c|c|c|c|}
\hline \multirow{2}{*}{\multicolumn{2}{|c|}{ Variável }} & \multicolumn{2}{|c|}{$\begin{array}{l}\text { Grupo clínico } \\
\text { G1 }(\mathrm{n}=40)\end{array}$} & \multicolumn{2}{|c|}{$\begin{array}{c}\text { Grupo comparação } \\
\qquad \text { G2 }(\mathrm{n}=40)\end{array}$} & \multicolumn{3}{|c|}{ Comparação estatística } \\
\hline & & $f$ & $\%$ & $f$ & $\%$ & $X^{2}$ & $p$ & $\boldsymbol{V}$ \\
\hline \multicolumn{9}{|c|}{ Tabagismo } \\
\hline & Sim & 25 & 62,5 & 23 & 57,5 & \multirow{2}{*}{0,208} & \multirow{2}{*}{0,648} & \multirow{2}{*}{0,051} \\
\hline & Não & 15 & 37,5 & 17 & 42,5 & & & \\
\hline \multicolumn{9}{|c|}{ Etilismo } \\
\hline & Sim & 19 & 47,5 & 10 & 25 & \multirow{2}{*}{4,381} & \multirow{2}{*}{0,036} & \multirow{2}{*}{0,234} \\
\hline & Não & 21 & 52,5 & 30 & 75 & & & \\
\hline \multicolumn{9}{|c|}{ Atividade física } \\
\hline & Sim & 15 & 37,5 & 21 & 52,5 & \multirow{2}{*}{1,818} & \multirow{2}{*}{0,178} & \multirow{2}{*}{0,175} \\
\hline & Não & 25 & 62,5 & 19 & 47,5 & & & \\
\hline
\end{tabular}

Nota: $f=$ Frequência; $\%$ = Porcentagem; $X^{2}=$ Teste Qui-Quadrado; $p=$ Nível de significância; $V=\mathrm{V}$ de Cramer.

Pela análise comparativa da distribuição dos casos entre G1 e G2 não foram encontradas diferenças estatisticamente significativas entre os grupos em termos de tabagismo e prática de atividade física. Em relação ao etilismo, os grupos se mostraram estatisticamente diferentes, sendo esse comportamento mais frequente no grupo clínico $(n=19)$ do que no grupo de comparação $(n=10)$, tendo essa diferença um tamanho de efeito próximo ao médio. A atividade física, variável considerada fator de proteção para as cardiopatias, foi relatada por mais participantes de G2, embora sem diferença estatisticamente significativa entre os grupos. Ao realizar análise de regressão logística sobre esses achados, não foi verificada tendência estatisticamente significativa (maior que 1) nas variáveis examinadas. 
Outras variáveis investigadas foram doenças pregressas e medicamentos utilizados pelos participantes do estudo. A Tabela 3 contém a caracterização dos grupos em função das patologias referidas pelos voluntários, sendo priorizada a depressão e as doenças mais relacionadas às cardiopatias: hipertensão, diabetes e colesterol alto.

Tabela 3. Caracterização da amostra em função de patologias.

\begin{tabular}{|c|c|c|c|c|c|c|c|}
\hline \multirow{3}{*}{ Patologia } & \multirow{2}{*}{\multicolumn{2}{|c|}{$\begin{array}{l}\text { Grupo clínico } \\
\text { G1 }(\mathrm{n}=40)\end{array}$}} & \multirow{2}{*}{\multicolumn{2}{|c|}{$\begin{array}{l}\text { Grupo de comparação } \\
\text { G2 }(\mathrm{n}=40)\end{array}$}} & \multicolumn{3}{|c|}{ Comparação estatística } \\
\hline & & & & & \multirow[b]{2}{*}{$X^{2}$} & \multirow[b]{2}{*}{$p$} & \multirow[b]{2}{*}{$\boldsymbol{V}$} \\
\hline & $f$ & $\%$ & $f$ & $\%$ & & & \\
\hline \multicolumn{8}{|l|}{ Diabetes } \\
\hline Sim & 12 & 30 & 8 & 20 & \multirow{2}{*}{1,067} & \multirow{2}{*}{0,302} & \multirow{2}{*}{0,115} \\
\hline Não & 28 & 70 & 32 & 80 & & & \\
\hline \multicolumn{8}{|l|}{ Hipertensão } \\
\hline Sim & 27 & 67,5 & 18 & 45 & \multirow{2}{*}{4,114} & \multirow{2}{*}{0,043} & \multirow{2}{*}{0,227} \\
\hline Não & 13 & 32,5 & 22 & 55 & & & \\
\hline \multicolumn{8}{|l|}{ Colesterol alto } \\
\hline Sim & 11 & 27,5 & 8 & 20 & \multirow{2}{*}{0,621} & \multirow{2}{*}{0,431} & \multirow{2}{*}{0,088} \\
\hline Não & 29 & 72,5 & 32 & 80 & & & \\
\hline \multicolumn{8}{|l|}{ Depressão } \\
\hline Sim & 6 & 15 & 1 & 2,5 & \multirow{2}{*}{7,342} & \multirow{2}{*}{0,048} & \multirow{2}{*}{0,221} \\
\hline Não & 34 & 85 & 39 & 97,5 & & & \\
\hline \multicolumn{8}{|l|}{ Outras patologias } \\
\hline Sim & 15 & 37,5 & 10 & 25 & \multirow{2}{*}{1,455} & \multirow{2}{*}{0,228} & \multirow{2}{*}{0,135} \\
\hline Não & 25 & 62,5 & 30 & 75 & & & \\
\hline
\end{tabular}

Nota: $f=$ Frequência; \% = Porcentagem; $X^{2}=$ Teste Qui-Quadrado; $p=$ Nível de significância; $V=\mathrm{V}$ de Cramer.

Em ambos os grupos houve participantes com doenças pregressas consideradas fatores de risco para cardiopatia. Ressalta-se que os grupos apresentaram diferença estatisticamente significativa em relação a hipertensão e depressão, sendo mais frequente entre participantes do G1 do que no G2. Realizando-se análise de regressão logística, verificou-se Odds Ratio (OR) de 1,929, evidenciando que ser cardiopata aumentou em 1,93 vezes a probabilidade de depressão. 
Outras patologias que foram referidas pelos participantes do estudo (em ambos os grupos) foram: apneia obstrutiva do sono $(n=3)$, artrite $(n=2)$, artrose (3), crise convulsiva $(n=2)$, epilepsia $(n=2)$, osteoporose $(n=2)$, ansiedade $(n=1)$, bicitopenia $(n=1)$, bronquite $(n=1)$, doença diverticular dos cólons $(n=1)$, erisipela de repetição $(n=1)$, esteatose hepática $(n=1)$, gastrite $(n=1)$, hiperucemia $(n=1)$, hipotireoidismo $(\mathrm{n}=1)$, labirintite $(\mathrm{n}=1)$, nefrolitíase $(\mathrm{n}=1)$, porfiria $(\mathrm{n}=1)$, psoríase $(\mathrm{n}=1)$, trombose $(n=1)$ e vitiligo $(n=1)$. De forma geral esses casos distribuíram-se de forma similar entre G1 e G2, sem caracterizar especificidades clínicas em algum grupo, possibilitando sua comparação nas variáveis psicológicas de interesse central. A existência desses relatos de patologias entre os participantes tende a acompanhar o existente na população nessa faixa etária avaliada (55 a 75 anos).

De modo a visualizar a rotina de medicações utilizadas pelos participantes do estudo foram sistematizadas suas informações sobre esse tópico. Esses dados compõem a Tabela 4 .

Tabela 4. Caracterização da amostra em relação ao uso de medicamentos.

\begin{tabular}{|c|c|c|c|c|c|c|c|}
\hline \multirow{2}{*}{$\begin{array}{l}\text { Medicamentos e sua } \\
\text { função terapêutica* }\end{array}$} & \multicolumn{2}{|c|}{$\begin{array}{l}\text { Grupo clínico } \\
\text { G1 }(\mathrm{n}=40)\end{array}$} & \multicolumn{2}{|c|}{$\begin{array}{l}\text { Grupo comparação } \\
\text { G2 }(\mathrm{n}=40)\end{array}$} & \multicolumn{3}{|c|}{ Comparação estatística } \\
\hline & $f$ & $\%$ & $f$ & $\%$ & $X^{2}$ & $p$ & $\boldsymbol{V}$ \\
\hline \multicolumn{8}{|l|}{$\begin{array}{c}\text { AAS } \\
\text { (anticoagulante) }\end{array}$} \\
\hline $\begin{array}{r}\text { Sim } \\
\text { Não }\end{array}$ & $\begin{array}{l}12 \\
28\end{array}$ & $\begin{array}{l}30 \\
70\end{array}$ & $\begin{array}{c}1 \\
39\end{array}$ & $\begin{array}{c}2,5 \\
97,5\end{array}$ & 11,114 & 0,001 & 0,373 \\
\hline \multicolumn{8}{|l|}{$\begin{array}{c}\text { Atenolol } \\
\text { (anti-hipertensivo) }\end{array}$} \\
\hline $\begin{aligned} \text { Sim } \\
\text { Não }\end{aligned}$ & $\begin{array}{c}7 \\
33\end{array}$ & $\begin{array}{l}17,5 \\
82,5\end{array}$ & $\begin{array}{c}5 \\
35\end{array}$ & $\begin{array}{l}12,5 \\
87,5\end{array}$ & 0,392 & 0,531 & 0,070 \\
\hline \multicolumn{8}{|l|}{$\begin{array}{c}\text { Atorvastatina } \\
\text { (redutor colesterol) }\end{array}$} \\
\hline $\begin{aligned} \text { Sim } \\
\text { Não }\end{aligned}$ & $\begin{array}{c}5 \\
35\end{array}$ & $\begin{array}{l}12,5 \\
87,5\end{array}$ & $\begin{array}{c}1 \\
39\end{array}$ & $\begin{array}{c}2,5 \\
97,5\end{array}$ & 3,016 & 0,090 & 0,190 \\
\hline \multicolumn{8}{|l|}{$\begin{array}{c}\text { Carvedilol } \\
\text { (beta bloqueador) }\end{array}$} \\
\hline $\begin{aligned} \text { Sim } \\
\text { Não }\end{aligned}$ & $\begin{array}{c}3 \\
37\end{array}$ & $\begin{array}{c}7,5 \\
92,5\end{array}$ & $\begin{array}{c}0 \\
40\end{array}$ & $\begin{array}{c}0 \\
100\end{array}$ & 3,117 & 0,077 & 0,197 \\
\hline \multicolumn{8}{|l|}{$\begin{array}{c}\text { Clopidogrel } \\
\text { (antitrombolisante) }\end{array}$} \\
\hline $\begin{array}{rr}\text { Sim } \\
\text { Não }\end{array}$ & $\begin{array}{c}5 \\
35\end{array}$ & $\begin{array}{l}12,5 \\
87,5\end{array}$ & $\begin{array}{c}0 \\
40\end{array}$ & $\begin{array}{c}0 \\
100\end{array}$ & 5,333 & 0,021 & 0,258 \\
\hline
\end{tabular}




\section{Enalapril \\ (anti-hipertensivo)}

$\begin{array}{cccccccc}\text { Sim } & 12 & 30 & 4 & 10 & 5,000 & 0,025 & 0,250 \\ \text { Não } & 28 & 70 & 37 & 90 & & & \end{array}$

Hidroclorotiazida

(diurético)

$\begin{array}{cccccccc}\text { Sim } & 6 & 15 & 4 & 10 & 0,457 & 0,499 & 0,076 \\ \text { Não } & 34 & 85 & 36 & 90 & & & \end{array}$

Insulina

(fármaco para diabetes)

$\begin{array}{cccccccc}\text { Sim } & 4 & 10 & 4 & 10 & \leq 0,001 & 1,000 & - \\ \text { Não } & 36 & 90 & 36 & 90 & \end{array}$

Losartana

(anti-hipertensivo)

$\begin{array}{llllllll}\text { Sim } & 11 & 27,5 & 11 & 27,5 & \leq 0,001 & 1,000 & \text { - } \\ \text { Não } & 29 & 72,5 & 29 & 72,5\end{array}$

(fármaco para diabetes)

$\begin{array}{cccccccc}\text { Sim } & 8 & 20 & 7 & 17,5 & 0,082 & 0,775 & 0,032 \\ \text { Não } & 32 & 80 & 33 & 82,5 & & & \end{array}$

\section{Sertralina}

(antidepressivo)

$\begin{array}{cccccccc}\text { Sim } & 5 & 12,5 & - & - & 5,333 & 0,021 & 0,258 \\ \text { Não } & 35 & 87,5 & 40 & 100 & & & \end{array}$

Sinvastatina

(redutor colesterol)

$\begin{array}{cccccccc}\text { Sim } & 7 & 17,5 & 6 & 15 & 0,092 & 0,762 & 0,034 \\ \text { Não } & 33 & 82,5 & 34 & 85 & & & \end{array}$

Outras medicações

\begin{tabular}{llllllll} 
Sim & 23 & 57,5 & 13 & 32,5 & 5,051 & 0,025 & 0,251 \\
Não & 17 & 42,5 & 27 & 67,5 & & \\
\hline
\end{tabular}

Nota: $f$ = Frequência; $\%=$ Porcentagem; $X^{2}=$ Teste Qui-Quadrado; $p=$ Nível de significância; $V=\mathrm{V}$ de Cramer; AAS = Ácido Acetilsalicílico.

* Elencada apenas a função terapêutica principal de cada medicamento.

Houve diferenças estatisticamente significativas entre G1 e G2 quanto ao uso de Acído Acetilsalicílico (AAS), Clopidogrel, Enalapril, Sertralina e outras medicações, com uso mais frequente entre cardiopatas. Esse achado acompanha as características clínicas encontradas entre os participantes de G1, ou seja, com presença de cardiopatia crônica, hipertensão e quadros depressivos, sendo as medicações supracitadas utilizadas para tratamento dessas patologias. Na análise de regressão logística, foi observado OR elevado para as seguintes medicações: AAS ( $\mathrm{OR}=2,816)$, Atorvastatina $(\mathrm{OR}=1,718)$, 
Carvedilol $(\mathrm{OR}=2,023)$, Clopidogrel $(\mathrm{OR}=2,530)$, Enalapril $(\mathrm{OR}=1,350)$ e Sertralina $(\mathrm{OR}=2,530)$. Os achados apontaram maior probabilidade de cardiopatas utilizarem tais medicações em relação ao grupo de comparação.

As outras medicações referidas pelos participantes foram: Omeprazol (9 casos), Furosemida (6), Anlodipino (5), Alopurinol (4), Doxazosina (3), Espironolactona (3), Gliclazida (3), Isordil (3), Propanolol (3), Trimetazidina (3), Bisoprolol (2), Ciprofibrato (2), Clonazepan (2), Clonidina (2), Diltiazem (2), Glibenclamida (2), Levoid (2), Risperidona (2), Selozok (2), Sulfato Ferroso (2), Varfarina (2), Alendronato (1), Amitriptilina (1), Betarsec (1), Bravan (1), Carbamazepina (1), Captopril (1), Diclofenaco (1), Domperidona (1), Enoxoparina (1), Forxiga (1), Gabapentina (1), Hidralazina (1), Hidroxizina (1), Ivabradina (1), Rosuvastatina (1), Torsilax (1), Trayenta (1), Tridil (1), Verapamil (1), Vertix (1), Xarelto (1) e Zolpidem (1). Percebe-se que entre esses medicamentos, o uso mais frequente é do Omeprazol, remédio que diminui a secreção gástrica e o desconforto gástrico ocasionado por outros medicamentos.

Vale ressaltar que as patologias pregressas e medicamentos utilizados foram acessados por meio do prontuário médio eletrônico no G1 e por meio do autorrelato no G2. No entanto, o uso de medicações é autorrelatado pelo paciente na sua chegada à UCo, sendo considerado, portanto, que a fonte de informações sobre essa variável foi a mesma nos dois grupos.

Em termos gerais pode-se apontar que G1 e G2 mostraram-se constituídos de forma adequada para os objetivos desta investigação científica. Suas particularidades, no entanto, deverão ser consideradas na interpretação dos resultados dos instrumentos de avaliação psicológica.

Resta ainda apresentar informações específicas sobre as características clínicas de G1 em seu registro médico na atual internação hospitalar. O tempo médio de internação foi de dois dias ( $\mathrm{DP}=1,03$ ), seguindo o preconizado na rotina da UCo. Os sintomas mais frequentes relatados pelos participantes, sendo o atual motivo de procura do serviço de saúde, estão descritos na Tabela 5.

Tabela 5. Distribuição dos sintomas relatados pelo grupo clínico $(G 1, n=40)$.

\begin{tabular}{ccc}
\hline Sintomas & $f$ & $\%$ \\
\hline Dor no peito & 29 & 72,5
\end{tabular}


Dor no braço

Falta de ar

Outros sintomas
12,5

\section{7,5}

42,5

Nota: $f=$ frequência; $\%=$ porcentagem

Conforme esperado pelo perfil da doença cardíaca, o sintoma mais evidente foi a dor no peito, mais frequente no Infarto Agudo do Miocárdio (IAM) pela diminuição ou bloqueio do fluxo sanguíneo para o músculo cardíaco. Outros sintomas citados foram cansaço (2), falta de ar (2), tontura (2), congestão (1), desmaio (1), dor na boca do estômago (1), dor na garganta (1), dor na lateral do corpo (1), dor nas costas (2), dor nas pernas (1), formigamento da face (1), formigamento das mãos (1), indisposição (1), mal-estar (1), "moleza" (1), parada cardiorrespiratória (1), suor frio (1), Alguns pacientes relataram vivência de mais de um dos sintomas clínicos citados.

Os participantes do G1 ainda foram classificados de acordo com o perfil da patologia na atual internação hospitalar. O grupo ficou constituído por 55\% (n=22) de casos de hospitalização devido primeiro evento cardíaco e $45 \%(\mathrm{n}=18)$ de pacientes com cardiopatia prévia que necessitaram de internação por agudização ou novo evento cardíaco. Na Tabela 6, será apresentado o diagnóstico principal dos participantes, de acordo com os perfis supracitados.

Tabela 6. Frequência e análise estatística do diagnóstico principal do grupo clínico $(G 1, n=40)$, em função do perfil da patologia (primeiro evento ou crônico).

\begin{tabular}{ccccc}
\hline & \multicolumn{2}{c}{$\begin{array}{c}\text { Primeiro evento cardíaco } \\
\text { Diagnóstico principal }\end{array}$} & \multicolumn{2}{c}{$\begin{array}{c}\text { Cardiopatia crônica } \\
(\mathrm{n}=22)\end{array}$} \\
& $f$ & $\%=18)$ & $\%$ \\
\hline IAM com SST & 13 & 59,0 & 1 & 5,5 \\
IAM sem SST & 4 & 18,2 & 1 & 5,5 \\
DAC & - & - & 5 & 27,7 \\
ICFER & - & - & 2 & 11,2 \\
IC & - & - & 2 & 11,2 \\
BAVT & 2 & 9,0 & - & - \\
Estenose aórtica & - & - & 2 & 11,2 \\
Angina Instável & 1 & 4,6 & 1 & 5,5 \\
MCP isquêmica & - & - & 1 & 5,5
\end{tabular}


Fibrilação Atrial

Dor Precordial

IAM NE

Doença de Chagas

\section{Total}

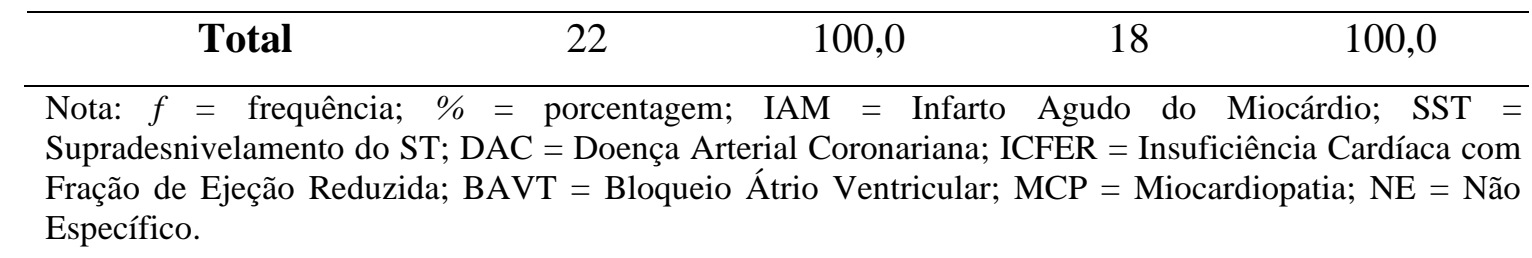

No primeiro evento cardíaco, a patologia mais prevalente foi o Infarto Agudo do Miocárdio (IAM), sendo esse diagnóstico responsável por 81,8\% (n = 18) das hospitalizações. Essa elevada incidência do IAM seria esperada por se tratar de um dos componentes das Síndromes Coronarianas Agudas (SCA), frequentes em primeiros eventos agudos. Já entre os pacientes crônicos, o diagnóstico principal de cardiopatia variou muito, sendo o mais frequente a Doença Arterial Coronariana (DAC), correspondendo a $27,7 \%(n=5)$ da amostra desse subgrupo.

O diagnóstico cardíaco que motivou a internação dos pacientes de ambos os subgrupos de G1 no momento da coleta de dados também foi levantado para este trabalho. A frequência e porcentagem das patologias atuais em cada subgrupo estão expostas na Tabela 7.

Tabela 7. Diagnóstico da internação atual do grupo clínico $(G 1, n=40)$, subdivido entre pacientes de primeiro evento cardíaco $(n=22)$ e cardiopatas crônicos $(n=18)$.

\begin{tabular}{ccccc}
\hline $\begin{array}{c}\text { Diagnóstico da } \\
\text { internação }\end{array}$ & \multicolumn{2}{c}{$\begin{array}{c}\text { Primeiro evento cardíaco } \\
(\mathrm{n}=22)\end{array}$} & \multicolumn{2}{c}{ Cardiopatia crônica } \\
& $f$ & $\%$ & $f$ & $\%$ \\
\hline IAM com SST & 13 & 59,0 & 3 & 16,6 \\
IAM sem SST & 4 & 18,2 & 4 & 22,2 \\
Angina Instável & 1 & 4,6 & 3 & 16,6 \\
Fibrilação Atrial & - & - & 3 & 16,6 \\
BAVT & 2 & 9,0 & - & - \\
Dor Precordial & 1 & 4,6 & - & - \\
Angina de Prinzmetal & - & - & 1 & -
\end{tabular}




\begin{tabular}{|c|c|c|c|c|}
\hline Estenose aórtica & - & - & 1 & 5,6 \\
\hline Valvulopatia & - & - & 1 & 5,6 \\
\hline ICFER & - & - & 1 & 5,6 \\
\hline IC perfil B & - & - & 1 & 5,6 \\
\hline Total & 22 & 100,0 & 18 & 100,0 \\
\hline
\end{tabular}

No subgrupo de pacientes crônicos, os diagnósticos que motivaram a internação estavam mais relacionados às Síndromes Coronarianas Agudas (SCA) e não apenas a aguzidação do quadro clínico vigente. No subgrupo de primeiro evento cardíaco, o motivo da hospitalização foi análogo ao diagnóstico principal, uma vez que este último foi adquirido na internação atual. Não foi possível realizar análise estatística de comparação entre esses subgrupos em função do reduzido número de casos em cada categoria (patologia).

Em síntese, pode-se afirmar que foi possível constituir neste trabalho dois grupos contrastantes em termos clínicos (G1 versus $\mathrm{G} 2)$, como inicialmente delineado. Os participantes de G1 também puderam ser subdivididos em pacientes de Primeiro Evento Cardíaco versus Crônicos, permitindo investigação de suas características psicológicas como também pensado para esse estudo.

\subsection{Patient Health Questionnaire-9 (PHQ-9) e Beck Anxiety Inventory (BAI)}

Para rastreio dos sintomas depressivos e de ansiedade nos participantes, foram utilizados os instrumentos PHQ-9 e BAI, respectivamente. A nota de corte para indicador positivo de depressão foi considerada igual ou acima de nove pontos, conforme Santos et al. (2013), utilizado como referência nesse trabalho. Já a nota de corte para indicador positivo de ansiedade foi considerado acima de 20 pontos, caracterizando ansiedade moderada ou grave, segundo Cunha (2001). A frequência e porcentagem dos indicadores de sintomas depressivos e de ansiedade dos participantes do grupo clínico e do grupo de comparação, bem como sua comparação estatística estão na Tabela 8. 
Tabela 8. Indicadores de depressão (PHQ-9) e ansiedade (BAI) e sua comparação estatística entre os grupos.

\begin{tabular}{|c|c|c|c|c|c|c|c|}
\hline \multirow[t]{2}{*}{ Indicadores } & \multicolumn{2}{|c|}{ G1 $(n=40)$} & \multicolumn{2}{|c|}{$\mathrm{G} 2(\mathrm{n}=40)$} & \multicolumn{3}{|c|}{ Comparação estatística } \\
\hline & $f$ & $\%$ & $f$ & $\%$ & $X^{2}$ & $p$ & $V$ \\
\hline \multicolumn{8}{|l|}{ PHQ-9 } \\
\hline Clínico & 12 & 30,0 & 4 & 10,0 & \multirow{3}{*}{5,000} & \multirow{3}{*}{0,025} & \multirow{3}{*}{0,250} \\
\hline Não clínico & 28 & 70,0 & 36 & 90,0 & & & \\
\hline \multicolumn{5}{|l|}{ BAI } & & & \\
\hline Clínico & 9 & 22,5 & - & - & \multirow{2}{*}{10,141} & \multirow{2}{*}{0,001} & \multirow{2}{*}{0,356} \\
\hline Não clínico & 31 & 77,5 & 40 & 100,0 & & & \\
\hline
\end{tabular}

Nota: $f=$ Frequência; $\%$ = Porcentagem; $X^{2}=$ Teste Qui-Quadrado; $p=$ Nível de significância; $V=\mathrm{V}$ de Cramer; PHQ-9 = Patient Health Questionnaire-9; BAI =Beck Anxiety Inventory.

Notou-se maior número de participantes com indicadores positivamente identificados com depressão em G1 $(n=12)$ comparativamente a G2 $(n=4)$, tornando os grupos significativamente diferentes nessa variável. Ao realizar análise de regressão logística, verificou-se que os indicadores de depressão eram 1,350 mais frequentes no G1 em relação ao G2. No entanto, em ambos os grupos predominaram indivíduos que não atingiram pontuação no PHQ-9 compatível com indicadores depressivos (nove ou mais pontos no PHQ-9).

Segundo Cunha (2001), os indicadores de ansiedade mensurados pelo BAI também podem ser discriminados em quatro níveis: mínimo (0 - 10 pontos), leve (11 19 pontos), moderada ( 20 - 30 pontos) e grave ( $31-63$ pontos). Na Tabela 9 , então, está apresentada frequência, porcentagem e comparação estatística entre os grupos de acordo com essa classificação dos níveis de ansiedade.

Tabela 9. Níveis de ansiedade (BAI) e sua comparação estatística entre os grupos.

\begin{tabular}{cccccccc}
\hline Níveis de & \multicolumn{2}{c}{$\mathrm{G} 1(\mathrm{n}=40)$} & \multicolumn{2}{c}{$\mathrm{G} 2(\mathrm{n}=40)$} & \multicolumn{3}{c}{ Comparação estatística } \\
ansiedade & $f$ & $\%$ & $f$ & $\%$ & $X^{2}$ & $p$ & $V$ \\
\hline Mínimo & 24 & 60,0 & 35 & 87,5 & & & \\
Leve & 7 & 17,5 & 5 & 12,5 & 11,384 & 0,010 & 0,377 \\
Moderado & 7 & 17,5 & - & 0 & & &
\end{tabular}


Grave $\quad 2 \quad 5,0 \quad-\quad 0$

Nota: $f=$ Frequência; $\%=$ Porcentagem; $X^{2}=$ Teste Qui-Quadrado; $p=$ Nível de significância;

$V=\mathrm{V}$ de Cramer; $\mathrm{BAI}=$ Beck Anxiety Inventory.

Em relação à ansiedade, verificou-se que apenas G1 $(n=9)$ apresentou casos com indicadores positivos para esta variável. Ao considerar os quatro níveis de ansiedade propostos por Cunha (2001), G1 obteve maior incidência de participantes com sinais leves, além de casos de intensidade moderada e grave, totalizando 16 casos $(40,0 \%)$ positivos para ansiedade pelo BAI. Enquanto isso, em G2 houve apenas cinco casos (12,5\%) identificados com leve ansiedade, com ausência de casos moderados ou graves. A comparação estatística desses dados apontou que os grupos foram significativamente diferentes em relação à distribuição de casos com indicadores positivos para ansiedade, sendo a maior ocorrência em G1. Em análise de regressão logística, essa diferença é expressa por indicadores 3,196 mais elevados em G1 em relação ao G2. Em outras palavras, os cardiopatas sinalizaram que a chance de sofrerem ansiedade é três vezes maior do que no grupo de não cardiopatas.

Em complemento a essa classificação dos casos nos indicadores de depressão e de ansiedade, foi possível sistematizar os resultados em termos descritivos para ambos os grupos, comparando-se suas médias (teste $t$ de Student para amostras independentes, com análise do tamanho do efeito pelo $d$ de Cohen). Essas informações compõem a Tabela 10.

Tabela 10. Níveis de depressão (PHQ-9) e de ansiedade (BAI) e sua comparação estatística entre os grupos.

\begin{tabular}{cccccccccc}
\hline \multirow{2}{*}{ Instrumento } & \multicolumn{3}{c}{ G1 $(\mathrm{n}=40)$} & \multicolumn{3}{c}{ G2 $(\mathrm{n}=40)$} & \multicolumn{3}{c}{ Comparação estatística } \\
& Média & DP & Min/Max & Média & DP & Min/Max & $t$ & $p$ & $d$ \\
\hline PHQ-9 & 6,40 & 6,60 & $0 / 21$ & 2,17 & 3,10 & $0 / 10$ & 3,62 & 0,001 & 0,811 \\
BAI & 10,37 & 9,40 & $0 / 35$ & 3,87 & 4,80 & $0 / 16$ & 3,86 & $\leq 0,001$ & 0,863 \\
\hline
\end{tabular}

Nota: DP = Desvio Padrão; Min = Mínimo; Max = Máximo; PHQ-9 = Patient Health Questionnaire-9; $\mathrm{BAI}=$ Beck Anxiety Inventory; $t=$ teste $\mathrm{t}$ de Student; $p=$ nível de significância; $d=d$ de Cohen .

Apesar da grande variabilidade interna nos resultados intragrupo (elevado valor de desvio-padrão), a análise comparativa de G1 e G2 evidenciou diferenças estatisticamente significativas em seus resultados médios indicativos de depressão e de 
ansiedade, com efeitos de alta magnitude. Nos dois casos o Grupo Clínico (G1) apresentou os maiores valores médios no PHQ-9 e no BAI.

Os indicadores de ansiedade e de depressão dos grupos também foram examinados em função do sexo dos respondentes. Os participantes foram subdivididos em quatro grupos, realizando-se comparação das médias dos resultados (ANOVA e tamanho do efeito pelo ETA). Os resultados estão na Tabela 11.

Tabela 11. Níveis de depressão (PHQ-9) e de ansiedade (BAI) e sua comparação estatística em função do sexo dos participantes dos grupos.

\begin{tabular}{|c|c|c|c|c|c|c|c|c|c|c|c|}
\hline \multirow[t]{2}{*}{ Instrumento } & \multicolumn{2}{|c|}{$\begin{array}{l}\text { G1 homens } \\
(\mathrm{n}=28)\end{array}$} & \multicolumn{2}{|c|}{$\begin{array}{c}\text { G1 mulheres } \\
(\mathrm{n}=12)\end{array}$} & \multicolumn{2}{|c|}{$\begin{array}{c}\text { G2 homens } \\
(\mathrm{n}=28)\end{array}$} & \multicolumn{2}{|c|}{$\begin{array}{c}\text { G2 mulheres } \\
(\mathrm{n}=12)\end{array}$} & \multicolumn{3}{|c|}{$\begin{array}{c}\text { Comparação } \\
\text { estatística }\end{array}$} \\
\hline & $M$ & $D P$ & $M$ & $D P$ & $M$ & $D P$ & $M$ & $D P$ & $F$ & $p$ & $\dot{\eta}^{2}$ \\
\hline PHQ-9 & 5,17 & 6,17 & 8,41 & 6,90 & 2,17 & 3,25 & 2,00 & 2,98 & 5,38 & 0,002 & 0,175 \\
\hline BAI & 8,50 & 8,05 & 14,75 & 11,33 & 3,46 & 4,75 & 4,75 & 5,25 & 7,41 & 0,001 & 0,226 \\
\hline
\end{tabular}

Replicou-se por essa análise a identificação de diferenças estatisticamente significativas entre os grupos em relação aos escores de depressão e ansiedade, avaliados pelo PHQ-9 e BAI. Foram realizadas comparações múltiplas entre os escores de cada subgrupo (teste de Bonferroni), verificando-se que os indicadores de depressão foram mais elevados entre as mulheres com cardiopatia, sem diferenciação dos subgrupos do sexo masculino.

O mesmo resultado foi encontrado na análise comparativa dos subgrupos em função dos indicadores de ansiedade (BAI). Não houve diferença estatisticamente significativa nos homens nessa variável, mas ocorreu no grupo feminino. Portanto, assim como no PHQ-9, averiguou-se que as mulheres cardiopatas apresentaram escores mais elevados de ansiedade em relação aos demais subgrupos avaliados. Em outras palavras, poder-se-ia apontar que uma mulher que apresente cardiopatia evidencia mais indicadores clínicos de depressão e de ansiedade, sugerindo especificidade clínica em função do sexo.

Outra subdivisão foi realizada entre os participantes do grupo clínico, de modo a examinar possível particularidade nas manifestações de ansiedade e de depressão associadas ao primeiro evento cardíaco (subgrupo G1a) ou à cronicidade da cardiopatia 
(subgrupo G1b). Seus achados foram comparados ao grupo de não pacientes (G2), como mostra a Tabela 12 .

Tabela 12. Níveis de depressão (PHQ-9) e de ansiedade (BAI) e sua comparação estatística em função da cronicidade (ou não) da cardiopatia entre os grupos.

\begin{tabular}{|c|c|c|c|c|c|c|c|c|c|}
\hline \multirow{3}{*}{ Variáveis } & \multicolumn{4}{|c|}{ Grupo Clínico (G1) } & \multirow{2}{*}{\multicolumn{2}{|c|}{$\begin{array}{c}\text { Grupo de } \\
\text { Comparação } \\
(\mathrm{G} 2, \mathrm{n}=40)\end{array}$}} & \multirow{2}{*}{\multicolumn{3}{|c|}{$\begin{array}{c}\text { Comparação } \\
\text { estatística }\end{array}$}} \\
\hline & \multicolumn{2}{|c|}{$\begin{array}{l}\text { Primeiro evento } \\
(\mathrm{G} 1 \mathrm{a}, \mathrm{n}=22)\end{array}$} & \multicolumn{2}{|c|}{$\begin{array}{c}\text { Crônicos } \\
(\mathrm{G} 1 \mathrm{~b}, \mathrm{n}=18)\end{array}$} & & & & & \\
\hline & $M$ & $D P$ & $M$ & $D P$ & $M$ & $D P$ & $F$ & $p$ & $\dot{\eta}^{2}$ \\
\hline PHQ-9 & 5,31 & 5,32 & 7,16 & 7,72 & 2,12 & 3,13 & 6,91 & 0,002 & 0,152 \\
\hline BAI & 11,18 & 10,06 & 9,38 & 8,85 & 3,85 & 4,88 & 7,74 & 0,001 & 0,168 \\
\hline
\end{tabular}

Nota: $\mathrm{M}=$ Média; $D P=$ Desvio Padrão; PHQ-9 = Patient Health Questionnaire-9; BAI =Beck Anxiety Inventory; $F=$ teste ANOVA; $p=$ nível de significância; $\dot{\eta}^{2}=$ eta.

Os grupos mostraram-se estatisticamente diferentes em relação aos escores do PHQ-9 e BAI, replicando achados prévios. Para verificar em quais subgrupos essas diferenças foram mais evidentes, foram realizadas comparações múltiplas entre os mesmos (teste de Bonferroni). No PHQ-9 não foi verificada diferença estatisticamente significativa entre os subgrupos clínicos. No entanto, foi encontrada diferença estatisticamente significativa entre G1b e G2, apontando que cardiopatas crônicos apresentaram escores de depressão mais elevados.

Em relação aos indicadores de ansiedade (BAI), as comparações múltiplas apontaram para diferenças estatisticamente significativas dos subgrupos clínicos em comparação ao G2. Assim, mostraram que estar internado por evento cardíaco se associou a maior ansiedade, seja num primeiro evento ou em um quadro crônico.

\subsection{Escala de Afetos}

A Escala de Afetos (EA) foi utilizada para mensurar afetos positivos e negativos vivenciados pelos participantes. Essa escala contém 20 itens, sendo 10 associados aos afetos positivos (AP) e 10 aos afetos negativos (AN), sendo que cada subescala pode ter pontual máxima igual a 50. Os resultados obtidos por G1 e G2 estão apresentados na Tabela 13. 
Tabela 13. Indicadores da Escala de Afetos (EA) e sua comparação estatística em função dos grupos.

\begin{tabular}{cccccccccc}
\hline Afetos & \multicolumn{3}{c}{$\mathrm{G} 1(\mathrm{n}=40)$} & \multicolumn{3}{c}{$\mathrm{G} 2(\mathrm{n}=40)$} & \multicolumn{3}{c}{ Comparação estatística } \\
& Média & DP & Min/Max & Média & DP & Min/Max & $t$ & $p$ & $d$ \\
\hline Positivos & 41,4 & 7,2 & $20 / 50$ & 44,3 & 5,5 & $29 / 50$ & $-2,041$ & 0,045 & $-0,456$ \\
Negativos & 27,6 & 9,5 & $12 / 50$ & 23,4 & 8,7 & $10 / 48$ & 2,094 & 0,039 & 0,468 \\
\hline
\end{tabular}

Nota: $D P=$ Desvio Padrão; Min = Mínimo; Max = Máximo; $t=$ Teste $\mathrm{t}$ de Student $p=$ nível de significância; $d=d$ de Cohen.

Pode-se notar que a vivência de afetos positivos (AP) obteve média bastante superior aos afetos negativos (AN) em ambos os grupos, correspondendo ao teoricamente previsto pelo instrumento (Zanon, Batianello, Paccio \& Hutz, 2013). Importante ressaltar que nesse artigo de adaptação da EA no Brasil obteve médias de $39,8( \pm 6,1)$ para afetos positivos e $27,8( \pm 7,3)$ para os afetos negativos. Comparando as médias de G1 e G2 com esses parâmetros de referência, percebe-se que as médias dos afetos positivos estão elevadas. Por outro lado, a média dos afetos negativos do grupo clínico está próxima ao estudo inicial da EA, enquanto em relação ao grupo de comparação está rebaixada. No entanto, o grupo avaliado para adaptação do instrumento era constituído de jovens universitários e os indivíduos da atual pesquisa são formados por pessoas com média de idade de 62 anos e escolaridade de ensino fundamental. Portanto, torna-se bastante limitada a comparação entre os achados das duas pesquisas, tendo em vista as diferenças de idade e escolaridade.

No tocante à comparação dos resultados médios dos dois grupos avaliados nesse trabalho, houve diferença estatisticamente significativa entre G1 e G2 na subescala AP e AN, em ambos os casos com importante tamanho de efeito. Assim, os indivíduos com cardiopatia (G1) apresentaram indicadores de menor intensidade de afetos positivos, porém maior força nas vivências de afetos negativos, quando comparados a indivíduos não pacientes (G2).

Os escores de vivências de Afetos Positivos e Afetos Negativos da EA também foram comparados entre os grupos em função do sexo dos participantes. Os resultados são apresentados na Tabela 14. 
Tabela 14. Indicadores da Escala de Afetos (EA) e sua comparação estatística em função do sexo dos participantes dos grupos.

\begin{tabular}{cccccccccccc}
\hline Afetos & \multicolumn{2}{c}{ G1 homens } & \multicolumn{2}{c}{ G1 mulheres } & \multicolumn{2}{c}{ G2 homens } & \multicolumn{2}{c}{ G2 mulheres } & \multicolumn{3}{c}{$\begin{array}{c}\text { Comparação } \\
\text { estatística }\end{array}$} \\
& $M$ & $D P$ & $M$ & $D P$ & $M$ & $D P$ & $M$ & $D P$ & $F$ & $p$ & $\dot{\eta}^{2}$ \\
\hline Positivos & 40,14 & 6,66 & 44,41 & 7,87 & 44,46 & 5,82 & 43,91 & 4,56 & 2,68 & 0,052 & 0,096 \\
Negativos & 27,78 & 10,01 & 27,41 & 8,56 & 22,32 & 9,16 & 26,50 & 7,35 & 1,92 & 0,133 & 0,071 \\
\hline \multicolumn{3}{l}{ Nota: M = Média; $D P=$ Desvio Padrão; $F=$ teste ANOVA; $p=$ nível de significância; $\dot{\eta}^{2}=$ eta. }
\end{tabular}

Não houve diferença estatisticamente significativa entre os grupos quando separados pelo sexo em relação à vivência de afetos positivos e negativos. Pode-se considerar que o sexo dos participantes não pareceu influenciar de modo relevante a expressão da afetividade nesses adultos avaliados.

Ao examinar possível influência da variável cronicidade (ou não) da cardiopatia na manifestação afetiva de adultos, chegou-se aos resultados sistematizados na Tabela 15. O Grupo Clínico foi subdividido em cardiopatas que sofreram primeiro evento cardíaco (G1a) e cardiopatas crônicos (G1b), comparando-os com os participantes de G2.

Tabela 15. Indicadores da Escala de Afetos (EA) e sua comparação estatística em função da cronicidade (ou não) da cardiopatia entre os grupos.

\begin{tabular}{cccccccccc}
\hline & \multicolumn{3}{c}{ Grupo Clínico $(\mathrm{G} 1)$} & \multicolumn{2}{c}{ Grupo de } & \multicolumn{3}{c}{ Comparação } \\
Afetos & Primeiro evento & \multicolumn{2}{c}{ Crônicos } & \multicolumn{2}{c}{$\begin{array}{c}\text { Comparação } \\
\text { estatística }\end{array}$} \\
& \multicolumn{2}{c}{ (G1a, $\mathrm{n}=22)$} & \multicolumn{2}{c}{$(\mathrm{G} 1 \mathrm{~b}, \mathrm{n}=18)$} & \multicolumn{2}{c}{$(\mathrm{G} 2, \mathrm{n}=40)$} & & & \\
& $M$ & $D P$ & $M$ & $D P$ & $M$ & $D P$ & $F$ & $p$ & $\dot{\eta}^{2}$ \\
\hline Positivos & 41,68 & 6,76 & 41,11 & 7,94 & 44,30 & 5,42 & 2,040 & 0,137 & 0,050 \\
Negativos & 26,54 & 8,29 & 29,05 & 10,87 & 23,57 & 8,78 & 2,373 & 0,100 & 0,058 \\
\hline
\end{tabular}

Nota: $\mathrm{M}=$ Média; $D P=$ Desvio Padrão; $F=$ teste ANOVA; $p=$ nível de significância; $\dot{\eta}^{2}=$ eta.

Ao realizar análise da variância dos resultados dos três subgrupos independentes, não foi encontrada diferença estatisticamente significativa. Mais uma vez, o fato do paciente estar passando por primeiro evento cardíaco ou já ter cardiopatia prévia 
pareceu não diferenciar de modo relevante suas vivências de afetos quando comparado a um grupo pareado em sexo e balanceado em idade, escolaridade e nível socioeconômico.

\subsection{Teste de Zulliger}

O Teste de Zulliger traz informações sobre variáveis relacionadas ao funcionamento psíquico e comumente denominadas como características de personalidade. Permitem levantar hipóteses acerca do funcionamento cognitivo, afetivo e sobre a adaptação social dos indivíduos, conforme diretrizes técnicas da Escola de Paris (Resende, 2016).

Com relação a esse método projetivo de avaliação psicológica o primeiro resultado a ser considerado é relativo a sua precisão, ou seja, a segurança técnica sobre os dados. Nesse trabalho foi realizado o cálculo de acordo entre juízes independentes na classificação das respostas ao Teste de Zulliger como indicador psicométrico de sua precisão, por meio do Coeficiente Kappa. Esse índice varia de 0 a 1, considerando-se como adequados valores superiores a 0,75 (Fonseca, Silva \& Silva, 2007; Matos, 2014). No presente trabalho, encontrou-se índice Kappa médio igual a 0,921 para as localizações das respostas no Zulliger; 0,912 para determinantes das respostas e 0,855 para seus conteúdos. Portanto, o acordo entre juízes foi considerado excelente para os protocolos analisados, atribuindo segurança aos achados (fidedignidade).

Garantida a precisão dos dados, inicialmente são apresentadas as variáveis relacionadas aos indicadores de produtividade (respostas, respostas adicionais, denegações e recusas) e de ritmo (tempo de latência, tempo total, tempo de reação médio) no Teste de Zulliger. A Tabela 16 traz esses resultados, comparando estatisticamente os grupos.

Tabela 16. Índices de produtividade e ritmo no Teste de Zulliger em função dos grupos.

\begin{tabular}{cccccccccc}
\hline Variável & \multicolumn{3}{c}{$\mathrm{G} 1(\mathrm{n}=40)$} & \multicolumn{3}{c}{$\mathrm{G} 2(\mathrm{n}=40)$} & \multicolumn{3}{c}{ Comparação estatística } \\
& Média & DP & Min/Max & Média & DP & Min/Max & $t$ & $p$ & $d$ \\
\hline Respostas & 7,87 & 2,78 & $3 / 16$ & 8,50 & 3,03 & $3 / 15$ & $-0,959$ & 0,384 & 0,214 \\
RA & 0,50 & 0,96 & $0 / 4$ & 0,57 & 0,78 & $0 / 3$ & $-0,383$ & 0,703 & 0,086 \\
Denegações & 0,30 & 0,68 & $0 / 3$ & 0,15 & 0,42 & $0 / 2$ & 1,173 & 0,244 & $-0,262$ \\
Recusas & - & - & - & - & - & - & - & - & -
\end{tabular}




$\begin{array}{cccccccccc}\text { TLm* } & 55,13 & 38,45 & 9 / 179 & 49,80 & 25,23 & 8 / 117 & 0,733 & 0,466 & -0,164 \\ \text { TT* }^{*} & 226,35 & 83,86 & 126 / 423 & 214,82 & 73,05 & 107 / 455 & 0,655 & 0,514 & -0,147 \\ \text { TRm* } & 31,37 & 13,68 & 13,8 / 69,7 & 27,66 & 10,70 & 9,6 / 51,2 & 1,351 & 0,181 & -0,302\end{array}$

Nota: $D P=$ Desvio Padrão; Min = Mínimo; $M a x=$ Máximo $; \mathrm{RA}=$ respostas adicionais; TLm = Tempo de Latência médio; TT $=$ Tempo Total; TRm $=$ Tempo médio de resposta; $t=$ Teste $t$ de Student; $p=$ nível de significância; $d=d$ de Cohen.

* Tempo descrito em segundos.

Observa-se que em relação ao ritmo de trabalho e aos indicadores de produtividade, os grupos não apresentaram diferenças estatisticamente significativas no Teste de Zulliger. Dessa forma, infere-se que os participantes de G1 e G2 apresentaram sinais similares de funcionamento associativo-interpretativo da realidade, com velocidade semelhante no processamento dos estímulos. O contexto de adoecimento pareceu não interferir na atividade produtiva dos participantes frente à tarefa de interpretar cartões com manchas imprecisas, sinalizando bom funcionamento produtivo.

Um segundo grupo de variáveis do Teste de Zulliger diz respeito aos processos de apreensão dos estímulos (localização das respostas). As análises descritiva e comparativa entre os grupos, no tocante aos modos de apreensão, estão apresentadas na Tabela 17.

Tabela 17. Modos de apreensão no Teste de Zulliger em função dos grupos.

\begin{tabular}{cccccccccc}
\hline Modos de & \multicolumn{3}{c}{ G1 $(\mathrm{n}=40)$} & \multicolumn{3}{c}{ G2 $(\mathrm{n}=40)$} & \multicolumn{3}{c}{ 'omparação estatística } \\
apreensão & Média & DP & Min/Max & Média & DP & Min/Max & $t$ & $p$ & $d$ \\
\hline G\% & 17,98 & 15,72 & $0 / 75$ & 18,80 & 17,41 & $0 / 83,3$ & $-0,222$ & 0,825 & 0,050 \\
D\% & 62,47 & 17,62 & $25 / 100$ & 61,05 & 18,29 & $0 / 85,7$ & 0,352 & 0,726 & $-0,079$ \\
Dd\% & 13,94 & 13,01 & $0 / 44,4$ & 11,52 & 10,54 & $0 / 44,4$ & 0,912 & 0,364 & $-0,204$ \\
Db1\% & 4,63 & 7,44 & $0 / 25$ & 6,94 & 8,01 & $0 / 33,3$ & $-1,332$ & 0,187 & 0,298 \\
\hline
\end{tabular}

Nota: $D P$ = Desvio Padrão; Min = Mínimo; Max = Máximo; G = Respostas Globais; D = Respostas de Grande Detalhe; Dd = Resposta de Pequeno Detalhe; Dbl = Resposta na parte branca do cartão; $t=$ Teste $t$ de Student; $p=$ nível de significância; $d=d$ de Cohen.

Ao examinar esses dados é possível notar a inexistência de diferenças estatisticamente significativas entre G1 e G2 nas proporções de uso das áreas globais $(\mathrm{G} \%)$, dos grandes detalhes $(\mathrm{D} \%)$, dos pequenos detalhes $(\mathrm{Dd} \%)$ ou das áreas brancas dos cartões (Dbl\%) do Teste de Zulliger. Nos dois grupos, predominaram as respostas de Grande Detalhe (D\%), seguidas pelas respostas Globais (G\%), com menor incidência 
de interpretação dos Pequenos Detalhes (Dd\%) e reduzido uso das partes brancas dos cartões (Dbl\%). Esses dados acompanham os achados relatados por Resende (2016) em indivíduos adultos da comunidade, portanto, indivíduos saudáveis. Permitem identificar que a atenção dos adultos avaliados está centrada em elementos relevantes da realidade (resposta em área D), associados a uma visão integradora dos estímulos (resposta global G), fortalecendo indicadores de preservação de seu funcionamento lógico.

Outro grupo de variáveis do Teste de Zulliger a ser examinado diz respeito aos determinantes das respostas. As categorias são variadas, envolvendo as combinações entre aspectos formais, cromáticos, de sombreado e de movimento das respostas, como preconizado pela Escola de Paris (Resende, 2016). Os achados relativos aos determinantes, em termos descritivos e comparativos entre os grupos, podem ser visualizados na Tabela 18.

Tabela 18. Determinantes das respostas no Teste de Zulliger em função dos grupos.

\begin{tabular}{|c|c|c|c|c|c|c|c|c|c|}
\hline \multirow{2}{*}{$\begin{array}{l}\text { Determi- } \\
\text { nantes }\end{array}$} & \multicolumn{3}{|c|}{ G1 $(n=40)$} & \multicolumn{3}{|c|}{$\mathrm{G} 2(\mathrm{n}=40)$} & \multicolumn{3}{|c|}{ Comparaçãoestatística } \\
\hline & Média & $D P$ & $\operatorname{Min} / \operatorname{Max}$ & Média & $D P$ & $\operatorname{Min} / \operatorname{Max}$ & $t$ & $p$ & $d$ \\
\hline $\mathrm{F} \% * *$ & 48,24 & 24,65 & $0 / 100,0$ & 52,39 & 25,74 & $0 / 100,0$ & 0,737 & 0,464 & 0,165 \\
\hline $\mathrm{F}+\% * *$ & 66,78 & 30,95 & $0 / 100,0$ & 65,17 & 29,44 & $0 / 100,0$ & $-0,231$ & 0,818 & $-0,053$ \\
\hline $\mathrm{F}+\operatorname{ext} \% * *$ & 44,54 & 17,86 & $0 / 85,7$ & 43,30 & 21,68 & $0 / 100,0$ & $-0,279$ & 0,781 & $-0,062$ \\
\hline $\mathrm{FC}^{*}$ & 0,55 & 0,84 & $0 / 3$ & 0,52 & 0,59 & $0 / 2$ & $-0,153$ & 0,879 & $-0,034$ \\
\hline $\mathrm{CF}^{*}$ & 0,82 & 0,93 & $0 / 3$ & 0,77 & 0,83 & $0 / 4$ & $-0,253$ & 0,801 & $-0,057$ \\
\hline $\mathrm{C}^{*}$ & - & - & - & 0,10 & 0,49 & $0 / 3$ & 1,275 & 0,206 & - \\
\hline$\sum \mathrm{Cp}^{*}$ & 1,10 & 0,96 & $0 / 3,5$ & 1,18 & 1,22 & $0 / 6$ & 0,354 & 0,724 & 0,079 \\
\hline $\mathrm{FE}^{*}$ & 0,42 & 0,59 & $0 / 2$ & 0,25 & 0,54 & $0 / 2$ & $-1,375$ & 0,173 & $-0,307$ \\
\hline $\mathrm{EF}^{*}$ & 0,40 & 0,67 & $0 / 2$ & 0,37 & 0,66 & $0 / 3$ & $-0,167$ & 0,868 & $-0,037$ \\
\hline $\mathrm{E}^{*}$ & - & - & - & 0,02 & 0,15 & $0 / 1$ & 1,000 & 0,320 & - \\
\hline$\sum \mathrm{Ep}^{*}$ & 0,61 & 0,73 & $0 / 2$ & 0,53 & 0,71 & $0 / 3$ & $-0,460$ & 0,647 & $-0,103$ \\
\hline FClob* & 0,07 & 0,26 & $0 / 1$ & 0,05 & 0,22 & $0 / 1$ & $-0,457$ & 0,649 & $-0,102$ \\
\hline ClobF* & 0,02 & 0,15 & $0 / 1$ & - & - & - & $-1,000$ & 0,320 & - \\
\hline Clob* & - & - & - & 0,02 & 0,15 & $0 / 1$ & 1,000 & 0,320 & - \\
\hline $\mathrm{K}^{*}$ & 0,55 & 0,59 & $0 / 2$ & 0,70 & 0,75 & $0 / 3$ & 0,983 & 0,328 & 0,220 \\
\hline $\begin{array}{l}\sum \text { pequenas } \\
\text { cinestesias* }\end{array}$ & 0,97 & 0,89 & $0 / 3$ & 1,10 & 0,87 & $0 / 3$ & 0,634 & 0,528 & 0,142 \\
\hline
\end{tabular}


Nota: $D P=$ Desvio Padrão; Min = Mínimo; $\operatorname{Max}=$ Máximo $t=$ Teste $t$ de Student $p=$ nível de significância; $d=d$ de Cohen.

*Determinantes expressos em frequência simples; **Determinantes expressos em porcentagem.

Em relação aos determinantes não houve diferença estatisticamente significativa entre os grupos. Faz-se relevante destacar que praticamente metade dos protocolos do Zulliger, tanto em G1 quanto em G2, tiveram suas respostas prioritariamente determinadas pela forma, como indica a variável $\mathrm{F} \%$. $\mathrm{O}$ ajuste perceptivo dessas interpretações, por sua vez, sinalizado pelas variáveis F+\% e F+ext\% mostrou-se compatível a indicativos de adequado funcionamento lógico, acompanhando expectativas normativas para adultos (Resende, 2016). Outros sinalizadores nessa direção são os determinantes formais associados a cor e a sombreado (FC e FE), porém ajustados às áreas interpretadas, representando adequação racional nessas respostas. Nota-se, por fim, que determinantes dissociados dos elementos formais (respostas sem forma) ocorreram em baixíssima frequência nos dois grupos, reafirmando sinais de preservação em seu funcionamento lógico.

Outro conjunto de variáveis analisadas nesse método se refere aos conteúdos das respostas fornecidas, o que pode ser visualizado na Tabela 19. Os dados estão apresentados de forma descritiva e com análise estatística comparativa entre resultados médios de G1 e G2.

Tabela 19. Conteúdos das respostas no Teste de Zulliger em função dos grupos.

\begin{tabular}{cccccccccc}
\hline \multirow{2}{*}{ Conteúdos } & \multicolumn{3}{c}{ G1 (n=40) } & \multicolumn{3}{c}{ G2 (n=40) } & \multicolumn{3}{c}{ Comparação estatística } \\
& Média & DP & Min/Max & Média & DP & Min/Max & $t$ & $p$ & $d$ \\
\hline A* & 3,60 & 2,04 & $0 / 11$ & 3,87 & 1,96 & $0 / 9$ & 0,613 & 0,542 & 0,137 \\
(A)* & 0,32 & 0,82 & $0 / 4$ & 0,30 & 0,56 & $0 / 2$ & $-0,158$ & 0,875 & $-0,035$ \\
Ad* $^{*}$ & 0,30 & 0,56 & $0 / 2$ & 0,47 & 0,81 & $0 / 3$ & 1,116 & 0,268 & 0,249 \\
$(\mathrm{Ad})^{*}$ & 0,12 & 0,33 & $0 / 1$ & 0,10 & 0,37 & $0 / 2$ & $-0,313$ & 0,755 & $-0,070$ \\
A\%** & 54,23 & 15,29 & $22 / 81$ & 55,86 & 20,75 & $0 / 100$ & 0,402 & 0,689 & 0,090 \\
$\mathrm{H}^{*}$ & 0,87 & 0,88 & $0 / 3$ & 0,95 & 1,06 & $0 / 4$ & 0,344 & 0,732 & 0,077 \\
$(\mathrm{H})^{*}$ & 0,42 & 0,54 & $0 / 2$ & 0,32 & 0,57 & $0 / 2$ & $-0,797$ & 0,428 & $-0,178$ \\
$\mathrm{Hd}^{*}$ & 0,35 & 0,69 & $0 / 3$ & 0,30 & 0,68 & $0 / 2$ & 0,772 & 0,748 & $-0,072$ \\
$(\mathrm{Hd})^{*}$ & 0,07 & 0,26 & $0 / 1$ & 0,05 & 0,22 & $0 / 1$ & 0,361 & 0,649 & $-0,102$ \\
$\mathrm{H}^{* *}$ & 22,44 & 12,26 & $0 / 50$ & 19,73 & 15,44 & $0 / 66$ & $-0,869$ & 0,388 & $-0,194$ \\
\hline
\end{tabular}




\begin{tabular}{cccccccccc}
\hline Anat* & 0,22 & 0,47 & $0 / 2$ & 0,32 & 0,57 & $0 / 2$ & 0,847 & 0,400 & 0,189 \\
Sg* & - & - & - & - & - & - & - & - & - \\
Sex* & - & - & - & 0,02 & 0,15 & $0 / 1$ & 1,000 & 0,320 & - \\
Obj* & 0,40 & 0,74 & $0 / 3$ & 0,27 & 0,64 & $0 / 3$ & $-0,805$ & 0,423 & $-0,180$ \\
Art* & 0,02 & 0,15 & $0 / 1$ & 0,02 & 0,15 & $0 / 1$ & 0,000 & 1,000 & 0,000 \\
Arq* & 0,05 & 0,22 & $0 / 1$ & 0,10 & 0,30 & $0 / 1$ & 0,842 & 0,402 & 0,188 \\
Simb* & 0,27 & 0,45 & $0 / 1$ & 0,17 & 0,54 & $0 / 3$ & $-0,889$ & 0,377 & $-0,199$ \\
Abs* & - & - & - & 0,15 & 0,66 & $0 / 4$ & 1,433 & 0,156 & - \\
Bot* & 0,75 & 0,83 & $0 / 3$ & 0,80 & 0,88 & $0 / 3$ & 0,260 & 0,796 & 0,058 \\
Geo* & 0,02 & 0,15 & $0 / 1$ & 0,07 & 0,34 & $0 / 2$ & 0,824 & 0,413 & 0,184 \\
Nat* & - & - & - & 0,05 & 0,22 & $0 / 1$ & 1,433 & 0,156 & - \\
Pais* & - & - & - & 0,07 & 0,26 & $0 / 1$ & 1,778 & 0,079 & - \\
Elem* & 0,02 & 0,15 & $0 / 1$ & 0,05 & 0,22 & $0 / 1$ & 0,582 & 0,562 & 0,000 \\
Frag* & - & - & - & 0,12 & 0,33 & $0 / 1$ & 2,360 & 0,021 & - \\
Ban\%** & 26,79 & 18,6 & $0 / 100$ & 28,15 & 14,27 & $0 / 75$ & 0,366 & 0,715 & 0,082 \\
\hline
\end{tabular}

Nota: $D P=$ Desvio Padrão; Min = Mínimo; Max = Máximo; $t=$ Teste $t$ de Student; $p=$ nível de significância; $d=d$ de Cohen.

*Medidas expressas em frequência simples; **Valores expressos em porcentagem.

É fácil identificar grande dispersão nos conteúdos das respostas dos indivíduos avaliados. Dos conteúdos expressos por G1 e G2, apenas a variável Fragmento (Frag) apresentou diferença estatisticamente significativa entre os grupos, porém em baixíssima frequência e, portanto, reduzido significado clínico. No G1 essa variável foi ausente, o que não permitiu calcular o tamanho do efeito dessa variável nas análises comparativas. As respostas concentraram-se em conteúdos animais (mais da metade das interpretações) e humanos (cerca de $20 \%$ das respostas), deixando para as demais categorias pluralidade de expressões, revelando diversidade de interesses dos participantes. Esses achados são compatíveis com os encontrados por Resende (2016) em seu trabalho, evidenciando que os participantes desse estudo apresentam diversidade de interesses semelhante ao grupo normativo, independente do adoecimento.

No entanto, no que diz respeito à frequência das Banalidades (Ban\%), os grupos apresentaram médias mais baixas do que o grupo normativo (segundo Resende, 2016, seu valor atinge $34,2 \% \pm 18,8 \%)$. Essa variável pode ser sugestiva de menor conformismo social ou criatividade aguçada quando interpretada com outras variáveis, 
porém qualquer inferência se fragiliza por ser uma única variável isolada no conjunto dos demais indicadores técnicos desse método projetivo de avaliação psicológica.

O Teste de Zulliger possibilita, dentro da perspectiva da Escola Francesa, análise dos tipos vivenciais da afetividade a partir de duas variáveis, a saber: a) primeira fórmula afetiva $=$ Tipo de Ressonância Íntima (TRI), calculado pela proporção de respostas de movimento $(\mathrm{K})$ em relação à soma ponderada das respostas de cor $\left(\sum \mathrm{Cp}\right)$; b) segunda fórmula afetiva = calculado pela proporção da soma ponderada das pequenas cinestesias ( $\sum$ pequenas cinestesias) em relação à soma ponderada das respostas com sombreado ( $\left.\sum E p\right)$. A partir dessas variáveis, os indivíduos são classificados em tipos de vivência afetiva, podendo ser: introversivo, extratensivo ou coartação emocional (também denominado como evitativo). Associadas a essas variáveis também é analisada a Fórmula da Angústia, indicador que se torna sinal de ansiedade clínica quando superior a $12 \%$.

Na Tabela 20 estão sistematizadas as informações relativas à classificação dos adultos em função dos tipos de vivência afetiva pelos indicadores do Teste de Zulliger. São apresentados resultados descritivos e comparativos dos grupos avaliados.

Tabela 20. Tipos Vivenciais e Fórmula da Angústia no Teste de Zulliger em função dos grupos.

\begin{tabular}{|c|c|c|c|c|c|c|c|}
\hline \multirow{2}{*}{$\begin{array}{c}\text { Variável e } \\
\text { Tipos Vivenciais }\end{array}$} & \multicolumn{2}{|c|}{$\mathrm{G} 1(\mathrm{n}=40)$} & \multicolumn{2}{|c|}{$\mathrm{G} 2(\mathrm{n}=40)$} & \multicolumn{3}{|c|}{ Comparação estatística } \\
\hline & $f$ & $\%$ & $f$ & $\%$ & $X^{2}$ & $p$ & $V$ \\
\hline \multicolumn{8}{|l|}{$1^{a}$. fórmulaafetiva TRI } \\
\hline Introversivo & 9 & 22,5 & 10 & 25,0 & \multirow{3}{*}{1,561} & \multirow{3}{*}{0,458} & \multirow{3}{*}{0,140} \\
\hline Extratensivo & 17 & 42,5 & 21 & 52,5 & & & \\
\hline Coartado & 14 & 35,0 & 9 & 22,5 & & & \\
\hline \multicolumn{8}{|l|}{$2^{a}$. fórmula afetiva } \\
\hline Introversivo & 16 & 40,0 & 19 & 47,5 & \multirow{3}{*}{2,305} & \multirow{3}{*}{0,316} & \multirow{3}{*}{0,170} \\
\hline Extratensivo & 9 & 22,5 & 4 & 10,0 & & & \\
\hline Coartado & 15 & 37,5 & 17 & 42,5 & & & \\
\hline \multicolumn{8}{|l|}{ Fórmula Angústia } \\
\hline Clínica & 12 & 30,0 & 12 & 30,0 & \multirow{2}{*}{$\leq 0,001$} & \multirow{2}{*}{1,000} & \multirow{2}{*}{$\leq 0,001$} \\
\hline Não clínica & 28 & 70,0 & 28 & 70,0 & & & \\
\hline
\end{tabular}

Nota: $f=$ frequência; $\%$ = porcentagem; $\mathrm{X}^{2}=$ Qui-Quadrado; $p=$ nível de significância; $V=V$ de $C r a m e r ;$ TRI = Tipo de Ressonância Íntima (primeira fórmula afetiva). 
Não houve diferenças estatisticamente significativas em relação à distribuição dos indivíduos de G1 ou G2 pelos tipos vivenciais ou Fórmula da Angústia. No TRI, houve predomínio do tipo Extratensivo em ambos os grupos, seguido pelo tipo Coartado no G1 e Introversivo no G2.

Ao comparar esses achados frente ao descrito como normativo para adultos (Resende, 2016), nota-se nos indivíduos avaliados maior número de extratensivos do que o esperado. Assim, os participantes da pesquisa evidenciaram estilo habitual de vivências afetivas mais voltadas ao mundo externo, com expressão mais direta dos afetos.

No que concerne à Fórmula da Angústia, os grupos se mostraram análogos. Desse modo, os achados apontaram que a cardiopatia não pareceu potencializar indicadores clínicos de angústia na estrutura de personalidade em adultos.

As variáveis do Teste de Zulliger também foram comparadas em função do sexo dos participantes de cada grupo. Foram selecionadas as variáveis mais relevantes entre os indicadores de ritmo e produtividade, modos de apreensão, determinantes e conteúdos. Os resultados constam na Tabela 21.

Tabela 21. Principais variáveis do Teste de Zulliger e sua comparação estatística em função do sexo dos participantes dos grupos.

\begin{tabular}{ccccccccccccc}
\hline Variável & \multicolumn{2}{c}{ G1 homens } & \multicolumn{2}{c}{ G1 mulheres } & \multicolumn{2}{c}{ G2 homens } & \multicolumn{2}{c}{ G2 mulheres } & \multicolumn{3}{c}{ Comparação } \\
Zulliger & $(\mathrm{n}=28)$ & \multicolumn{2}{c}{$(\mathrm{n}=12)$} & $(\mathrm{n}=28)$ & \multicolumn{2}{c}{$(\mathrm{n}=12)$} & \multicolumn{3}{c}{ estatística } \\
& $M$ & $D P$ & $M$ & $D P$ & $M$ & $D P$ & $M$ & $D P$ & $F$ & $p$ & $\dot{\eta}^{2}$ \\
\hline Respostas* & 7,82 & 3,11 & 8,00 & 1,90 & 8,57 & 3,31 & 8,33 & 2,38 & 0,328 & 0,805 & 0,013 \\
TLm*** & 50,61 & 34,53 & 65,66 & 46,29 & 52,89 & 24,53 & 42,58 & 26,42 & 1,069 & 0,367 & 0,040 \\
TRm*** & 32,66 & 14,42 & 28,34 & 11,75 & 28,29 & 11,90 & 26,19 & 7,45 & 1,028 & 0,385 & 0,039 \\
G\%** & 19,13 & 16,89 & 15,29 & 12,84 & 14,85 & 14,24 & 28,04 & 21,09 & 2,035 & 0,116 & 0,074 \\
D\%** & 60,87 & 18,27 & 66,19 & 16,12 & 63,67 & 12,68 & 54,94 & 27,08 & 0,958 & 0,417 & 0,036 \\
Dd\%** & 14,73 & 13,72 & 12,09 & 11,52 & 13,54 & 11,40 & 6,80 & 6,38 & 1,344 & 0,267 & 0,050 \\
Db1\%** & 4,89 & 7,96 & 4,03 & 6,31 & 7,91 & 8,23 & 4,65 & 7,27 & 1,120 & 0,346 & 0,042 \\
F\%** & 48,07 & 24,01 & 48,63 & 27,21 & 53,94 & 25,44 & 48,78 & 27,21 & 0,293 & 0,830 & 0,011 \\
F+\%** & 67,22 & 30,79 & 65,83 & 32,67 & 63,40 & 32,45 & 69,35 & 21,45 & 0,121 & 0,948 & 0,005 \\
F+ext\%** & 45,69 & 17,73 & 41,88 & 18,66 & 42,80 & 22,94 & 44,47 & 19,28 & 0,146 & 0,932 & 0,006
\end{tabular}




$\begin{array}{cccccccccccc}\sum \mathbf{C p} * & 1,03 & 1,03 & 1,25 & 0,81 & 0,85 & 0,97 & 1,95 & 1,45 & 3,201 & 0,028 & 0,112 \\ \sum \mathrm{Ep}^{*} & 0,66 & 0,73 & 0,50 & 0,76 & 0,50 & 0,65 & 0,62 & 0,88 & 0,284 & 0,837 & 0,011 \\ \mathrm{~K}^{*} & 0,53 & 0,57 & 0,58 & 0,66 & 0,82 & 0,77 & 0,41 & 0,66 & 1,339 & 0,268 & 0,050 \\ \sum_{\text {pequenascinestesias* }} & 0,92 & 0,81 & 1,08 & 1,08 & 1,14 & 0,84 & 1,00 & 0,95 & 0,288 & 0,834 & 0,011 \\ \text { A\%** } & 53,48 & 17,29 & 55,98 & 9,51 & 56,37 & 19,13 & 54,68 & 25,02 & 0,128 & 0,943 & 0,005 \\ \text { H\%** } & 22,55 & 11,86 & 22,19 & 13,69 & 23,97 & 15,00 & 9,85 & 11,87 & 3,420 & 0,021 & 0,119 \\ \text { Ban\%** } & 28,87 & 19,58 & 21,93 & 15,95 & 27,54 & 16,37 & 29,58 & 7,81 & 0,573 & 0,634 & 0,022\end{array}$

Nota: $\mathrm{M}=$ Média; $D P=$ Desvio Padrão; $F=$ teste ANOVA; $p=$ nível de significância; $\dot{\eta}^{2}=$ eta .

*** Tempo expresso em segundos.

*Medidas expressas em frequência simples; **Valores expressos em porcentagem.

Não foram encontradas diferenças estatisticamente significativas entre os subgrupos na maioria das variáveis. As exceções foram o somatório de cor ponderada ( $\left.\sum \mathrm{Cp}\right)$ e o conteúdo de figuras humanas (H\%), variáveis relacionadas ao controle afetivo $\left(\sum \mathrm{Cp}\right)$ e a disposição para o contato interpessoal $(\mathrm{H} \%)$. No entanto, o tamanho do efeito dessas diferenças foi reduzido, limitando seu valor interpretativo perante o conjunto de variáveis examinadas. Desse modo, têm-se evidências de ausência de influência do sexo no padrão de respostas ao teste de Zulliger entre os adultos avaliados.

Outra análise realizada entre os subgrupos focalizou a questão da cronicidade (ou não) da cardiopatia nos resultados desse método projetivo. O grupo clínico foi subdividido em pacientes de primeiro evento cardíaco (G1a) e pacientes cardiopatas crônicos (G1b), além do grupo de comparação (G2), realizando-se análise da variância dos resultados nas principais variáveis do Teste de Zulliger. Esses achadosestão expostos na Tabela 22.

Tabela 22. Principais indicadores do Teste de Zulliger e sua comparação estatística em função da cronicidade (ou não) da cardiopatia entre os grupos.

\begin{tabular}{cccccccccc}
\hline Variável & \multicolumn{3}{c}{ Grupo clínico $(\mathrm{G} 1)$} & \multicolumn{2}{c}{ Grupo de } \\
Zulliger & $\begin{array}{c}\text { Primeiro evento } \\
\text { (G1a, } \mathrm{n}=22)\end{array}$ & \multicolumn{2}{c}{ Crônicos } & \multicolumn{2}{c}{$\begin{array}{c}\text { Comparação } \\
(\mathrm{G} 1 \mathrm{~b}, \mathrm{n}=18)\end{array}$} & \multicolumn{2}{c}{ Comparação Estatística } \\
& $M$ & $D P$ & $M$ & $D P$ & $M$ & $D P$ & $F$ & $p$ & $\eta^{2}$ \\
\hline Respostas* & 8,22 & 2,38 & 7,44 & 3,22 & 8,50 & 2,38 & 0,814 & 0,447 & 0,021 \\
TLm*** & 51,83 & 35,17 & 59,16 & 42,80 & 49,80 & 25,23 & 0,517 & 0,598 & 0,013 \\
TRm*** & 28,28 & 12,24 & 35,14 & 14,72 & 27,66 & 10,70 & 2,528 & 0,086 & 0,062
\end{tabular}




\begin{tabular}{|c|c|c|c|c|c|c|c|c|c|}
\hline $\mathrm{G} \% * *$ & 16,56 & 12,93 & 19,71 & 18,84 & 18,80 & 17,41 & 0,201 & 0,818 & 0,005 \\
\hline $\mathrm{D} \% * *$ & 62,74 & 16,17 & 62,13 & 19,74 & 61,05 & 18,29 & 0,067 & 0,936 & 0,002 \\
\hline $\mathrm{Dd} \% * *$ & 15,68 & 13,49 & 11,81 & 12,45 & 11,52 & 10,54 & 0,944 & 0,393 & 0,024 \\
\hline Dbl\%** & 3,25 & 6,49 & 6,32 & 8,33 & 6,94 & 8,01 & 1,684 & 0,192 & 0,042 \\
\hline $\mathrm{F} \% * *$ & 54,90 & 22,73 & 40,10 & 25,07 & 52,39 & 25,74 & 2,041 & 0,137 & 0,050 \\
\hline $\mathrm{F}+\% * *$ & 67,17 & 23,49 & 66,30 & 39,06 & 65,17 & 29,44 & 0,030 & 0,970 & 0,001 \\
\hline $\mathrm{F}+\operatorname{ext} \% * *$ & 47,89 & 13,14 & 40,45 & 22,04 & 43,30 & 21,68 & 0,736 & 0,482 & 0,019 \\
\hline$\sum \mathrm{Cp} *$ & 1,00 & 0,97 & 1,22 & 0,97 & 1,18 & 1,22 & 0,260 & 0,771 & 0,007 \\
\hline$\sum \mathrm{Ep}^{*}$ & 0,54 & 0,72 & 0,69 & 0,76 & 0,53 & 0,71 & 0,310 & 0,734 & 0,008 \\
\hline $\mathrm{K}^{*}$ & 0,45 & 0,50 & 0,66 & 0,68 & 0,70 & 0,75 & 0,962 & 0,387 & 0,024 \\
\hline $\begin{array}{l}\sum \text { pequenas } \\
\text { cinestesias* }\end{array}$ & 0,86 & 0,83 & 1,11 & 0,96 & 1,10 & 0,87 & 0,590 & 0,557 & 0,015 \\
\hline $\mathrm{A} \% * *$ & 55,57 & 12,32 & 52,59 & 18,54 & 55,86 & 20,75 & 0,210 & 0,811 & 0,005 \\
\hline $\mathrm{H} \% * *$ & 23,19 & 13,40 & 21,52 & 11,02 & 19,73 & 15,44 & 0,444 & 0,643 & 0,011 \\
\hline $\operatorname{Ban} \% * *$ & 28,14 & 15,41 & 25,14 & 16,51 & 28,15 & 14,27 & 0,226 & 0,798 & 0,006 \\
\hline
\end{tabular}

Nota: $\mathrm{M}=$ Média; $D P=$ Desvio Padrão; $F=$ teste ANOVA; $p=$ nível de significância; $\eta^{2}=$ eta .

*** Tempo expresso em segundos

*Medidas expressas em frequência simples; **Valores expressos em porcentagem.

De acordo com as análises realizadas, não foram encontradas diferenças estatisticamente significativas entre os subgrupos em nenhuma das variáveis. Desse modo, é possível inferir que os subgrupos G1a, G1b e G2 apresentaram resultados estatisticamente semelhantes nos indicadores do Teste de Zulliger relacionados ao funcionamento cognitivo e afetivo.

Há que se comentar, portanto, que a hipótese de possível diferenciação em vivências emocionais e no funcionamento lógico de adultos em um primeiro evento cardíaco não obteve sustentação empírica nos atuais achados. Os pacientes com cardiopatia também não se diferenciaram, de modo estatisticamente significativo, nos indicadores do Teste de Zulliger, sugerindo preservação das características de personalidade apesar da doença física. Esses resultados puderam ser complementados pela análise de outro método projetivo, o Teste de Pfister, baseado em estímulos e atividade diferenciada, como a seguir explorado. 


\subsection{Teste das Pirâmides Coloridas de Pfister}

O Teste Pirâmides Coloridas de Pfister permite avaliação de variáveis relacionadas ao funcionamento cognitivo e vivências afetivas dos participantes (Villemor-Amaral, 2012). Neste trabalho, serão apresentadas as análises descritivas e comparativas da frequência de uso das cores e as síndromes cromáticas, as fórmulas cromáticas, o processo de execução e modo de colocação, além do aspecto formal das pirâmides executadas por G1 e G2.

Os resultados relativos ao uso das cores e síndromes cromáticas do Teste de Pfister pelos indivíduos cardiopatas (G1) e pelos não pacientes (G2) estão presentes na Tabela 23. Os valores da frequência de cada cor foram calculados de acordo com a porcentagem de seu uso e as síndromes cromáticas foram calculadas a partir da soma da porcentagem das cores. Serão apresentadas as síndromes cromáticas principais: normal, estímulo, fria e incolor.

Tabela 23. Cores e síndromes cromáticas no Teste de Pfister e sua comparação estatística em função dos grupos.

\begin{tabular}{cccccccccc}
\hline Cores e & \multicolumn{3}{c}{ Grupo clínico } & \multicolumn{3}{c}{ Grupo de comparação } & \multicolumn{3}{c}{ Comparação estatística } \\
Síndromes & \multicolumn{3}{c}{ G1 (n=40) } & \multicolumn{3}{c}{ G2 $=40)$} & & \\
Cromáticas* & Média & DP & Min/Max & Média & DP & Min/Max & $t$ & $p$ & $d$ \\
\hline Azul & 15,54 & 14,43 & $0 / 82,2$ & 17,10 & 10,25 & $0 / 48,9$ & $-0,557$ & 0,579 & $-0,125$ \\
Vermelho & 16,10 & 8,78 & $0 / 33,4$ & 14,94 & 9,72 & $0 / 37,8$ & 0,561 & 0,577 & 0,125 \\
Verde & 21,71 & 13,75 & $0 / 80,0$ & 19,00 & 9,08 & $0 / 33,4$ & 1,042 & 0,301 & 0,233 \\
Violeta & 9,21 & 7,45 & $0 / 31,1$ & 7,55 & 5,49 & $0 / 17,8$ & 1,137 & 0,259 & 0,254 \\
Laranja & 7,76 & 6,37 & $0 / 33,3$ & 7,05 & 6,99 & $0 / 31,2$ & 0,476 & 0,635 & 0,106 \\
Amarelo & 11,27 & 9,91 & $0 / 44,4$ & 13,06 & 9,50 & $0 / 37,8$ & $-0,826$ & 0,411 & $-0,185$ \\
Marrom & 6,76 & 7,27 & $0 / 33,4$ & 7,21 & 11,92 & $0 / 66,7$ & $-0,203$ & 0,840 & $-0,045$ \\
Preto & 3,20 & 4,79 & $0 / 20,0$ & 3,60 & 6,28 & $0 / 33,4$ & $-0,322$ & 0,756 & 0,070 \\
Branco & 4,60 & 10,72 & $0 / 67,0$ & 6,60 & 7,30 & $0 / 33,4$ & $-0,974$ & 0,008 & 0,607 \\
Cinza & 2,15 & 2,53 & $0 / 8,0$ & 3,82 & 6,04 & $0 / 33,4$ & $-1,613$ & 0,112 & $-0,360$ \\
Normal & 53,35 & 16,16 & $0 / 82,2$ & 51,02 & 12,70 & $0 / 73,4$ & 0,717 & 0,476 & 0,160 \\
Estímulo & 34,41 & 15,76 & $0 / 66,8$ & 35,05 & 11,75 & $0 / 66,8$ & $-0,205$ & 0,838 & $-0,046$ \\
Fria & 47,29 & 17,59 & $0 / 100,0$ & 46,65 & 15,43 & $0 / 66,8$ & 0,983 & 0,329 & 0,220 \\
\hline
\end{tabular}




$\begin{array}{llllllllll}\text { Incolor } & 8,58 & 6,44 & 0 / 20,0 & 13,60 & 12,23 & 0 / 66,8 & -2,300 & 0,024 & -0,514\end{array}$

Nota: $D P=$ Desvio Padrão; Min = Mínimo; $\operatorname{Max}=$ Máximo; $t=$ Teste $t$ de Student; $p=$ nível de significância; $d=d$ de Cohen.

*Dados expressos em porcentagem.

A frequência de utilização das cores do Pfister apresentou resultados médios bastante próximos entre os grupos avaliados, embora com acentuada variabilidade entre os dados (elevado valor de desvio-padrão). A única cor em que os grupos apresentaram diferença estatisticamente significativa (e com médio tamanho de efeito) foi o branco, com frequência menor em G1 $(4,60 \pm 10,72)$ comparativamente ao resultado médio de

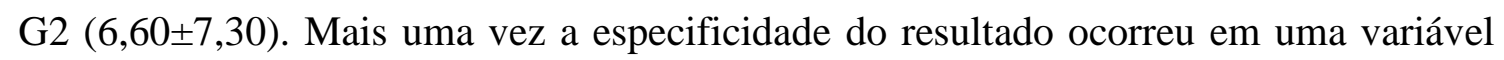
de baixa incidência em ambos os grupos, embora em valor assumidamente menor no Grupo Clínico. Por se tratar de apenas uma variável com diferença estatisticamente significativa, seu significado clínico fica reduzido na compreensão do conjunto dos achados, devendo ser examinada com cautela.

A maioria das frequências encontradas nos dois grupos foi compatível com a do grupo normativo exposto no manual do instrumento (Villemor-Amaral, 2012). A exceção se trata da cor marrom, que aparece elevada nos dois grupos em relação ao grupo normativo. Enquanto a média de marrom em G1 foi de 6,76\% e em G2 de 7,21\%, pelo grupo normativo é esperada frequência próxima a 4,0\%. O uso do marrom está associado a mecanismos defensivos mais primitivos e disposição a descarga emocional mais intensa e violenta, sendo encontrado em casos psicossomáticos (Villemor-Amaral, 2012). Dessa forma, levanta-se a hipótese que o grupo de indivíduos pesquisados recorreu a mecanismo de autocontrole pela rigidez (elevação do uso do marrom), independentemente de ter desenvolvido a cardiopatia.

Em relação às Síndromes Cromáticas, verificou-se mais uma vez que em apenas uma das variáveis examinadas foi identificada diferença estatisticamente significativa entre G1 e G2, a saber: na Síndrome Incolor, composta das cores branco, preto e cinza. Certamente a redução na frequência de uso da cor branca em G1 influenciou essa menor expressão da Síndrome Incolor nos indivíduos com cardiopatia, com média significativamente rebaixada $(\mathrm{G} 1=8,58 \pm 6,44)$ quando comparados com $\mathrm{G} 2$ $(13,60 \pm 12,23)$.

A partir da incidência das cores nas três pirâmides do Pfister foi possível constituir a Fórmula Cromática de cada caso, classificada em termos de sua amplitude e estabilidade das escolhas, com seus desvios representando tendências de abertura 
(desvio à esquerda) ou fechamento (desvio à direita) na captação emocional. Em termos interpretativos, a amplitude cromática diz respeito à abertura que o indivíduo tem para os estímulos do ambiente e a estabilidade das escolhas representa indicador da constância emocional (Villemor-Amaral, 2012). A distribuição das classificações das Fórmulas Cromáticas do Pfister dos casos avaliados consta na Tabela 24, incluindo sua análise estatística comparando G1 e G2.

Tabela 24. Fórmula Cromática do Teste Pfister e sua comparação estatística em função dos grupos.

\begin{tabular}{|c|c|c|c|c|c|c|c|}
\hline \multirow{2}{*}{$\begin{array}{l}\text { Fórmula } \\
\text { Cromática }\end{array}$} & \multicolumn{2}{|c|}{ G1 $(n=40)$} & \multicolumn{2}{|c|}{$\mathrm{G} 2(\mathrm{n}=40)$} & \multicolumn{3}{|c|}{ Comparação estatística } \\
\hline & $f$ & $\%$ & $f$ & $\%$ & $X^{2}$ & $p$ & $V$ \\
\hline \multicolumn{8}{|l|}{ Amplitude } \\
\hline Ampla & 24 & 60,0 & 24 & 60,0 & \multirow{3}{*}{$\leq 0,001$} & \multirow{3}{*}{1,000} & \multirow{3}{*}{$\leq 0,001$} \\
\hline Moderada & 8 & 20,0 & 8 & 20,0 & & & \\
\hline Restrita & 8 & 20,0 & 8 & 20,0 & & & \\
\hline \multicolumn{8}{|l|}{ Estabilidade } \\
\hline Estável & 3 & 7,5 & 9 & 22,5 & \multirow{3}{*}{3,549} & \multirow{3}{*}{0,170} & \multirow{3}{*}{0,211} \\
\hline Flexível & 28 & 70,0 & 23 & 57,5 & & & \\
\hline Instável & 9 & 22,5 & 8 & 20,0 & & & \\
\hline \multicolumn{8}{|l|}{ Desvio } \\
\hline Direita & 19 & 47,5 & 19 & 47,5 & \multirow{3}{*}{1,109} & \multirow{3}{*}{0,575} & \multirow{3}{*}{0,118} \\
\hline Esquerda & 4 & 10,0 & 7 & 17,5 & & & \\
\hline Sem desvio & 17 & 42,5 & 14 & 35,0 & & & \\
\hline \multicolumn{8}{|c|}{$\begin{array}{l}\text { Nota: } f=\text { Frequência; } \%=\text { Porcentagem; } X^{2}=\text { Teste Qui-Quadrado; } p=\text { Nível de significância; } V=\mathrm{V} \text { de } \\
\text { Cramer. }\end{array}$} \\
\hline \multicolumn{8}{|c|}{ Não foram encontradas diferenças estatisticamente significativas entre G1 e G2 } \\
\hline \multicolumn{8}{|c|}{ nas variáveis examinadas. Verificou-se em ambos os grupos predomínio de Fórmula } \\
\hline \multirow{2}{*}{\multicolumn{8}{|c|}{$\begin{array}{l}\text { Cromática do tipo Ampla (G1 e G2=60\%) e Flexível (G1 =70\%; G2=57,5\%), com } \\
\text { desvio para direita (G1 e G2=47,5\%). Segundo Villemor-Amaral (2012), este tipo de }\end{array}$}} \\
\hline & & & & & & & \\
\hline \multicolumn{8}{|c|}{$\begin{array}{l}\text { Fórmula Cromática é sugestivo de indivíduos com potencial para a ação direcionada a } \\
\text { objetivos específicos e capacidade de ajustamento pela flexibilidade, indicando }\end{array}$} \\
\hline
\end{tabular}


Outro grupo de variáveis do Teste de Pfister envolve o processo de execução e o modo de colocação dos quadrículos nas pirâmides, resultando em seu aspecto formal. A execução retrata como o indivíduo executou o conjunto de suas pirâmides, seguindo algum padrão de ordem (ou não), podendo ter mais alterações de ritmo e trocas durante o processo (Villemor-Amaral, 2012). Já o modo de colocação refere-se à maneira como o respondente dispõe os quadrículos em cada uma das três pirâmides produzidas. Os tipos mais comuns de colocação são: Ascendente (trabalho inicia-se na base e vai até o topo da pirâmide), Descendente (do topo da pirâmide para a base), Direta (da esquerda para a direita) e Inversa (da direita para a esquerda). A colocação ascendente está mais associada à estabilidade e maturidade, enquanto a colocação descendente é mais sugestiva de insegura e imaturidade. A colocação direta é a mais esperada, sinalizando acompanhando da lógica formal, enquanto a colocação inversa pode estar relacionada a sinal de oposição, negação ou insegurança.

O aspecto formal das pirâmides, por sua vez, pode ser classificado Tapete, Formação ou Estrutura, cada qual com seu subtipo conforme proposto por VillemorAmaral (2012). Os dados referentes a essas variáveis nos grupos pesquisados podem ser acessados na Tabela 25.

Tabela 25. Indicadores da execução, colocação e aspecto formal das pirâmides do Teste de Pfister e sua comparação em função dos grupos.

\begin{tabular}{|c|c|c|c|c|c|c|c|c|c|}
\hline \multirow{2}{*}{ Variável } & \multicolumn{3}{|c|}{ G1 $(n=40)$} & \multicolumn{3}{|c|}{$\mathrm{G} 2(\mathrm{n}=40)$} & \multicolumn{3}{|c|}{ Análise estatística } \\
\hline & $f$ & & $\%$ & $f$ & & $\%$ & $X^{2}$ & $p$ & $V$ \\
\hline \multicolumn{10}{|c|}{ Processo de execução } \\
\hline Ordenada & 39 & & 97,50 & 37 & & 92,50 & \multirow{2}{*}{1,053} & \multirow{2}{*}{0,305} & \multirow{2}{*}{0,115} \\
\hline \multirow[t]{2}{*}{ Desordenada } & 1 & & 2,50 & 3 & & 7,50 & & & \\
\hline & $M$ & $D P$ & $\operatorname{Min} / \operatorname{Max}$ & $M$ & $D P$ & Min/Max & $t$ & $p$ & $d$ \\
\hline \multicolumn{10}{|c|}{ Modo de colocação } \\
\hline Ascendente & 1,30 & 1,38 & $0 / 3$ & 1,32 & 1,40 & $0 / 3$ & 0,080 & 0,936 & 0,018 \\
\hline Descendente & 1,45 & 1,41 & $0 / 3$ & 1,20 & 1,34 & $0 / 3$ & $-0,811$ & 0,420 & $-0,181$ \\
\hline Outros & 0,25 & 0,66 & $0 / 3$ & 0,47 & 0,90 & $0 / 3$ & 1,263 & 0,210 & 0,283 \\
\hline \multicolumn{10}{|c|}{ Modo de colocação } \\
\hline Inversa & 1,05 & 1,10 & $0 / 3$ & 1,12 & 1,13 & $0 / 3$ & 0,299 & 0,766 & 0,067 \\
\hline Direta & 1,20 & 1,28 & $0 / 3$ & 1,00 & 1,21 & $0 / 3$ & $-0,714$ & 0,477 & $-0,160$ \\
\hline
\end{tabular}




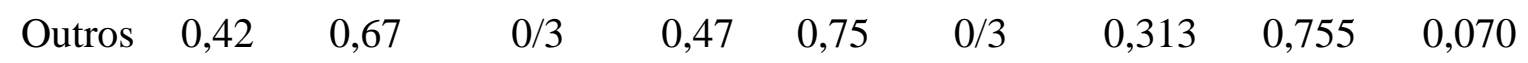

Aspecto Formal

$\begin{array}{rlllllllll}\text { Tapete } & 1,55 & 1,37 & 0 / 3 & 1,37 & 1,37 & 0 / 3 & -0,570 & 0,571 & -0,127 \\ \text { Formação } & 1,40 & 1,37 & 0 / 3 & 1,55 & 1,31 & 0 / 3 & 0,498 & 0,620 & 0,111 \\ \text { Estrutura } & 0,05 & 0,22 & 0 / 1 & 0,75 & 0,26 & 0 / 1 & 0,457 & 0,649 & 0,102\end{array}$

Nota: $f=$ Frequência; $\%$ = Porcentagem; $X^{2}=$ Teste Qui-Quadrado; $p=$ Nível de significância;

$V=\mathrm{V}$ de Cramer; $M=$ Média; $D P=$ Desvio Padrão; $M i n=$ Mínimo; Max = Máximo;

$t=$ Teste $t$ de Student; $d=d$ de Cohen.

Em termos de execução das pirâmides, os participantes de G1 e G2 montaram o conjunto das pirâmides seguindo um padrão ordenado de trabalho. Não houve diferenças estatisticamente significativas entre os grupos, denotando organização lógica preservada, ainda com certa flexibilidade.

O processo de execução foi analisado considerando-se a construção vertical (ascendente ou descendente) e depois a construção horizontal (direta ou inversa), comparando-se os grupos nesses subtipos. Não houve diferença estatisticamente significativa entre G1 e G2, com variabilidade entre os participantes na montagem das pirâmides.

Já no que compete ao Aspecto Formal das pirâmides, observou-se que em G1 houve predomínio de Tapetes e Formações, sem diferença estatisticamente significativa entre os grupos. O maior número de pirâmides menos organizadas (tapetes ou formações) em ambos os grupos e baixa incidência de Estruturas pode estar relacionado ao baixo nível de escolaridade dos indivíduos avaliados. As Estruturas tendem a ocorrer em indivíduos com maior treinamento acadêmico, no geral associado por nível intelectual elevado (Villemor-Amaral, 2012).

As variáveis do Teste de Pfister também foram analisadas e comparadas a partir do sexo dos participantes. A Tabela 26 apresenta a frequência das cores e Síndromes Cromáticas entre os quatro grupos independentes constituídos, homens e mulheres do Grupo Clínico e do Grupo de Comparação.

Tabela 26. Cores e Síndromes Cromáticas do Teste de Pfister e sua comparação estatística em função do sexo dos participantes. 


\begin{tabular}{|c|c|c|c|c|c|c|c|c|c|c|c|}
\hline \multirow{2}{*}{$\begin{array}{c}\text { Cores e } \\
\text { Síndromes } \\
\text { Cromáticas }\end{array}$} & \multicolumn{2}{|c|}{$\begin{array}{l}\text { G1 homens } \\
(\mathrm{n}=28)\end{array}$} & \multicolumn{2}{|c|}{$\begin{array}{l}\text { G1 mulheres } \\
(\mathrm{n}=12)\end{array}$} & \multicolumn{2}{|c|}{$\begin{array}{l}\text { G2 homens } \\
(\mathrm{n}=28)\end{array}$} & \multicolumn{2}{|c|}{$\begin{array}{c}\text { G2 mulheres } \\
(\mathrm{n}=12)\end{array}$} & \multicolumn{3}{|c|}{$\begin{array}{c}\text { Comparação } \\
\text { estatística }\end{array}$} \\
\hline & $M$ & $D P$ & $M$ & $D P$ & $M$ & $D P$ & $M$ & $D P$ & $F$ & $p$ & $\dot{\eta}^{2}$ \\
\hline Azul & 17,76 & 15,74 & 10,35 & 9,36 & 15,31 & 9,56 & 21,47 & 10,90 & 1,842 & 0,147 & 0,068 \\
\hline Vermelho & 15,22 & 8,83 & 18,15 & 8,69 & 12,41 & 9,72 & 20,92 & 7,07 & 2,963 & 0,037 & 0,105 \\
\hline Verde & 19,76 & 10,28 & 26,26 & 19,47 & 19,60 & 9,14 & 17,02 & 9,22 & 1,431 & 0,240 & 0,053 \\
\hline Violeta & 7,53 & 6,72 & 13,13 & 7,89 & 6,18 & 5,47 & 11,28 & 4,37 & 4,557 & 0,005 & 0,152 \\
\hline Laranja & 8,32 & 6,77 & 6,45 & 5,38 & 6,73 & 6,66 & 7,96 & 7,81 & 0,374 & 0,772 & 0,015 \\
\hline Amarelo & 12,14 & 10,94 & 9,24 & 6,93 & 14,60 & 10,55 & 8,72 & 4,50 & 1,487 & 0,225 & 0,055 \\
\hline Marrom & 8,00 & 7,96 & 3,88 & 4,35 & 9,20 & 13,76 & 2,57 & 2,28 & 1,839 & 0,147 & 0,068 \\
\hline Preto & 2,52 & 3,90 & 4,79 & 6,34 & 4,27 & 7,16 & 1,85 & 2,97 & 1,031 & 0,384 & 0,039 \\
\hline Branco & 2,60 & 3,07 & 9,27 & 18,73 & 7,61 & 8,55 & 5,50 & 3,96 & 2,118 & 0,105 & 0,077 \\
\hline Cinza & 2,36 & 2,69 & 1,65 & 2,14 & 4,04 & 6,96 & 2,39 & 2,20 & 1,042 & 0,379 & 0,040 \\
\hline Normal & 52,74 & 17,36 & 54,78 & 13,52 & 47,34 & 12,92 & 59,42 & 7,27 & 2,284 & 0,086 & 0,083 \\
\hline Estímulo & 34,17 & 16,55 & 34,96 & 14,43 & 33,80 & 13,41 & 37,59 & 6,62 & 0,222 & 0,881 & 0,009 \\
\hline Fria & 46,22 & 18,58 & 49,76 & 15,47 & 41,10 & 17,10 & 49,79 & 8,34 & 1,223 & 0,307 & 0,046 \\
\hline Incolor & 7,67 & 6,37 & 10,70 & 6,34 & 15,29 & 13,99 & 9,85 & 5,47 & 2,981 & 0,037 & 0,105 \\
\hline
\end{tabular}

Nota: $M=$ Média; $D P=$ Desvio Padrão; $F=$ teste ANOVA; $p=$ nível de significância; $\eta^{2}=e t a$.

*Dados expressos em porcentagem.

Foram encontradas diferenças estatisticamente significativas no uso das cores vermelho (vm) e violeta (vi), mas com tamanho de efeito de baixo impacto. Pela análise de Bonferroni, verificou-se que essa diferença na cor vermelha ocorreu, de modo estatisticamente significativo, apenas entre homens e mulheres do grupo de comparação, com maior uso dessa cor por parte do subgrupo feminino. A elevação do vermelho pode ser sugestiva de extroversão, irritabilidade, impulsividade e agressividade (VillemorAmaral, 2012).

Quanto ao uso do violeta pelos subgrupos, a análise de Bonferroni apontou para diferença estatisticamente significativa entre mulheres do G1 e homens do G2. As mulheres com cardiopatia apresentavam média mais elevada do violeta, sugerindo sinais de maior ansiedade que o subgrupo de homens não cardiopatas.

Em relação às Síndromes Cromáticas, foi verificada diferença estatisticamente significativa apenas na Síndrome Incolor, no entanto com reduzido tamanho de efeito. Aqui os subgrupos que se diferenciaram foram os homens de G1 e G2, sendo que os 
cardiopatas apresentaram média inferior da síndrome incolor. O rebaixamento dessa síndrome no grupo masculino com cardiopatia pode estar relacionado com diminuição ou ausência de elementos estabilizadores da personalidade (Villemor-Amaral, 2012).

Os quatro subgrupos constituídos a partir do sexo também foram analisados e comparados em relação à Fórmula Cromática. Os dados obtidos estão na Tabela 27.

Tabela 27. Fórmula Cromática do Teste de Pfister e sua comparação estatística em função do sexo dos participantes.

\begin{tabular}{|c|c|c|c|c|c|c|c|c|c|c|c|}
\hline \multirow[t]{2}{*}{$\begin{array}{l}\text { Fórmula } \\
\text { Cromática }\end{array}$} & \multicolumn{2}{|c|}{$\begin{array}{l}\text { G1 homens } \\
(\mathrm{n}=28)\end{array}$} & \multicolumn{2}{|c|}{$\begin{array}{l}\text { G1 mulheres } \\
(\mathrm{n}=12)\end{array}$} & \multicolumn{2}{|c|}{$\begin{array}{c}\text { G2 homens } \\
(\mathrm{n}=28)\end{array}$} & \multicolumn{2}{|c|}{$\begin{array}{c}\text { G2 mulheres } \\
(\mathrm{n}=12)\end{array}$} & \multicolumn{3}{|c|}{$\begin{array}{c}\text { Comparação } \\
\text { estatística }\end{array}$} \\
\hline & $f$ & $\%$ & $f$ & $\%$ & $f$ & $\%$ & $f$ & $\%$ & $X^{2}$ & $p$ & $V$ \\
\hline \multicolumn{12}{|l|}{ Amplitude } \\
\hline Ampla & 16 & 57,14 & 8 & 66,66 & 16 & 57,14 & 8 & 66,66 & & & \\
\hline Moderada & 6 & 21,42 & 2 & 16,66 & 5 & 17,85 & 3 & 25,00 & 1,825 & 0,935 & 0,107 \\
\hline Restrita & 6 & 21,42 & 2 & 16,66 & 7 & 25,00 & 1 & 8,33 & & & \\
\hline \multicolumn{12}{|l|}{ Estabilidade } \\
\hline Estável & 2 & 7,14 & 1 & 8,33 & 7 & 25,00 & 2 & 16,66 & & & \\
\hline Flexível & 20 & 71,42 & 8 & 66,66 & 14 & 50,00 & 9 & 75,00 & 5,948 & 0,429 & 0,193 \\
\hline Instável & 6 & 21,42 & 3 & 25,00 & 7 & 25,00 & 1 & 8,33 & & & \\
\hline \multicolumn{12}{|l|}{ Desvio } \\
\hline Direita & 14 & 50,00 & 5 & 41,66 & 11 & 39,28 & 3 & 25,00 & & & \\
\hline Esquerda & 2 & 7,14 & 2 & 16,66 & 6 & 21,42 & 1 & 8,33 & 4,604 & 0,595 & 0,170 \\
\hline Sem desvio & 12 & 42,82 & 5 & 41,66 & 11 & 39,28 & 8 & 66,66 & & & \\
\hline
\end{tabular}

Nota: $f=$ Frequência; $\%$ = Porcentagem; $X^{2}=$ Teste Qui-Quadrado; $p=$ Nível de significância; $V=\mathrm{V}$ de Cramer.

Não foram encontradas diferenças estatisticamente significativas nas Fórmulas Cromáticas dos subgrupos em função do sexo. Essa evidência empírica sugere reduzida influência do sexo nessa variável do Teste de Pfister.

Foram também comparados os processos de execução, modos de colocação e aspecto formal das pirâmides constituídas por homens e mulheres de G1 e G2. Os resultados e sua comparação estatística constam na Tabela 28. 
Tabela 28. Execução, colocação e aspecto formal das pirâmides no Teste de Pfister e sua comparação estatística em função do sexo dos participantes.

\begin{tabular}{|c|c|c|c|c|c|c|c|c|c|c|c|}
\hline \multirow[t]{2}{*}{$\begin{array}{l}\text { Variável } \\
\text { Pfister }\end{array}$} & \multicolumn{2}{|c|}{$\begin{array}{c}\text { G1 homens } \\
(\mathrm{n}=28)\end{array}$} & \multicolumn{2}{|c|}{$\begin{array}{l}\text { G1 mulheres } \\
\qquad(\mathrm{n}=12)\end{array}$} & \multicolumn{2}{|c|}{$\begin{array}{c}\text { G2 homens } \\
(\mathrm{n}=28)\end{array}$} & \multicolumn{2}{|c|}{$\begin{array}{c}\text { G2 mulheres } \\
\quad(\mathrm{n}=12)\end{array}$} & \multicolumn{3}{|c|}{$\begin{array}{c}\text { Comparação } \\
\text { estatística }\end{array}$} \\
\hline & $f$ & $\%$ & $f$ & $\%$ & $f$ & $\%$ & $f$ & $\%$ & $X^{2}$ & $p$ & $V$ \\
\hline \multicolumn{12}{|c|}{ Processo de execução } \\
\hline Ordenada & 28 & 100,00 & 11 & 91,66 & 27 & 96,42 & 10 & 83,33 & \multirow{2}{*}{5,313} & \multirow{2}{*}{0,150} & \multirow{2}{*}{0,258} \\
\hline \multirow[t]{2}{*}{ Desordenada } & - & - & 1 & 8,33 & 1 & 3,57 & 2 & 16,66 & & & \\
\hline & $M$ & $D P$ & $M$ & $D P$ & $M$ & $D P$ & $M$ & $D P$ & $F$ & $p$ & $\dot{\eta}^{2}$ \\
\hline \multicolumn{12}{|c|}{ Modo de colocação } \\
\hline Ascendente & 1,39 & 1,37 & 1,08 & 1,44 & 1,53 & 1,40 & 0,83 & 1,33 & 0,860 & 0,466 & 0,033 \\
\hline Descendente & 1,35 & 1,39 & 1,66 & 1,49 & 1,03 & 1,26 & 1,58 & 1,50 & 0,799 & 0,498 & 0,031 \\
\hline Outros & 0,25 & 0,58 & 0,25 & 0,86 & 0,42 & 0,83 & 0,58 & 1,08 & 0,624 & 0,602 & 0,024 \\
\hline \multicolumn{12}{|c|}{ Modo de colocação } \\
\hline Inversa & 1,14 & 1,07 & 0,83 & 1,19 & 1,00 & 1,05 & 1,41 & 1,31 & 0,627 & 0,600 & 0,024 \\
\hline Direta & 1,07 & 1,21 & 1,50 & 1,44 & 1,03 & 1,20 & 0,91 & 1,31 & 0,517 & 0,672 & 0,020 \\
\hline Outros & 0,42 & 0,57 & 0,41 & 0,90 & 0,57 & 0,83 & 0,25 & 0,45 & 0,599 & 0,618 & 0,023 \\
\hline \multicolumn{12}{|c|}{ Aspecto Formal } \\
\hline Tapete & 1,42 & 1,45 & 1,83 & 1,19 & 1,07 & 1,35 & 2,08 & 1,16 & 1,954 & 0,128 & 0,072 \\
\hline Formação & 1,53 & 1,45 & 1,08 & 1,16 & 1,85 & 1,32 & 0,83 & 1,02 & 2,123 & 0,104 & 0,077 \\
\hline Estrutura & 0,03 & 0,18 & 0,08 & 0,28 & 0,07 & 0,26 & 0,08 & 0,28 & 0,178 & 0,911 & 0,007 \\
\hline
\end{tabular}

Nota: $f=$ Frequência; $\%=$ Porcentagem; $X^{2}=$ Teste Qui-Quadrado; $p=$ Nível de significância; $v=\mathrm{V}$ de Cramer; $\mathrm{M}=$ Média; $D P=$ Desvio Padrão; $F=$ teste ANOVA; $p=$ nível de significância; $\dot{\eta}^{2}=$ eta.

Ao realizar comparações estatísticas das variáveis do Pfister relacionadas ao processo de execução, modo de colocação e aspecto formal das pirâmides, não houve diferenças estatisticamente significativas entre os subgrupos. Assim, o sexo dos adultos avaliados pareceu não interferir de modo relevante em sua forma de organização e estruturação das pirâmides.

Por fim, foi examinado o possível efeito da cronicidade (ou não) da cardiopatia nas variáveis do Teste de Pfister. Inicialmente foram comparados os subgrupos em relação a frequência do uso de cores e as Síndromes Cromáticas, resultados apresentados na Tabela 29. 
Tabela 29. Cores e Síndromes Cromáticas no Teste de Pfister e sua comparação estatística em função da cronicidade (ou não) da cardiopatia entre os grupos.

\begin{tabular}{|c|c|c|c|c|c|c|c|c|c|}
\hline \multirow{3}{*}{$\begin{array}{c}\text { Cores e } \\
\text { Síndromes } \\
\text { Cromáticas* }\end{array}$} & \multicolumn{4}{|c|}{ Grupo clínico (G1) } & \multicolumn{2}{|c|}{ Grupo de } & \multirow{2}{*}{\multicolumn{3}{|c|}{ Comparação Estatística }} \\
\hline & \multicolumn{2}{|c|}{$\begin{array}{l}\text { Primeiro evento } \\
(\mathrm{G} 1 \mathrm{a}, \mathrm{n}=22)\end{array}$} & \multicolumn{2}{|c|}{$\begin{array}{c}\text { Crônicos } \\
(\mathrm{G} 1 \mathrm{~b}, \mathrm{n}=18)\end{array}$} & \multicolumn{2}{|c|}{$\begin{array}{l}\text { Comparação } \\
(\mathrm{G} 2, \mathrm{n}=40)\end{array}$} & & & \\
\hline & $M$ & $D P$ & $M$ & $D P$ & $M$ & $D P$ & $F$ & $p$ & $\dot{\eta}^{2}$ \\
\hline Azul & 17,87 & 17,41 & 12,69 & 9,35 & 17,16 & 10,25 & 1,023 & 0,364 & 0,026 \\
\hline Vermelho & 16,15 & 8,74 & 16,03 & 9,08 & 14,96 & 9,75 & 0,149 & 0,862 & 0,004 \\
\hline Verde & 21,41 & 10,80 & 22,07 & 17,01 & 18,83 & 9,12 & 0,618 & 0,542 & 0,016 \\
\hline Violeta & 9,18 & 8,68 & 9,25 & 5,87 & 7,71 & 5,63 & 0,509 & 0,603 & 0,013 \\
\hline Laranja & 7,35 & 7,57 & 8,26 & 4,68 & 7,10 & 6,94 & 0,186 & 0,831 & 0,005 \\
\hline Amarelo & 11,71 & 11,71 & 10,73 & 7,45 & 12,84 & 9,49 & 0,308 & 0,735 & 0,008 \\
\hline Marrom & 4,83 & 5,32 & 9,12 & 8,69 & 7,21 & 11,92 & 0,964 & 0,386 & 0,024 \\
\hline Preto & 1,80 & 2,21 & 4,92 & 6,40 & 3,55 & 6,27 & 1,632 & 0,202 & 0,041 \\
\hline Branco & 5,45 & 14,15 & 3,56 & 3,81 & 6,99 & 7,48 & 0,686 & 0,424 & 0,022 \\
\hline Cinza & 1,90 & 2,75 & 2,45 & 2,27 & 3,55 & 5,95 & 0,988 & 0,377 & 0,025 \\
\hline Normal & 55,43 & 17,72 & 50,81 & 14,08 & 50,97 & 12,72 & 0,769 & 0,467 & 0,020 \\
\hline Estímulo & 33,30 & 18,83 & 35,77 & 11,33 & 34,93 & 11,83 & 0,168 & 0,846 & 0,004 \\
\hline Fria & 48,65 & 18,59 & 45,62 & 16,65 & 43,70 & 15,44 & 0,628 & 0,536 & 0,016 \\
\hline Incolor & 6,64 & 6,12 & 10,94 & 6,16 & 13,66 & 12,26 & 3,687 & 0,030 & 0,087 \\
\hline
\end{tabular}

Nota: $\mathrm{M}=$ Média; $D P=$ Desvio Padrão; $F=$ Teste ANOVA; $p=$ nível de significância; $\dot{\eta}^{2}=$ eta .

* Valores expressos em porcentagem.

As análises realizadas permitiram verificar que os subgrupos G1a e G1b e o grupo G2 apresentaram diferença estatisticamente significativa apenas na Síndrome Cromática Incolor, com tamanho de efeito de baixo impacto. Na análise de Bonferroni foi possível verificar que essa diferença se dá entre G1a e o G2, ou seja, cardiopatas de primeiro evento cardíaco e não cardiopatas. Observou-se que o G1a apresentou média rebaixada da Síndrome Incolor em comparação a G2, sugestiva de rebaixamento ou ausência de elementos estabilizadores em cardiopatas de primeiro evento cardíaco. A seguir foram consideradas as Fórmulas Cromáticas do Pfister. Esses dados compõem a Tabela 30 .

Tabela 30. Fórmula Cromática do Teste de Pfister e sua comparação estatística em função da cronicidade (ou não) da cardiopatia. 


\begin{tabular}{|c|c|c|c|c|c|c|c|c|c|}
\hline \multirow{3}{*}{$\begin{array}{l}\text { Fórmula } \\
\text { Cromática }\end{array}$} & \multicolumn{4}{|c|}{ Grupo clínico (G1) } & \multirow{2}{*}{\multicolumn{2}{|c|}{$\begin{array}{c}\text { Grupo de Comparação } \\
\qquad(\mathrm{G} 2, \mathrm{n}=40)\end{array}$}} & \multirow{2}{*}{\multicolumn{3}{|c|}{$\begin{array}{l}\text { Comparação } \\
\text { Estatística }\end{array}$}} \\
\hline & \multicolumn{2}{|c|}{$\begin{array}{l}\text { Primeiro evento } \\
(\mathrm{G} 1 \mathrm{a}, \mathrm{n}=22)\end{array}$} & \multicolumn{2}{|c|}{$\begin{array}{c}\text { Crônicos } \\
(\mathrm{G} 1 \mathrm{~b}, \mathrm{n}=18)\end{array}$} & & & & & \\
\hline & $f$ & $\%$ & $f$ & $\%$ & $f$ & $\%$ & $X^{2}$ & $p$ & $V$ \\
\hline \multicolumn{10}{|l|}{ Amplitude } \\
\hline Ampla & 12 & 54,54 & 12 & 66,66 & 24 & 60,00 & & & \\
\hline Moderada & 4 & 18,18 & 4 & 22,22 & 8 & 20,00 & 1,616 & 0,806 & 0,101 \\
\hline Restrita & 6 & 27,27 & 2 & 11,11 & 8 & 20,00 & & & \\
\hline \multicolumn{10}{|l|}{ Estabilidade } \\
\hline Estável & 2 & 9,09 & 1 & 5,55 & 9 & 22,50 & & & \\
\hline Flexível & 16 & 72,72 & 12 & 66,66 & 23 & 57,50 & 4,118 & 0,390 & 0,160 \\
\hline Instável & 4 & 18,18 & 5 & 27,77 & 8 & 20,00 & & & \\
\hline \multicolumn{10}{|l|}{ Desvio } \\
\hline Direita & 10 & 45,45 & 3 & 16,66 & 19 & 47,50 & & & \\
\hline Esquerda & 1 & 22,72 & 9 & 50 & 7 & 17,50 & 2,919 & 0,571 & 0,135 \\
\hline Sem desvio & 11 & 50 & 6 & 33,33 & 14 & 35,00 & & & \\
\hline
\end{tabular}

Nota: $f=$ Frequência $; \%$ = Porcentagem; $X^{2}=$ Teste Qui-Quadrado; $p=$ Nível de significância; $V=V$ de Cramer.

Não foram verificadas diferenças estatisticamente significativas entre os subgrupos, com maior incidência de Fórmulas Cromáticas classificadas como Amplase Flexíveis. Assim, por essa variável do Teste de Pfister ratificou-se que os participantes do estudo apresentaram traços sugestivos de organização para objetivos específicos e flexibilidade em seu mundo interno, independente do adoecimento ou não.

Por fim, foram analisadas as variáveis referentes ao processo de execução, modo de colocação e aspecto formal das pirâmides elaboradas pelos participantes dos subgrupos G1a e G1b e pelo grupo G2. Os resultados estão apresentados na Tabela 31.

Tabela 31. Execução, colocação e aspecto formal das pirâmides no Teste de Pfister e sua comparação estatística em função da cronicidade (ou não) da cardiopatia.

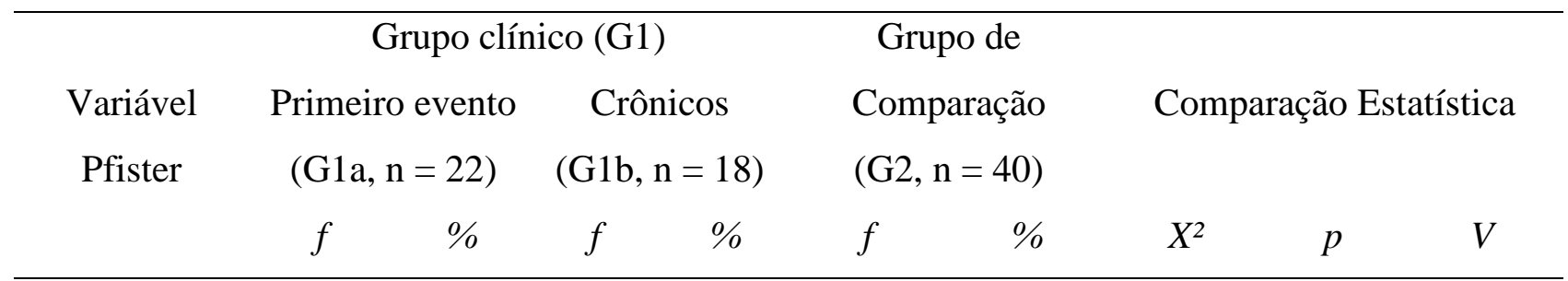




\begin{tabular}{|c|c|c|c|c|c|c|c|c|c|}
\hline \multicolumn{10}{|c|}{ Processo de execução } \\
\hline Ordenada & 22 & 100 & 17 & 94,44 & 37 & 92,5 & \multirow{2}{*}{1,696} & \multirow{2}{*}{0,428} & \multirow{2}{*}{0,146} \\
\hline \multirow[t]{2}{*}{ Desordenada } & - & - & 1 & 5,55 & 3 & 7,5 & & & \\
\hline & $M$ & $D P$ & $M$ & $D P$ & $M$ & $D P$ & $F$ & $p$ & $\dot{\eta}^{2}$ \\
\hline \multicolumn{10}{|c|}{ Modo de colocação } \\
\hline Ascendente & 1,40 & 1,43 & 1,16 & 1,33 & 1,32 & 1,40 & 0,152 & 0,859 & 0,004 \\
\hline Descendente & 1,45 & 1,37 & 1,44 & 1,50 & 1,20 & 1,34 & 0,325 & 0,724 & 0,008 \\
\hline Outros & 0,13 & 0,46 & 0,38 & 0,84 & 0,47 & 0,90 & 1,296 & 0,280 & 0,033 \\
\hline \multicolumn{10}{|c|}{ Modo de colocação } \\
\hline Inversa & 1,27 & 1,16 & 0,77 & 1,00 & 1,12 & 1,13 & 1,019 & 0,366 & 0,026 \\
\hline Direta & 1,04 & 1,25 & 1,38 & 1,33 & 1,00 & 1,21 & 0,625 & 0,538 & 0,016 \\
\hline Outros & 0,36 & 0,58 & 0,50 & 0,78 & 0,47 & 0,75 & 0,228 & 0,797 & 0,006 \\
\hline \multicolumn{10}{|c|}{ Aspecto Formal } \\
\hline Tapete & 1,27 & 1,42 & 1,05 & 1,25 & 1,37 & 1,37 & 1,173 & 0,315 & 0,030 \\
\hline Formação & 1,68 & 1,42 & 1,05 & 1,25 & 1,55 & 1,31 & 1,212 & 0,303 & 0,031 \\
\hline Estrutura & 0,04 & 0,21 & 0,05 & 0,23 & 0,07 & 0,26 & 0,111 & 0,895 & 0,003 \\
\hline
\end{tabular}

Nota: $M=$ Média; $D P=$ Desvio Padrão; $F=$ Teste ANOVA; $p=$ nível de significância; $\dot{\eta}^{2}=$ eta .

As análises estatísticas realizadas não evidenciaram diferenças estatisticamente significativas entre os subgrupos e o $\mathrm{G} 2$ em relação ao processo de execução, modo de colocação e aspecto formal das pirâmides. Dessa forma, pode-se inferir que os participantes do estudo foram semelhantes na organização e estruturação de seu funcionamento lógico perante o Teste de Pfister.

\subsection{Síntese dos achados empíricos}

Ao reunir as evidências empíricas aqui colecionadas a partir de multimétodos, incluindo questionários de autorrelato e métodos projetivos de avaliação psicológica, foi possível identificar algumas características psicológicas associadas ao grupo de indivíduos com cardiopatia. Assim, ocorreu com os indicadores de depressão e ansiedade, mais frequentes entre os cardiopatas (G1). Quando realizadas comparações em função do sexo, as mulheres cardiopatas destacaram-se com indicadores mais elevados de depressão e ansiedade em relação aos homens (cardiopatas ou não). Já a comparação entre os subgrupos de Pacientes Cardiopatas de primeiro evento, Pacientes 
Cardiopatas crônicos e não pacientes, apontaram para indicadores de depressão mais elevados nos cardiopatas crônicos em relação aos outros dois subgrupos.

No que diz respeito às vivências de afetos, o grupo de cardiopatas (G1) evidenciou menor intensidade dos afetos positivos e maior intensidade dos afetos negativos, quando comparados com indivíduos não cardiopatas (G2). Não foram encontradas diferenças estatisticamente significativas em função do sexo ou da cronicidade do quadro clínico dos participantes no tocante à afetividade positiva e negativa, conforme avaliação da Escala de Afetos.

No Teste de Zulliger foram encontradas algumas particularidades, porém em variáveis específicas e pontuais, reduzindo o significado clínico desses achados. Houve, por exemplo, diferenças estatisticamente significativas em função do sexo nas variáveis somatório de respostas de Cor Ponderada e nos conteúdos humanos (entre homens cardiopatas e mulheres não pacientes), mas com reduzido tamanho de efeito. Essas especificidades no padrão de apenas algumas variáveis do Zulliger ocorreram de modo isolado, com reduzido valor interpretativo quando não associada a outros indicadores.

E, por fim, no Teste de Pfister foi possível identificar diferenças estatisticamente significativas entre os grupos no uso da cor branca e na Síndrome Incolor. O rebaixamento da Síndrome Incolor no grupo clínico pode sinalizar menos recursos estabilizadores internos, favorecendo vivência afetiva mais intensa. Em relação às demais variáveis desse método projetivo não foram encontradas outras diferenças estatisticamente significativas. O perfil geral dos indicadores apontou que os adultos avaliados apresentaram bons sinais de capacidade de trabalho na atividade, com flexibilidade para mudanças e funcionamento lógico com menor abstração, frequente em indivíduos com menor treino acadêmico.

Ao realizar análise das variáveis do Pfister em função do sexo, foi observada elevação da cor violeta entre as mulheres cardiopatas em relação aos homens não pacientes. Essa elevação pode ser sugestiva de tensão e ansiedade, o que foi verificado também nos indicadores de ansiedade referidos pelo instrumento de autorrelato. Os homens cardiopatas apresentaram rebaixamento da Síndrome Incolor, sugerindo menos recursos de estabilização psíquica.

Ao se considerar a cronicidade (ou não) da cardiopatia, notou-se novamente rebaixamento da Síndrome Incolor no Teste de Pfister entre cardiopatas de primeiro evento cardíaco. Desse modo, indicaram que vivenciar repentinamente a cardiopatia pode interferir no equilíbrio emocional, comparativamente a adultos não pacientes. 


\section{DISCUSS $\tilde{A} O$}

Para facilitar a compreensão dos achados frente à literatura científica da área, a discussão foi organizada em três tópicos. O primeiro focaliza a temática da ansiedade e depressão, recorrentemente trabalhada e apontada nesse campo dos estudos sobre cardiopatia. O segundo tópico aborda as vivências de afetos e suas interações a partir dos instrumentos de avaliação psicológica aqui utilizados. Por fim, o terceiro tópico integra os dados empíricos às questões relativas ao funcionamento cognitivo e afetivo dos adultos avaliados a partir de métodos projetivos.

\subsection{Ansiedade e depressão}

Segundo a World Health Organization (WHO, 2017b), em 2015 a prevalência estimada de depressão na população mundial era de 4,4\%, enquanto os índices de ansiedade atingiram 3,6\%. No presente trabalho, os indicadores clínicos de depressão foram mais elevados em ambos os grupos ( $\mathrm{G} 1=30,0 \% ; \mathrm{G} 2=10,0 \%)$ quando comparados com os dados da WHO, mais agravado no grupo clínico. Em relação à ansiedade, apenas G1 apresentou indicadores clínicos de ansiedade $(\mathrm{G} 1=22,5 \%)$, proporção bem maior do que a encontrada na população mundial. Na comparação entre os grupos avaliados, os indicadores de depressão foram 1,350 vezes mais elevados em G1, enquanto a ansiedade foi 3,196 vezes mais prevalente em G1. Dessa forma, é possível afirmar que os indicadores de depressão e ansiedade foram mais frequentes entre os cardiopatas avaliados do que o esperado para a população em geral.

A elevada taxa de sinais de ansiedade e depressão encontrada entre os cardiopatas examinados acompanha achados disponíveis na literatura científica. Sobre a depressão, McGuire, Eastwood, Macabasco-O’Cornnell, Hays e Doering (2013) encontraram incidência de $23,0 \%$ desse indicador entre cardiopatas com Síndrome Coronariana Aguda, avaliados com o PHQ-9 dentre outros instrumentos. Outros estudos (Beach et al., 2013; Faller, Stork, Gelbrich, Schowalter, Ertl \& Angermann, 2015) associaram os escores elevados no PHQ-9 ao aumento na taxa de reinternação e mortalidade desses pacientes, demonstrando a relevância dos sinais depressivos nesse grupo de indivíduos.

Ao investigar a possível influência do sexo e da cronicidade (ou não) da cardiopatia nos indicadores de depressão, verificou-se associação positiva e 
estatisticamente significativa entre essas variáveis. Houve sinais de que mulheres cardiopatas apresentam mais indicadores de depressão, sobretudo aquelas com quadro crônico da doença.

Em relação ao efeito do sexo nesse contexto, há tendência mundial de maior incidência de depressão entre as mulheres em todas as regiões do mundo, independentemente do adoecimento (WHO, 2017b). A fim de compreender o impacto desse indicador clínico entre mulheres com doenças cardíacas, Coperland et al. (2017) realizaram pesquisa com 2.216 mulheres cardiopatas afro-americanas, utilizando o instrumento Composite International Diagnostic Interview (CIDI). Encontraram indicadores de depressão em 6,7\% das participantes do estudo e estas apresentavam mais morbidades, como diabetes e hipertensão, em comparação às participantes sem depressão. Outro estudo que verificou especificidades de manifestação depressiva em pacientes cardiopatas em função do sexo, encontrou diferenças significativas apenas no que se refere à fadiga, sendo esta mais elevada nas mulheres (Grace, Yee, Reid \& Stewart, 2013).

Essas diferenças nos indicadores técnicos de depressão são apontadas como relacionadas a fatores biológicos e psicossociais. Neste último componente, atribuem-se aspectos relacionados ao papel da mulher na sociedade, como a sobrecarga com responsabilidades domésticas e profissionais, maior propensão a situações de abuso diversas (físico, sexual, psicológico, dentre outros) e tendência a interiorizar e ruminar mais os eventos estressores de seu meio (Baptista, Baptista \& Oliveira, 1999; Justo\& Calil, 2006). Outro fator relevante seria o padrão típico de respostas emocionais de cada sexo. As mulheres tendem a receber maior treinamento e aceitação sociocultural em expressar suas emoções, enquanto homens são estimulados a não revelarem abertamente seus sentimentos no meio social ou o fazerem de forma abrupta, recorrendo a agressividade.

Essa aceitação e estímulo social diferenciados na forma de lidar com emoções entre os sexos, culturalmente reconhecida nas culturas ocidentais, podem interferir na maneira como os adultos responderam ao instrumento de autorrelato para identificação da depressão e da ansiedade. O impacto da desejabilidade social é fortemente apontado na literatura científica, devendo ser considerado no processo interpretativo dos resultados. A desejabilidade social trata do movimento individual de oferecer respostas sabiamente positivas sobre si para aparentar uma imagem pessoal socialmente mais valorizada. Esse comportamento está relacionado à necessidade de aprovação social e é 
um dos vieses mais importantes dos instrumentos de avaliação psicológica por meio de autorrelato (Costa \& Hauck Filho, 2017). Nesse sentido, os homens, cardiopatas ou não, poderiam oferecer respostas mais socialmente aceitáveis do que fidedignas com o que realmente sentem, disfarçando indicadores de depressão ou outra expressão emocional.

Vale ressaltar, ainda, que o mecanismo psíquico aparentemente protetivo da mulher seria sua tendência à conscienciosidade, ou seja, serem mais preocupadas com a própria saúde e se envolverem mais em comportamentos saudáveis e com tratamentos de saúde. Esse indicador pode estar diretamente associado ao fato das doenças cardíacas serem mais frequentes em homens do que em mulheres (com mais cuidados em saúde), como foi o caso da amostra desse trabalho (Hauck Filho \& Teixeira, 2013).

Em relação à cronicidade da cardiopatia, há evidências advindas de estudos com delineamento longitudinal apontando impactos negativos da depressão entre os pacientes. Exemplo disso é o trabalho de Zuidersma, Conradi, Melle, Ormal e Jonge (2013), identificando menor taxa de sobrevida e reinternações mais frequentes entre cardiopatas depressivos. Os pesquisadores citados avaliaram 311 pacientes cardiopatas com depressão, sendo que 168 destes aceitaram receber tratamento farmacológico e não farmacológico. Foi realizada uma avaliação inicial da depressão durante a hospitalização, com reavaliação a cada três meses os pacientes, até completarem um ano do primeiro evento cardíaco. Contatou-se que os pacientes que receberam tratamento para a depressão apresentaram taxa de sobrevida maior que o grupo sem tratamento. No entanto, o estudo não conseguiu especificar se esse fenômeno se associou ao tratamento oferecido (com melhora nos padrões de cuidado da própria cardiopatia) ou se os cardiopatas que aceitaram tratamento da depressão já apresentavam privilegiada motivação para o autocuidado em saúde, comparativamente aos demais indivíduos.

Os sintomas depressivos, no geral, associam-se à falta de motivação do paciente para se dedicar e aderir corretamente ao tratamento farmacológico e não farmacológico das doenças cardíacas. Segundo Hutz, Bandeira, Trentini e Remor (2019), a vivência da depressão pode dificultar a compreensão da doença e o envolvimento com os cuidados necessários, o que ocasiona a má adesão ao tratamento ou total abandono no decorrer dos anos. Dessa forma, é possível que os indicadores mais elevados de depressão entre os pacientes com cardiopatia prévia atendidos em contexto de emergência sejam um indício da sua dificuldade de adesão ao tratamento e autocuidados, aumentando a possibilidade de descompensação do quadro clínico. 
No que diz respeito à ansiedade, esteve presente em intensidade moderada a grave no grupo de cardiopatas $(\mathrm{G} 1=22,5 \%)$ e ausente no grupo de comparação. Nas análises realizadas sobre a influência do sexo e do perfil da cardiopatia (crônica ou primeiro evento) nos indicadores de ansiedade, a única diferença estatisticamente significativa encontrada foi em relação às mulheres cardiopatas e os homens do grupo de comparação. Dessa forma, os atuais achados empíricos não oferecem suporte para uma hipótese de associação entre essas variáveis nos sintomas de ansiedade. Entretanto, pode-se comentar que, como ocorreu com os indicadores de depressão, a ansiedade também tem incidência mais elevada entre as mulheres do que entre os homens na população em geral, em todas as regiões do mundo (WHO, 2017b). Dessa forma, a prevalência de indicadores de ansiedade em mulheres cardiopatas pode seguir a tendência mundial e ser agravada pelo contexto de adoecimento e hospitalização, como no caso da depressão.

A literatura científica da área é vasta em investigar conjuntamente sinais de ansiedade e de depressão na cardiopatia, apontando seu impacto negativo sobre o quadro clínico, elevando o risco de desenvolvimento de doenças cardiovasculares e aumento da taxa de mortalidade entre os cardiopatas. Alguns artigos que apontam essa tendência foram descritos na introdução dessa dissertação.

Alhurani et al. (2015) investigaram a associação entre risco de re-hospitalização e mortalidade com depressão e ansiedade em 1.260 pacientes com Insuficiência

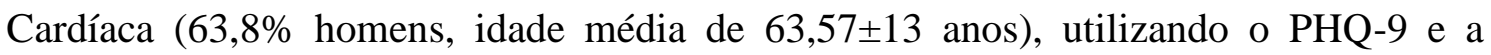
subescala de ansiedade do Inventário Breve de Sintomas (Brief Symptom Inventory BSI). Encontram que indicadores positivos de ansiedade e depressão aumentavam em 1,02 vezes o risco de mortalidade entre os pacientes.

Em estudo realizado em território nacional, Kemp et al. (2015) avaliaram 15.501 funcionários públicos e verificaram que 7\% $(\mathrm{n}=721)$ desenvolveram doenças cardíacas,

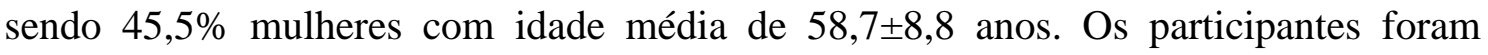
avaliados com Clinical Interview Schedule-Revised Version (CIS-R), observando-se que os indicadores de ansiedade e depressão estavam três vezes maiores em pacientes cardiopatas $(\mathrm{n}=434)$ quando comparados aos não pacientes $(\mathrm{n}=1.844)$.

Estudos específicos de indicadores sobre ansiedade são menos frequentes nessa área, embora existam pesquisas focalizando diferentes níveis desse indicador (fobia, pânico, preocupação) entre cardiopatas. Um desses trabalhos foi o de Batellan, Ten Have, Van Balkom, Tuithof e de Graaf (2014), que contou com a participação de 5.149 


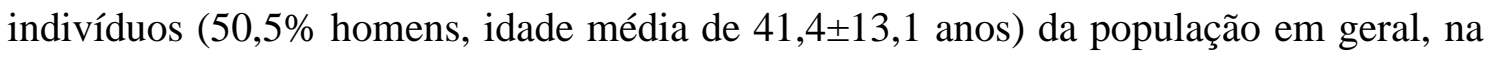
Holanda. Os participantes foram avaliados com os instrumentos Composite International Diagnostic Interview (CIDI) e Questionário clínico e sociodemográfico, e acompanhados durante três anos. Da amostra da pesquisa 1,3\% casos $(n=62)$ desenvolveram doenças cardíacas e destes, 10 indivíduos foram diagnosticados com algum transtorno de ansiedade, cinco tiveram transtorno ou ataques de pânico, três apresentaram fobia social ou agorafobia e quatro vivenciaram transtorno de ansiedade generalizada. Em comparação com os participantes sem patologia, os cardiopatas apresentaram 1,30 vezes mais risco de desenvolver transtorno de ansiedade, 1,15 vezes mais pânico, 0,56 vezes mais fobia e 3,74 vezes mais transtorno de ansiedade generalizada.

Outro autor fez investigação do impacto do transtorno de pânico em pacientes com Insuficiência Cardíaca, residentes na Austrália. Participaram do estudo 73 pacientes $(52,1 \%$ homens, com idade média de $60,6 \pm 13,4$ anos), que responderam ao Composite International Diagnostic Interview (CIDI). Como resultados, obteve-se que 27,4\% dos pacientes tinham transtorno de pânico prévio, 24,7\% apresentaram este transtorno após o diagnóstico cardíaco e 47,9\% não apresentavam pânico. Foi verificado que os pacientes que foram diagnosticados com transtorno de pânico após diagnóstico de Insuficiência Cardíaca apresentaram maior número de internações psiquiátricas e associadas à condição cardíaca, do que aqueles com transtorno de pânico prévio ou sem esse diagnóstico (Tully, 2015). Hutz, Bandeira, Trentini e Remor (2019) também pontuam que a ansiedade e o estresse podem provocar reações fisiológicas semelhantes e muito frequentes em pacientes cardiopatas, como elevação da pressão arterial e aumento da frequência cardíaca, fatores de risco para doenças cardiovasculares a longo prazo.

Os resultados encontrados no trabalho atual são compatíveis com os achados dos trabalhos citados. Foi verificada uma incidência mais elevada de depressão e ansiedade entre os pacientes cardiopatas. Diferentemente das pesquisas específicas sobre o tema, este trabalho não procurou diferenciar os tipos de transtorno de ansiedade, fazendo uso do Beck Anxiety Inventory (BAI) como ferramenta para mensuração dos indicadores de ansiedade de forma global. No entanto, os indicadores de ansiedade apresentaram diferença estatisticamente significativa e a Análise de Regressão Logística entre os dados de ambos os grupos permitiu identificar que a ansiedade foi 3,196 vezes mais elevada em G1. Essa proporção é próxima a encontrada por Batellan, Ten Have, Van 
Balkom, Tuithof e de Graaf (2014) em relação à ansiedade generalizada. A prevalência de ansiedade encontrada neste estudo (22,5\% em G1) foi semelhante aos índices encontrado por Tully (2015) em relação ao transtorno de pânico, principalmente entre os cardiopatas que haviam desenvolvido o transtorno após evento cardíaco $(24,7 \%$ dos casos).

Em termos de síntese dos atuais achados, pode-se argumentar que os pacientes foram avaliados em unidade cardiológica de hospital de urgência e emergência, o que pode ter favorecido os índices mais elevados de ansiedade e de depressão entre os participantes cardiopatas, dado o contexto em que eles estão inseridos (hospitalizados), bem como sua recente vivência de intenso estresse (quadro de cardiopatia). É importante ressaltar que no contexto de emergência são atendidos pacientes que passaram por situações agudas, seja pelo primeiro evento cardíaco ou agudização de um quadro crônico instaurado. Tal situação pode favorecer uma descompensação emocional, ocasionando momento de crise ao paciente (Almeida \& Ribeiro, 2008), o que pareceu confirmado pelos atuais achados empíricos.

\subsection{Vivência de afetos positivos e negativos}

Neste trabalho considerou-se como relevante investigar, por meio do autorrelato, como estaria a afetividade de indivíduos adultos em termos de vivências consideradas positivas e negativas. Pela fundamentação da escala de avaliação psicológica utilizada (Zanon, Batianello, Paccio \& Hutz, 2013), a expressão dessas experiências psíquicas representaria componentes internos relativos à satisfação (ou não) com a vida e o próprio equilíbrio (ou desequilíbrio) psíquico. $\mathrm{Na}$ área dos estudos relativos à cardiopatia e sua interface com as emoções, há clássicas evidências e estudos contemporâneos apontando influência da negatividade do afeto como fator de risco para intercorrências cardiológicas (Annagur, Demir, Avci \& Uygur, 2017; Batselé et al., 2017; Braunwald, 2006; Christodoulou et al., 2013; Freak-Poli, Mirza, Franco, Ikram, Hofman \& Tiemeier, 2015; Kaur, Zainal, Low, Ramasamy \& Sidhu, 2014; Montero, Bermudez \& Rueda, 2017; Steca et al., 2016; Suguihura, 2014; Weng et al., 2013). Dessa linhagem de investigações surgiram inclusive os tipos psicológicos esperados em quadros de cardiopatia (Denollet, Sys \& Brutsaert, 1995).

Com base nessas considerações, os adultos deste estudo responderam a Escala de Afetos Positivos e Negativos (EA). O dado de destaque foi o predomínio do 
autorrelato de afetos positivos em relação aos afetos negativos em adultos com e sem cardiopatia. Diferenciaram-se estatisticamente, no entanto, na ponderação dessa polaridade afetiva, sendo que os cardiopatas apresentaram menor intensidade dos afetos positivos $(\mathrm{G} 1=41,4 \pm 7,2 ; \mathrm{G} 2=44,3 \pm 5,5)$ e maior força de vivência de afetos negativos $(\mathrm{G} 1=27,6 \pm 9,5 ; \mathrm{G} 2=23,4 \pm 8,7)$ em comparação ao grupo de não pacientes. A vivência de afetos não apresentou diferenças estatisticamente significativas em função do sexo ou do perfil (crônico ou não) da doença.

Ao comparar os resultados obtidos nesta pesquisa com o artigo de adaptação da Escala de Afetos (EA) ao Brasil (Zanon, Batianello, Paccio \& Hutz, 2013), os adultos agora avaliados apresentaram maior intensidade de afetos positivos. Quanto aos afetos negativos, o grupo de cardiopatas alcançou resultado similar ao grupo de padronização do instrumento, enquanto o grupo de comparação apresentou médias inferiores. No entanto, há que comentar que o grupo utilizado para adaptação da EA difere muito do grupo agora estudado em termos de idade e escolaridade, o que limita a análise interpretativa a partir dessa comparação inicial entre amostras de diferentes regiões do país. Optou-se por destacar a análise entre o grupo clínico e o de comparação do atual estudo, compostos por adultos pareados em função do sexo e balanceados em idade, escolaridade e nível socioeconômico. Dessa forma, poder-se-ia pensar que houve maior expressão da afetividade negativa entre os cardiopatas presentemente examinados.

De acordo com Hutz (2014), os afetos positivos e negativos representam experiências emocionais percebidas como positivas e negativas, as quais são relativamente estáveis durante a vida. Pessoas que sentem mais frequentemente tristeza, raiva, solidão, preocupação e outras emoções negativas apresentam níveis mais elevados de afetos negativos. Em contrapartida, aquelas que sentem mais prazer, alegria, confiança e emoções positivas em geral, tem maior intensidade de afetos positivos. Os níveis de afetos, juntamente com a satisfação de vida, compõem as esferas do bem-estar subjetivo, que está associado à felicidade (Hutz, 2014).

Conforme a literatura científica da área, a vivência de negativos é considerada fator de risco para as doenças cardíacas, no entanto os afetos positivos não são considerados fatores de proteção (Freak-Poli, Mirza, Franco, Ikram, Hofman \& Tiemeier, 2015). Os afetos negativos são discutidos principalmente como um dos componentes da personalidade tipo D (constituída por afeto negativo e inibição social), sendo constantemente associada às cardiopatias (Annagur, Demir, Avci, Uygur, 2017; Batselé et al., 2017; Montero, Bermudez \& Rueda, 2017). Diversos estudos relacionam 
a personalidade tipo D a outros indicadores significativos nos quadros cardiológicos, como ansiedade, depressão, hostilidade, ruminação da raiva e resposta inadequada ao estresse (Christodolou et al., 2013; Kupper, Denollet, Widdershoven \& Kop; 2013; Lin et al., 2017).

Dessa forma, a vivência mais intensa de afetos negativos entre os participantes do grupo clínico seria esperada conforme literatura científica da área, o que ficou confirmado pelos atuais achados empíricos. Como pontua Hutz (2014), essa intensidade dos afetos negativos se mantém durante a vida e não está necessariamente relacionada a eventos negativos, como o quadro agudo de cardiopatia, no caso dos pacientes cardiopatas atendidos no contexto de emergência. Esses afetos negativos mais intensos encontrados no grupo clínico desse estudo podem, em contrapartida, estar associados ao próprio processo de adoecimento e apresentar impacto em outros componentes que influenciam na cardiopatia. Na perspectiva de detalhar a análise das vivências afetivas é que se buscou examinar os indicadores advindos dos métodos projetivos de avaliação psicológica, como a seguir explorado.

\subsection{Funcionamento cognitivo a afetivo avaliado pelos métodos projetivos}

Para investigação de elementos psicodinâmicos dos indivíduos desse estudo, contemplando componentes conscientes e inconscientes do funcionamento psíquico, recorreu-se ao Teste de Zulliger e ao Teste das Pirâmides coloridas de Pfister. Eles ofereceram outro tipo de indicadores, ultrapassando o autorrelato, ou seja, oferecendo sinais indiretos dos processos psíquicos através de interpretação de manchas de tinta (no caso do Zulliger) ou pela construção de pirâmides coloridas (no caso do Pfister).

No Teste de Zulliger, os grupos avaliados não apresentaram diferenças estatisticamente significativas que mereçam destaque no conjunto de indicadores técnicos examinados. As poucas diferenças encontradas entre G1 e G2 foram de baixo impacto pelo tamanho de efeito e valor interpretativo reduzido por serem variáveis isoladas. Desse modo, cardiopatas e não cardiopatas sinalizaram, pelo Zulliger, similaridade no funcionamento psíquico. Ao comparar, no entanto, o padrão de respostas do grupo normativo do Teste de Zulliger (Resende, 2016) com os atuais achados, foi identificado rebaixamento no número de respostas banais em ambos os grupos e diferenças quanto ao Tipo de Ressonância Íntima (TRI). 
O número rebaixado de respostas banais nos protocolos deste trabalho contraria os achados de Dritto et al. (2015). Embora tenham utilizado o Método de Rorschach na abordagem Escola de Paris, encontraram $42 \%$ de respostas banais nos protocolos de pacientes cardiopatas, considerado um indicador de necessidade e aceitação social. No presente estudo, esse aparente rebaixamento das respostas banais pode ser justificado pelo diferente instrumento utilizado, ou seja, o Teste de Zulliger que, embora similar, apresenta menor número de estímulos (três cartões enquanto no Rorschach são 10 os cartões do teste) e menor proporção de respostas.

Outra diferença encontrada entre os adultos avaliados e o grupo normativo de Resende (2016) diz respeito ao Tipo de Ressonância Íntima (TRI). No presente trabalho, o TRI predominante entre os grupos foi Extratensivo ( $\mathrm{G} 1=42,5 \%$; $\mathrm{G} 2=52,5 \%$ ), seguido de presença de coartação no G1 (35\% e G2=22,5\%) e Introversivo no G2 (25\% e G1=22,5\%). No grupo normativo houve 50,8\% de TRI com coartação, 25,2\% Introversivo e 18,5\% Extratensivo (Resende, 2016). A extratensividade predominante nos adultos avaliados neste trabalho revela facilidade de expressão emocional no meio, com tendência a instabilidade emocional e dramaticidade. Pessoas com esse perfil tendem a ter facilidade no contato social, porém de modo mais superficial (Resende, 2016). Esse achado contradiz outras investigações da área que utilizaram Método de Rorschach, que encontraram predomínio do tipo Coartado (Abduch, 1990) e Introversivo (Dritto et al., 2015) entre os pacientes cardiopatas. Isso faz pensar que os estilos de personalidade podem ser variados nessa patologia.

Ao examinar possível influência do sexo e da cronicidade (ou não) da cardiopatia nos resultados do Teste de Zulliger, poucos sinais apareceram como relevantes. Houve duas variáveis com diferença estatisticamente significativa entre G1 e G2, a saber: homens cardiopatas apresentaram número rebaixado de respostas com uso de cor e elevado número de respostas com conteúdo de Figuras Humanas, em relação às mulheres não cardiopatas.

O número reduzido de respostas de cor em pacientes cardiopatas é compatível com os achados descritos na literatura científica da área, nos estudos que utilizaram o Método de Rorschach (Abduch, 1990; Bertran, 1996; Dritto et al., 2015), sugestivo de inibição social e bloqueio da manifestação afetiva. Esses traços são frequentemente descritos em estudos com cardiopatas, sendo inclusive a inibição social um dos componentes da personalidade tipo D (Hutz, 2014). 
No tocante às respostas de conteúdo humano mais frequente em homens cardiopatas em relação a mulheres não pacientes (homens $\mathrm{G} 1=22,5 \pm 11,86$; mulheres G2=9,85 $\pm 11,87$ ), verificou-se que a porcentagem expressa pelo grupo clínico está de acordo com o grupo normativo $(21,6 \pm 14,3)$ de Resende (2016). O rebaixamento no conteúdo de Figuras Humanas no grupo de mulheres não cardiopatas pode sinalizar interesse diminuído pelas interações humanas por eventual fragilidade de identificação. No entanto, não foram encontradas outras variáveis nos protocolos que sustentem essa hipótese, podendo ser expressão de uma diferença ocorrida ao acaso entre os participantes avaliados.

No Teste das Pirâmides Coloridas de Pfister também foram encontradas algumas diferenças estatisticamente significativas entre os grupos avaliados. As diferenças referiram-se à frequência do uso de cores e Síndromes Cromáticas, apresentando médio impacto, pelo tamanho de efeito calculado. Quando os grupos foram avaliados em função de sexo e cronicidade da patologia, também surgiram diferenças na frequência de uso de cores e Síndromes Cromáticas, porém com tamanho de efeito considerado de baixo impacto.

Ao comparar a frequência do uso das cores deste trabalho com o grupo normativo do manual do Teste de Pfister de Villemor-Amaral (2012), verificou-se que a cor marrom se encontrava aumentada nos grupos avaliados $(\mathrm{G} 1=6,76 \pm 7,27 \mathrm{X}$ $\mathrm{G} 2=7,21 \pm 11,29 \mathrm{X}$ Normativo $=4,0 \pm 5,0)$. $\mathrm{O}$ aumento dessa cor pode ser relacionado ao uso de mecanismos de defesa primitivos, com possibilidade de descarga intensa dos impulsos, sendo associado a quadros psicossomáticos. Também é sugestivo de dificuldades de adaptação e tendência a comportamentos mais enrijecidos e padronizados (Villemor-Amaral, 2012). Nos pacientes cardiopatas, esses comportamentos mais rígidos e padronizados em normas e regras foi descrito na literatura científica da área. Abduch (1990) e Dritto et al. (2015) encontraram resultados análogos a estes utilizando o Método de Rorschach para avaliação de indivíduos com cardiopatia. Esse aumento no uso da cor marrom também pode estar associado ao contexto em que os pacientes se encontravam. Conforme pontuado por Almeida e Ribeiro (2008), o adoecimento provoca uma cisão no momento de vida do indivíduo e ele passa a ter que se haver com uma nova condição de saúde, o que pode ser favorecedor de conflitos psíquicos. O uso aumentado da cor marrom pode sinalizar a dificuldade de adaptação a este novo contexto, de adoecimento agudo e hospitalização em situação de emergência. 
Entre os grupos avaliados, foi encontrada diferença estatisticamente significativa quanto a frequência de uso da cor branca $(\mathrm{G} 1=4,60 \pm 10,72 \mathrm{X}$ G2=6,60 $\pm 7,30 \mathrm{X}$ Normativo $=8,3 \pm 7,1)$ e, consequentemente, a porcentagem da Síndrome Incolor $(\mathrm{G} 1=8,58 \pm 6,44 \times \mathrm{X} 2=13,60 \pm 12,23 \mathrm{X}$ Normativo=15,8 $\pm 10,0)$. Esses componentes apareceram rebaixados no grupo de pacientes cardiopatas em relação ao grupo de não pacientes e grupo normativo. Segundo Villemor-Amaral (2012), o uso do branco representa a anulação ou diluição das cores e, quando aumentado, tem representação simbólica associada à vulnerabilidade, ausência de mecanismos de controle e no contato com a realidade. Porém, seu uso é importante enquanto representante de recursos estabilizadores do funcionamento psíquico, vistos na Síndrome Incolor. Essa síndrome cromática aparece de forma reduzida em comparação às outras três principais síndromes (normal, estímulo e fria) e tem a função de calibrar os afetos pela negação, atenuação ou repressão dos estímulos (Villemor-Amaral, 2012).

Nos pacientes cardiopatas, o rebaixamento da Síndrome Incolor pode ser associado a outros componentes que foram expressos nos métodos projetivos, como o Tipo de Ressonância Íntima (TRI) Extratensivo no Teste de Zulliger e o aumento da cor marrom no Teste de Pfister. Dessa forma, o grupo de cardiopatas pode apresentar necessidade de expressão das suas vivências afetivas no meio ambiente (TRI Extrantensivo) de forma mais intensa (aumento da cor marrom), porém com a Síndrome Incolor rebaixada (menor equilibração interna) podem vivenciar dificuldades nesse processo. Quando o nível de elaboração psíquica dessas vivências afetivas não se mostra suficiente, elas podem ser expressas por vias mais primitivas, utilizando mecanismos de defesa mais arcaicos, como a expressão psicossomática. Daí a relação com a cardiopatia. Um fator que pode potencializar esse aparente desequilíbrio psíquico é a hospitalização em contexto de emergência. Internações em situação de emergência são compreendidas como momentos de crise e, consequentemente, podem favorecer descompensação do estado emocional (Almeida \& Ribeiro, 2008; Franco, 2015), o que pode impactar, de forma relevante, os elementos reguladores do mundo interno.

Ao analisar os grupos em função do sexo e da cronicidade (ou não) da cardiopatia, encontrou-se que a Síndrome Incolor apresentou diferença estatisticamente significativa entre os homens cardiopatas e não pacientes (homens G1=7,67 $\pm 6,37$; homens $G 2=15,29 \pm 13,99$; Normativo $=15,8 \pm 10,0$ ) e entre os pacientes com cardiopatia crônica e o grupo de comparação (G1b=6,64 $\pm 6,12 ; \quad \mathrm{G} 2=13,66 \pm 12,26$; Normativo=15,8 $\pm 10,0)$. Em ambas as comparações, o grupo composto por pacientes 
cardiopatas apresentou média muito abaixo do grupo de comparação e do grupo normativo.

Essa diferença da porcentagem da Síndrome Incolor em função do sexo pode ser sugestiva de dificuldade dos homens cardiopatas em equilibrar seus afetos, pela aparente limitação de componentes que estabilizem seu funcionamento psíquico. Para evitar a angústia suscitada pelas vivências afetivas tendem a reprimi-las como mecanismo de defesa psíquico. Dessa forma, emerge o bloqueio da manifestação afetiva, também encontrado no Teste de Zulliger pela diminuição do uso de cor ponderada nas respostas dos homens cardiopatas.

Essa tendência de repressão das vivências afetivas confirma achados de trabalhos que utilizaram Método de Rorschach para investigação (Abduch, 1990; Bertran, 1996; Dritto et al., 2015) de pacientes cardiopatas. Os traços sugestivos de repressão dos sentimentos e emoções também foram discutidos nos instrumentos de autorrelato, na investigação dos indicadores de depressão e ansiedade (Costa \& Hauck Filho, 2017). A repressão das vivências afetivas, seja por desejabilidade social ou evitação da angústia, pode ser tão intensa nos homens que chega a dificultar a expressão dos seus conflitos internos de modo geral e, consequentemente, o contato com suas próprias emoções.

Por fim, ao comparar a frequência do uso das cores do Teste de Pfister entre ambos os grupos em função do sexo, encontrou-se que as mulheres cardiopatas apresentaram uso mais frequente da cor violeta do que os homens não pacientes (mulheres G1=13,13 $\pm 7,89$; homens G2=6,18 $\pm 5,47$; Normativo=8,5 $\pm 7,5$ ). Segundo Villemor-Amaral (2012), o aumento da cor violeta pode estar relacionado à tensão e ansiedade, pela mistura das cores azul e vermelho, que são antagonistas. Esse achado confirma os resultados encontrados no Beck Anxiety Inventory (BAI), que evidenciou indicadores mais intensos de ansiedade em mulheres cardiopatas em relação a homens sem doença cardíaca. Dessa maneira, evidenciou-se a correspondência positiva entre o que foi autorrelatado pelos participantes com o que foi expresso por via indireta, em método projetivo de avaliação psicológica.

Além dos achados advindos da comparação estatística entre os grupos, é importante ressaltar a validade clínica do conjunto de informações obtidas pelos vários instrumentos aqui utilizados. De acordo com Tavares (2003), a validade de um instrumento é dada pela capacidade de transformar as informações coletadas em indicadores qualitativos, que tenham significado simbólico. Os instrumentos devem 
apresentar validade nomotética, ou seja, relativa aos grupos avaliados, além de relevância idiográfica, vinculada às particularidades do indivíduo. A abordagem nomotética analisa os princípios gerais de padrões de resposta de grupos de indivíduos (recorrendo a estratégias psicométricas), procurando identificar tendências de comportamento aplicáveis à população em geral. Já a abordagem idiográfica corresponde à comparação do indivíduo com ele mesmo, avaliado em diferentes momentos ou por métodos independentes, integrando indicadores técnicos às vivências particulares daquele caso, constituindo evidências com validade clínica. Sendo assim, considera-se que a avaliação psicológica do indivíduo é realizada pela integração dos indicadores encontrados nos diferentes instrumentos, com a produção de sentido aferida pelo avaliador (Tavares, 2003).

Assim, a análise individual da produção em cada instrumento de avaliação psicológica permitiu integrar informações específicas de cada caso presentemente avaliado. Desse processo derivou um retrato próprio para cada participante do estudo, condizente com seu histórico de vida, atribuindo um sentido bastante peculiar a cada processo de avaliação psicológica. Paralelamente ao esforço de identificar marcadores grupais da cardiopatia em termos psicológicos, foi possível compreender a dinâmica psíquica de cada indivíduo em seu momento particular de existência nessa internação hospitalar de emergência. Vieram à tona variáveis e elementos compreensivos de particularidades de vida que, ao serem integrados, favoreçam a pesquisadora e sua equipe hospitalar a identificar alternativas mais promissoras para a intervenção imediata com cada caso. Do estudo derivaram, portanto, corolários práticos úteis na rotina hospitalar, evidenciando a riqueza das informações advindas de instrumentos de avaliação psicológica, integrando autorrelato e métodos projetivos. Ao interpretar os indicadores dos diferentes instrumentos avaliativos, foi produzido um conhecimento relevante sobre cada indivíduo, permitindo refletir sobre estratégias de intervenção individualizadas, evidências empíricas de sua validade clínica (Tavares, 2003).

No estudo atual, foi possível identificar indicadores de características psicológicas específicos de pacientes cardiopatas atendidos em contexto de emergência e compará-los com adultos não cardiopatas, conforme proposto como objetivo geral. Alguns achados acompanharam tendências descritas na literatura científica da área, como os indicadores elevados de ansiedade e depressão e a vivência de afetos negativos mais intensa entre os cardiopatas. 
Os resultados encontrados no Teste de Zulliger também ratificam dados encontrados por outros autores, embora tenham recorrido ao Método de Rorschach na investigação da psicodinâmica de pacientes. No entanto, foi possível verificar algumas contradições em relação às pesquisas anteriores, como o Tipo de Ressonância Íntima Extratensivo e o rebaixamento das respostas banais, predominantes nessa amostra. Já o uso do Teste das Pirâmides Coloridas de Pfister apresentou nova contribuição à área, uma vez que não foram encontrados outros estudos que utilizaram esse método projetivo para investigação de pacientes cardiopatas. Alguns principais indicadores verificados foram o uso de mecanismos de defesa mais primitivos entre os pacientes cardiopatas (uso aumentado da cor marrom), bem como a diminuição dos recursos estabilizadores do funcionamento psíquico (Síndrome Incolor rebaixada).

A descrição e comparação das características psicológicas em função do sexo dos participantes e o tipo de patologia (se primeiro evento cardíaco ou paciente com cardiopatia crônica) permitiu ampliar a área do conhecimento, tendo em vista que poucos trabalhos se dedicaram a essa temática. Os achados foram considerados de baixo e médio impacto, pelo tamanho de efeito alcançado, porém oferecem indícios que poderão ser problematizados e aprofundados em pesquisas futuras.

$\mathrm{O}$ fato dos pacientes estarem inseridos em contexto de emergência, devido evento cardíaco agudo, seja primeiro evento ou cardiopatia crônica agudizada, também pode ter apresentado impacto no funcionamento psíquico e expressão das vivências afetivas. Como já dito, a internação em contexto de emergência pode ser compreendida como momento de crise e suscitar reações físicas e emocionais emergentes e que necessitam de cuidado imediato (Almeida \& Ribeiro, 2018; Franco, 2015). Segundo Almeida e Ribeiro (2018), estar em pronto-socorro cardiológico pode permitir que o indivíduo pare e reflita sobre sua vida, os desafios e as potencialidades que o cercam. Esse movimento reflexivo pode suscitar diversos sentimentos e emoções e, quando combinado com características psicológicas desses indivíduos, pode favorecer uma mobilização de recursos ainda mais exacerbada.

Por isso a importância da investigação e descrição desses indicadores psicológicos no contexto de emergência, tanto em nível de tendências gerais como pessoais. A análise dos resultados do grupo (perspectiva nomotética) permite pensar na estruturação do serviço de psicologia e as principais demandas a serem investigadas. Já em uma análise idiográfica, podem ser consideradas as particularidades de cada caso, 
para intervenção e elaboração de projeto terapêutico singular junto a equipe de cuidados em saúde.

Apesar das contribuições oferecidas pelo trabalho, algumas limitações precisam ser levadas em consideração. O número de participantes da pesquisa pode ser considerado baixo, tendo em vista a alta prevalência de doenças cardíacas e número de internações de emergência cardíaca na população em geral. A pesquisa foi realizada em um hospital de referência de uma cidade do interior do estado de São Paulo, não incluindo outros centros de pesquisa, o que dificulta a generalização dos dados. O sexo dos participantes e o tipo de patologia não foram pareados, existindo mais homens e pacientes de primeiro evento cardíaco. E, por fim, não foram controladas as morbidades de risco para cardiopatia (diabetes, hipertensão e colesterol alto) em ambos os grupos, sendo que essa pode ser importante variável interveniente nos resultados, a exigir análises complementares em momento oportuno.

Em pesquisas futuras que se dediquem a investigação na mesma temática, sugere-se ampliação do número de participantes na amostra, a fim de ampliar o poder estatístico das análises realizadas. Outra sugestão seria a inclusão mais equilibrada de participantes de ambos os sexos e tipos de patologia, para análises dessas especificidades. O protocolo de avaliação psicológica também poderia ser revisto, para incluir outros indicadores psicológicos relatados como significativos na literatura científica, como o estresse, a hostilidade e a ruminação da raiva, nesse momento não selecionados como foco e não explorados de modo específico. 


\section{CONCLUSÃO}

No presente trabalho, foi possível identificar indicadores de depressão, ansiedade, vivência de afetos positivos e negativos e componentes cognitivos e afetivos da personalidade de cardiopatas internados em emergência hospitalar em comparação a pessoas sem cardiopatia prévia. De modo geral, verificou-se que os cardiopatas manifestaram indicadores mais elevados de depressão e ansiedade, menor intensidade de afetos positivos e vivência de afetos negativos aumentada em comparação ao grupo de não pacientes. E quanto ao funcionamento psicodinâmico, os cardiopatas apresentaram-se aparentemente preservados em relação ao funcionamento cognitivo e afetivo, apesar de algumas especificidades, verificadas por diferenças em determinados indicadores. Dentre estas, ressalta-se a diminuição dos elementos estabilizadores, verificado no rebaixamento da Síndrome Incolor no Teste das Pirâmides Coloridas de Pfister.

Algumas diferenças encontradas já foram bastante elucidadas na literatura científica da área, sendo agora percebidas também em pacientes atendidos em contexto de emergência. O uso dos métodos projetivos e a comparação dos grupos avaliados em função do sexo e do tipo de patologia do grupo clínico (primeiro evento cardíaco ou cardiopatia crônica) apresentaram algumas especificidades que contribuem para o avanço do conhecimento na área, podendo ser aprofundadas em novas pesquisas sobre o tema. Além disso, a análise dos instrumentos avaliativos de cada participante confirmou a validade clínica do protocolo escolhido, sendo possível identificar componentes de risco para posterior intervenção profissional.

Sendo assim, o presente trabalho permitiu avanço na compreensão das características psicológicas de pacientes cardiopatas atendidos em contexto de emergência. A partir dos achados, é possível discutir sobre os indicadores mais relevantes e planejar intervenções direcionadas para indivíduos neste contexto, permitindo dar início a reabilitação cardíaca do ponto de vista da psicologia. 


\section{REFERÊNCIAS}

ABEP (Associação Brasileira de Empresas de Pesquisa) (2015). Critérios de Classificação Econômica Brasil. Recuperado em maio, 2018, de www.abep.org/Servicos/Download.aspx?id=09

Abduch, M. (1990). Doença Arterial Coronária: contribuição do psicodiagnóstico de Rorschach. Dissertação de Mestrado, Universidade de São Paulo, São Paulo, Brasil.

Alhurani, A. S., Dekker, R. L., Abed, M. A., Khalil, A., Al Zaghal, M. H., Lee, K. S., ... Moser, D. K. (2015) The association of co-morbid symptoms of depression and anxiety with all-cause mortality and cardiac rehospitalization in patients with heart failure. Psychosomatics, 56(4), 371-380.

Almeida, C. P. \& Ribeiro, A. L. A. (2008). Psicologia em Cardiologia: novas tendências. Campinas (SP): Alínea.

Almeida, O. P., Alfonso, H., Yeap, B. B., Hankey, G. J., \& Flicker, L. (2013). Cardiovascular disease do not influence the mental health outcome of older men with depression over 6 years. Journal of Affective Disorders, 144(3), 248-252.

American Heart Association Statistics Committee and Stroke Statistics Subcommitte (2014).Heart Disease and Stroke Statistics-2014 Update: A Report From the American Heart Association. Greenville Avenue, Dallas, USA.

American Heart Association (2015). Acute Coronary Syndrome.Recuperado em 22 agosto, 2018, de http://www.heart.org/en/health-topics/heart-attack/about-heartattacks/acute-coronary-syndrome.

American Heart Association (2017).Lifestyle Changes for Heart Failure. Recuperado em 22 agosto, 2018, de http://www.heart.org/en/health-topics/heartfailure/treatment-options-for-heart-failure/lifestyle-changes-for-heart-failure.

Andrade, J. P. (2009). III Diretriz Brasileira de Insuficiência Cardíaca Crônica. Arquivos Brasileiros de Cardiologia, 93(1), 1 - 71.

Annagur, B. B., Demir, K., Avci, H., \& Uygur, O. F. (2015). Is there any difference between the early age myocardial infarction and late age myocardial infarction in terms of psychiatric morbidity in patients who have survived acute myocardial infarction? Comprehensive Psychiatry, 1-6.

Annagur, B. B., Demir, K., Avci, H., \& Uygur, O. F. (2017). Impact of type D personality on clinical and psychometric properties in a sample of Turkish patients with first myocardial infarction. Journal of Psychiatric Pratice, 23(1), 3-10.

Anzieu, D. (1986). Os métodos projetivos. Tradução de Maria Lúcia do Eirado Silva. 4a.ed. Rio de Janeiro: Campus.

Baptista, M. N., Baptista, A. S. D., \& Oliveira, M. G. (1999). Depressão e gênero: por que as mulheres deprimem mais que os homens? Temas em Psicologia, 7(2), 143156. 
Batelaan, N. M., ten Have, M., van Balkom, A. J., Tuithof, M., \& de Graaf, R. (2014). Anxiety disorders and onset of cardiovascular disease: the differencial impact of panic, phobias and worry. Journal of Anxiety Disorders, 28(2), 252-258.

Batelaan, N. M., Seldenrijk, A., Bot, M., van Balkom, A. J. L., \& Penninx, B. W. J. H. (2016). Anxiety and new onset of cardiovascular disease: critical review and metaanalysis. The British Journal of Psychiatry, 208, 223-231.

Batséle, E., Denollet, J., Lussier, A., Loas, G., Eynde, S. V., Van de Born, P., \& FantiniHauwel, C. (2017). Type D personality: Application of DS14 on French version in general and clinical populations. Journal of Health Psychology, 22(8), 1075-1083.

Beach, S. R., Januzzi, J. L., Mastromauro, C. A., Healy, B. C., Beale, E. E., Celano, C. M., \& Huffman, J. C. (2013). Patient Health Questionnaire-9 score and adverse cardiac outcomes in patients hospitalized for acute cardiac disease. Journal of Psychossomatic Reseach, 75(5), 409-413.

Bertran, A. M. T. (1996). The Rorschach in the Study of Coronary Heart Disease: A Rewiew. Rorschachiana, 21, 18-29.

Brasil (2011a). Portaria $n^{o}$ 1600, de 7 de julho de 2011. Reformula a Política Nacional de Atenção às Urgências e institui a Rede de Atenção às Urgências no Sistema Único de Saúde (SUS). Recuperado em 27 de agosto de 2018, de http://bvsms.saude.gov.br/bvs/saudelegis/gm/2011/prt1600_07_07_2011.html

Brasil (2011b). Portaria $n^{o}$ 2395, de 1 de outubro de 2011. Organiza o Componente Hospitalar da Rede de Atenção às Urgências no âmbito do Sistema Único de Saúde (SUS). Brasília, DF. Recuperado em 27 de agosto de 2018, dehttp://bvsms.saude.gov.br/bvs/saudelegis/gm/2011/prt2395_11_10_2011.html

Brasil (2013). Manual Instrutivo da Rede de Atenção às Urgências e Emergências no Sistema Único de Saúde (SUS). Brasília (DF): Editora do Ministério da Saúde.

Brasil (2014). Portaria $n^{\circ} 483$, de $1^{\circ}$ de abril de 2014. Redefine a Rede de Atenção à Saúde das Pessoas com Doenças Crônicas no âmbito do Sistema Único de Saúde (SUS) e estabelece diretrizes para a organização das suas linhas de cuidado.

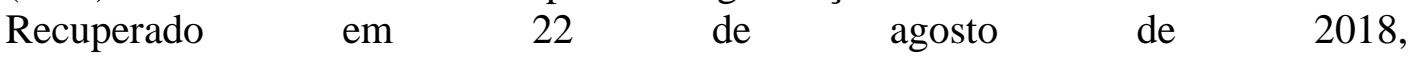
dehttp://bvsms.saude.gov.br/bvs/saudelegis/gm/2014/prt0483_01_04_2014.html

Brasil (2017). Doenças Cardiovasculares são principal causa de morte no mundo. Recuperado em 22 de agosto de 2018, de http://www.brasil.gov.br/editoria/saude/2017/09/doencas-cardiovasculares-saoprincipal-causa-de-morte-no-mundo.

Braunwald, E. (2006). Tratado de medicina cardiovascular (6.ed.) São Paulo (SP): Roca.

Brucki, S. M. D., Nitrini, R., Caramelli, P., Bertolucci, P. H. F., \& Okamoto, I. H. (2003). Sugestão para uso do Mini-Exame de Saúde Mental no Brasil. Arquivos de Neuropsiquiatria, 61(3-B), 777-781. 
Chabert, C. (2004). Psicanálise dos Métodos Projetivos. Tradução de José Álvaro Lelé e Eliane M. Almeida Costa e Silva. São Paulo: Vetor.

Christodoulou, C., Douzenis, A., Mommersteeg, P. M., Rallidis, L., Poulios, A., Efstathiou, V., ... Lykouras, L. (2013). A case-control validation of type D personality in Greek patients with stable coronary heart disease. Annals of General Psychiatry, 12(38), 1-7.

Cohen, R. J., Swerdlik, M. E., \& Sturman, E. D. (2014). Testagem e Avaliação Psicológica. São Paulo: Amgh Editora.

Condén, E., Rosenblad, A., Ekselius, L.,\& Åslund, C. (2014). Prevalence of Type D personality and factorial and temporal stability of the DS14 after myocardial Condén, Emelie Rosenblad, Andreas Ekselius, Lisa Åslund, Ceciliainfarction in a Swedish population. Scandinavian Journal of Psychology, 55(6), 601-610.

Conselho Federal de Medicina - CFM (1995). Resolução $n^{\circ}$ 1451/95. Recuperado em 27 de agosto de 2018, de http://www.portalmedico.org.br/resolucoes/cfm/1995/1451_1995.htm

Conselho Federal de Medicina - CFM (2014). Resolução CFM $n^{\circ}$ 2.077/14. Dispõe sobre a normatização do funcionamento dos Serviços Hospitalares de Urgência e Emergência, bem como do dimensionamento da equipe médica e do sistema de trabalho. Recuperado em 28 de agosto de 2018, de https://portal.cfm.org.br/images/PDF/resolucao2077.pdf

Coperland, V. C., Newhill, C. E., Foster, L. J. J., Braxter, B. J., Doswell, W. M., Lewis, A. N., \& Eack, S. M. (2017). Major depressive disorder and cardiovascular disease in African-American women. Journal of Social Service Research, 43(5), 624-634.

Costa, A. R. L., \& Hauck Filho, N. (2017). Menos desejabilidade social é mais desejável: Neutralização de instrumentos avaliativos de personalidade. Interação em Psicologia, 21(3), 239-249.

Cozby, P. C. (2006) Métodos de pesquisa em Ciências do Comportamento. São Paulo (SP): Atlas.

Cunha, J. A. (2001) Manual da versão em português das Escalas Beck. São Paulo (SP): Casa do Psicólogo.

Cunha, S. S., Miyazaki, M. C. O. S., Villafanha, D. F., Junior, R. S., Domingos, N. A. M. (2014). Psychological assessment of patients undergoing cardiac transplant in teaching hospital (2004 to 2012).Brazilian Journal od Cardiovascular Surgery, 29(3), 350-354.

DATASUS (2019). Informações de Saúde (TABNET). Recuperado em 20 de maio de 2019, de http://www2.datasus.gov.br/DATASUS/index.php?area=02.

Denollet, J., Sys, S. U. \& Brutsaert, D. L. (1995). Personality and mortality after myocardial infarction. Psychosomatic Medicine, 57(6), 582-591 
Denollet, J. (1998). Personality and coronary heart disease: The type-D scale-16 (DS16). Annals of Behavioral Medicine, 20(3), 209-215.

Denollet, J. (2005). DS14: standart assessment of negative affectivity, social inhibition, and Type D personality. Psychosomatic Medicine, 67(1), 89-97.

Dewes, J. O. (2013). Amostragem em Bola de Neve e Respondent-Driven Sampling: uma descrição de métodos. Monografia para obtenção de grau de Bacharel em Estatística, Universidade Federal do Rio Grande do Sul, Porto Alegre, Rio Grande do Sul, Brasil.

Dritto, I. P., Tummineri, A., Moscuzza, V., Perri, M. C. D., Rizzo, A., Liotta, M., ... Cicciarelli, C. (2015). Type D Personality in infarcted patients a study with the Rorschach projective technique. Mediterranean Journal of Clinical Psychology, $3(3), 1-10$.

Field, A. (2009). Descobrindo a estatística usando o SPSS. $2^{\mathrm{a}}$ ed. Porto Alegre (RS): Artmed.

Faller, H., Stork, S., Gelbrich, G, Schowalter, M., Ertl, G., \& Angermann, C. E. (2015). Depressive symptoms in heart failure: Independent prognostic factor or marker of funcional status? Journal of Psychosomatic Research, 78, 569-572.

Fonseca, R., Silva, P., Silva, R. (2007). Acordo inter-juízes: O caso do coeficiente de Kappa. Laboratório de Psicologia, 5(1), 81-90.

Franco, M. H. P. (2015). A intervenção psicológica em emergências: fundamentos para a prática. São Paulo (SP): Summus Ed.

Freak-Poli, R., Mirza, S. S., Franco, O. H., Ikram, M. A., Hofman, A., \& Tiemeie, H. (2015). Positive affect is not associated with incidence of cardiovascular disease: a population-based study of older persons. Preventive Medicine,74, 14-20.

Frestad, D., \& Prescott, E. (2017). Vital Exhaustion and Coronary Heart Disease Risk: a Systematic Review and Meta-Analysis. Psychosomatic Medicine, 79, 260-272.

Friedman, M. (1977). Type A behavior pattern: some of its pathophysiological components. Bulletin of the New York Academy of Medicine, 53(7), 593 - 604.

Gao, W., Zhao, J., Li, Y., \& Cao, F. L. (2015). Post-traumatic stress disorder symptoms in first-time myocardial infarction patients: Roles of attachment and alexithymia. Journal of Advanced Nursing, 71(11), 2575-2584.

Garcez, M. R., Pereira, J. L., Fontanelli, M. M., Marchioni, D. M. L., Fisberg, R. M. (2014). Prevalência de dislipdemia Segundo estado nutricional em amostra representativa de São Paulo. Arquivos Brasileiros de Cardiologia, 103(6), 476-484.

Grace, S. L., Yee, J., Reid, R. D., \& Stewart, D. E. (2013). Mensurement of depressive symptoms among cardiac patients: should sex diferences be considered? Journal of Health Psychological, 19(7), 943-952. 
Grazziotin, J.B.D.D. \& Scortegagna, S.A. (2016). Revisão de pesquisas brasileiras sobre o Teste de Zulliger publicadas em artigos. Avaliação Psicológica, 15(2), 227-235. Recuperado em 22 de outubro de 2018, de http://pepsic.bvsalud.org/scielo.php?script=sci_arttext\&pid=S1677$\underline{04712016000200012 \& \operatorname{lng}=p t \& t \operatorname{lng}=\text { pt. }}$

Harris, P. R., Sommargren, C. E., Stein, P. K., Fung, G. L., \& Drew, B. J. (2014). Heart rate variability measurement and clinical depression in acute coronary syndrome patients: narrative review of recent literature. Neuropsychiatric Disease Treatment, 18(10), 1335-1347.

Hauck Filho, N., Teixeira, M. A. P. (2013). Funcionamento diferencial do item no Alcohol Use Disorders Identification Test. Avaliação Psicológica, 12(1), 19-25.

Hutz, C. S. (2014). Avaliação em Psicologia Positiva. (1 $1^{\mathrm{a}}$ ed.). Porto Alegre: Artmed.

Hutz, C. S., Bandeira, D. R., Trentini, C. M., \& Remor, E. (2019). Avaliação Psicológica nos contextos de saúde e hospitalar (1 ${ }^{\mathrm{a}}$ ed.). Porto Alegre: Artmed.

Justo, L. P., \& Calil, H. M. (2006). Depressão - o mesmo acometimento para homens e mulheres? Revista de Psiquatria Clínica, 33(2), 74-79.

Kaufman, R., Azevedo, V. M. P., Xavier, R. M. A., Geller, M., Chaves, R. B. M., \& Castier, M. B. (2015). Insuficiência Cardíaca: análise de 12 anos da evolução em internações hospitalares e mortalidade. Internacional Journal of Cardiovascular Sciences, 28(4), 276-281.

Kaur, S., Zainal, N. Z., Low, W. Y., Ramasamy, R., Sidhu, J. S. (2014).Factor Structure of Type D Scale in Malaysian patients with Coronary Artery Disease. ASEAN Journal of Psychiatry, 15(2), 186-195.

Kemp, A. H., Brunoni, A. R., Nunes, M. A., Santos, I. S., Goulart, A. C., Ribeiro, A. L., ... Lotufo, P.A. (2015). The association between mood and anxiety disorders, and coronary heart disease in Brazil: A cross-sectional analysis on the Brazilian longitudinal study of adult health (ELSA-Brasil). Frontiers in Psychology, 6, 1-9.

Kim, H. Y. (2013). Statistical notes for clinical researchers: assessing normal distribution (2) using skewness and kurtosis. Restorative Dentistry \& Endodontics, $38(1), 52-54$.

Kupper, N., Denollet, J., Widdershoven, J., \& Kop, W. J. (2013). Type D personality is associated with low cardiovascular reactivity to acute mental stress in heart failure patients. International Journal of Psychophysiology, 90(1), 44-49.

Lagraauw, H. M., Kuiper, J., \& Bot, I. (2015). Acute and chronic psychological stress as risk factors for cardiovascular disease: insights gained from epidemiological, clinical and experimental studies. Brain, Behavior, and Immunity, 50, 18-30.

Lemos, C. M. M., Moraes, D. W., Pellanda, L. C. (2016). Resiliência em pacientes portadores de Cardiopatia Isquêmica. Arquivos Brasileiros de Cardiologia, 106(2), 130-135. 
Lin, I. M., Wang, S. Y., Chu, I. H., Lu, Y. H., Lee, C. S., Lin, T. H., Fan, S. Y. (2017). The association of type D personality with heart rate variability and lipid profiles among patients with Coronary Heart Disease. International Journal of Behavioral Medicine, 24(1), 101-109.

Matos, D. B. S. (2014). Confiabilidade e concordância entre juízes: aplicações na area educacional. Estudos em Avaliação Educacional, 25(59), 298-324.

McGuire, A. W., Eastwood, J., Macabasco-O'Cornnell, A., Hays R. D., \& Doering, L. V. D. (2013) Depression Screeaning: Utility of the Patient Health Questionnaire in Patients with Acute Coronary Syndrome. American Journal of Critical Care, 22(1), 12-19.

Meister, R. E., Weber, T., Princip, M., Schnyder, U., Barth, J., Znoj, H., ... J., von Känel, R. (2016). Perception of a hectic hospital environment at admission relates to acute stress disorder symptoms in myocardial infarction patients. General Hospital Psychiatry, 39, 8-14.

Mendes, G. S., Moraes, C. F., \& Gomes, L. (2014). Prevalência de pressão arterial sistêmica em idosos no Brasil entre 2006 e 2010. Revista Brasileira de Medicina de Família e Comunidade, 9(32), 273-278

Meyer, G. J., Katko, N. J., Mihura, J. L., Klag, M. J., Meoni, L. A. (2017). The Incremental Validity of Self-Report and Performance-Based Methods for Assessing Hostility to Predict Cardiovascular Disease in Physicians. Journal of Personality Assessment, 100(1), 68-83.

Milicic, D., Brajkovi, L., Ljubas, J., Andri, A., Ardali, Ž., Buratovi, T., \& Mar, D. (2016). Type a Personality, Stress, Anxiety and Health Locus of Control in Patients With Acute Myocardial Infarction. Psychiatria Danubina, 28(4), 409-414.

Montero, P., Bermúdez, J., \& Rueda, B. (2017). Adaptación al castellano de la Escala DS-14 («Type D Scale-14») para la medida de la personalidad tipo D. Revista de Psicopatología y Psicología Clínica, 22(1), 55-67.

Osório, F. L., Mendes, A. V., Crippa, J.A. S., \& Loureiro, S.R. (2009) Study of discriminative validity of the PHQ-9 and PHQ-2 in a sample of Brazilian women in the context of primary health care. Perspectives in Psychiatric Care, 45, 216-227.

Pagotto, V., Silveira, E. A., \& Velasco, W. D. (2012). Perfil das hospitalizações e fatores associados em idosos usuários do SUS. Ciência \& Saúde Coletiva, 18(10), 3061-3070.

Pasian, S. R. \& Amparo, D. (2018). O Método de Rorschach na perspectiva da Escola de Paris (Escola Francesa). In C. S. Hutz, D. R. Bandeira, \& C. M. Trentini (Orgs), Avaliação Psicológica da Inteligência e da Personalidade (1a ed., Cap. 16.1.3, pp. 339-353). Porto Alegre: Artmed.

Rafanelli, C., Gostoli, S., Tully, P. J., \& Roncuzzi, R. (2016).Hostility and the clinical course of outpatients with congestive heart failure. Psychology \& health, 31(2), 228-238. 
Resende, M. A. (2016). O Teste de Zulliger - estudo psicométrico para concessão de porte de arma de fogo e para normatização com adultos de Belo Horizonte (MG). Tese de Doutorado, Universidade Federal de Minas Gerais, Belo Horizonte, Minas Gerais, Brasil.

Resende, M. A., Nascimento, E. (2019). Z-SEP: Teste de Zulliger no sistema Escola de Paris. $2^{\text {a }}$ ed. São Paulo (SP): Hogrefe.

Sampieri, R. H., Collado, C. F., \& Lucio, M. P. B. (2013). Metodologia de Pesquisa. Porto Alegre (RS): Penso

Santos, I. S., Tavares, B. F., Munhoz, T. N., Almeida, L. S. P., Silva, N. T. B., Tams, B. D., ... Matijasevich, A. (2013). Sensibilidade e especificidade do Patient Health Questionnaire-9 (PHQ-9) entre adultos da população geral. Cadernos de Saúde Pública, 29(8), 1533-1543.

Sardinha, A., Nardi, A. E., Araújo, C. G. S., Ferreira, M. C., \& Eifert, G. H. (2013). Validação da Versão Brasileira do Questionário de Ansiedade Cardíaca. Arquivos Brasileiros de Cardiologia, 101(6), 554-561.

Seldenrijk, A., Vogelzangs, N., Batelaan, N. M., Wieman, I., Schaik, D. J., \& Penninx, B. J. (2014).Depression, anxiety and 6-year risk of cardiovascular disease. Journal of Psychosomatic Research, 78(2), 123-129.

Simonetti, A. (2016). Manual de Psicologia Hospitalar: o mapa da doença. São Paulo (SP): Casa do Psicólogo.

Silva, A. B., Engroff, P., Sgnaolin, V., Ely, L. S., Gomes, I. (2016). Prevalência de diabetes mellitus e adesão medicamentosa em idosos da Estratégia Saúde da Família de Porto Alegre/RS. Cadernos de Saúde Coletiva, 24(3), 308-316.

Sociedade Brasileira de Cardiologia (2013). Diretrizes da Sociedade Brasileira de Cardiologia: Pocket Book 2011-2013. Recuperado em 22 de agosto de 2018, de http://publicacoes.cardiol.br/consenso/pocketbook/20112013/Livro_Pockt_Book_Completo_interativa.pdf.

Sociedade Brasileira de Cardiologia (2018). Diretriz Brasileira de Insuficiência Cardíaca Crônica e Aguda. Recuperado em 18 de junho de 2019, de http://publicacoes.cardiol.br/portal/abc/portugues/2018/v11103/pdf/11103021.pdf

Steca, P., D’Addario, M., Magrin, M. E., Miglioretti, M., Monzani, D., Pancani, L., ... Greco, A. (2016). A Type A and Type D combined personality typology in essential hypertension and acute coronary syndrome patients: associations with demographic, psychological, clinical, and lifestyle indicators. PLOS ONE, 11(9), 128 .

Suguihura, A. L. M. (2014). Personalidade tipo D e doenças cardiovasculares: adaptação de uma escala. Dissertação de Mestrado, Universidade de São Paulo, Ribeirão Preto, São Paulo, Brasil.

Tavares, M. (2003). Validade Clínica. Psico-USF, 8(2), 125-136. 
Tully, P. J., Cosh, S. M., \& Baumeister, H. (2014). The anxious heart in whose mind? A systematic review and meta-regression of factors associated with anxiety disorder diagnosis, treatment and morbidity risk in coronary heart disease. Journal of Psychossomatic Research, 77(6), 439-448.

Tully, P. J. (2015).A good time to panic? Premorbid and postmorbid panic disorder in heart failure affects cardiac and psychiatric cause admissions. Autralasian Psychiatry, 23(2), 124-127.

Vaz, C. E. \& Alchieri, J. C. (2016) Z-Teste: coletivo e individual: Técnica de Zulliger. $3^{\mathrm{a}}$ ed. São Paulo (SP): Hogrefe CETEPP.

Villemor-Amaral, A. E. (2012). As Pirâmides Coloridas de Pfister - manual. São Paulo (SP): Casa do Psicólogo.

Vilchinsky, N., Ginzburg, K., Fait, K., \& Foa, E. B. (2017). Cardiac-disease-induced PTSD (CDI-PTSD): A systematic review. Clinical Psychology Review, 55, 92-106.

Vitoi, N. C., Fogal, A. S., Nascimento, C. M., Franceschini, S. C. C., Ribeiro, A. Q. (2015). Prevalência e fatores associados a diabetes em idosos no município de Viçosa, Minas Gerais. Revista Brasileira de Epidemiologia, 18(4), 953-965.

Weng, C., Denollet, J., Lin, C., Lin, T., Wang, W., Lin, J., ... Mols, F. (2013). The validity of the Type D construct and its assessment in Taiwan. BMC Psychiatry, 13(1), 46-55.

World Health Organization (2010). Self-Help Strategies: for cutting down or stopping substance use. Recuperado em 01 de dezembro de 2019, de https://apps.who.int/iris/bitstream/handle/10665/44322/9789241599405_eng.pdf?se quence $=1$

World Health Organization (2017a). Cardiovascular disease (CVDs). Recuperado em 22 agosto de 2018, de http://www.who.int/en/news-room/factsheets/detail/cardiovascular-diseases-(cvds).

World Health Organization (2017b). Depression and Other Common Mental Disorders. $\begin{array}{lllll}\text { Recuperado em } & \text { agosto de }\end{array}$ https://apps.who.int/iris/bitstream/handle/10665/254610/WHO-MSD-MER-2017.2eng.pdf;jsessionid=A2245526199A6DD69AE57CC19F37F4FC? sequence $=1$

Zanon, C., Bastianello, M. R., Pacico, J. C., \& Hutz, C. S. (2013). Desenvolvimento e validação de uma escala de afetos positivos e negativos. Psico-USF, 18(2), 193202.

Zattar, L. C., Boing, A. F., Giehl, M. W. C., \& D’Orsi, E. (2013). Prevalência e fatores associados à pressão arterial elevada, seu conhecimento e tratamento em idosos do sul do Brasil. Caderno de Saúde Pública, 29(3), 507-521.

Zuidersma, M., Conradi, H. J., Melle, J. P., Ormal, J., \& Jonge, P. (2013). Depression treatment after myocardial infarction and long-term risk of subsequent cardiovascular events and mortality: a randomized controlled trial. Journal of Psychosomatic Research, 74, 25-30. 
9. ANEXOS e APÊNDICES 
ANEXO 1 - Carta de aprovação do projeto pelo Comitê de Ética em Pesquisa com Seres Humanos da Faculdade de Filosofia, Ciências e Letras de Ribeirão Preto (FFCLRP/USP)

Universldade de Săo Paujo

Faculdade de Filosofia, Ciéncias e Letras de Ribeirăo Preto Comitê de Ética em Pesquisa

Of.CEtPiFFCLRP-USP/120-dgfs.

Campus de Ribeiräo Preto

Ribeiräo Preto, 28 de novembro de 2017.

Prezado(a) Pesquisador(a).

Comunicamos a V.Sa. que o projeto de pesquisa intitulado "Características psicológicas de pacientes cardiopatas agudos e crōnicos atendidos em contexto de emergéncia" foi analisado pelo Comité de Ética em Pesquisa da FFCLRP-USP, em sua 172 Reuniāo Ordinària, realizada em 23.11.2017, a enquadrado na categoria: APROVADO (CAAE $\left.n^{\circ} 74133317,0.0000 .5407\right)$.

Solicitamos que eventuais modificaçōes ou emendas ao projeto de pesquisa sejam apresentadas ao CEP, de foma sucinta, identificando a parte do projeto a ser modificada e suas justificativas. De acordo com a Resoluçăo $n^{\circ} 466$ de 12/12/2012, devem ser entregues

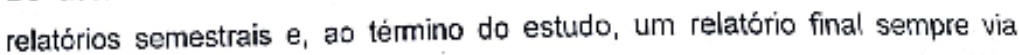
Plataforma Brasil.

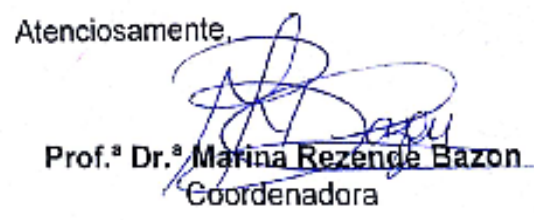

$A \circ(A)$ Senhor(a)

Aline Cristina Antonechen

Programa de Pós-graduaçäo em Psicologia da FFCLRPIUSP

CEP - Conilé de Ética em Pesquisa da FFCLRP USP

Fone: \{16\} 3315-4511 Avenida Bandeirantes, 3950 - bloco 01 da Administraçaso - sala 07

14040-501 - Ribeiräo Preto - SP - Bresil

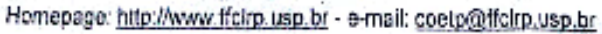


ANEXO 2 - Carta de autorização do estudo pelo Centro de Estudos de Emergência em Saúde da Unidade de Emergência do Hospital das Clínicas da Faculdade de Medicina de Ribeirão Preto (UE - HCFMRP/USP)

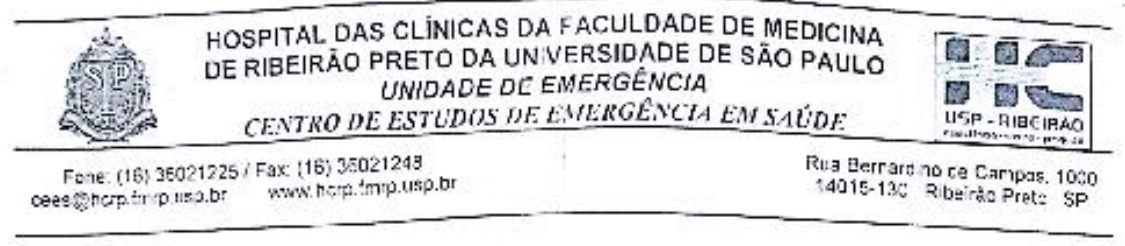

CENTRO DE ESTUDOS DE EMERGÉNCIA EM SAÚDE DA U.E.-HCFMRP-USP

PARECER

O trabalho intitulado "Características Psicológicas de pacientes cardiopatas agudos c crônicos atendidos em contexto de emergência", apresentado sob a respursabilidade da Prof $\mathrm{Dr}^{\natural}$ Sonia Regina Pasian como Projeto de Pesquisa a ser realizado na Unidade de Emergência, pela psicóloga Aline Cristina Antonechen, foi aprovado pelo Centro Integrado de Emergências em Saúde (CIES).

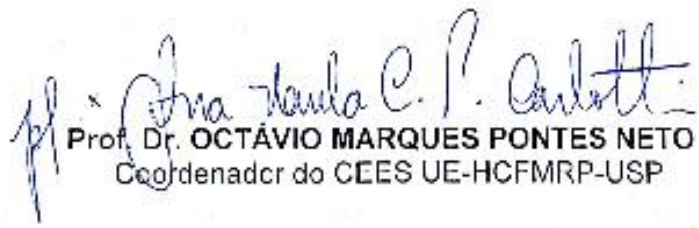




\section{ANEXO 3 - Mini Exame de Estado Mental (MEEM)}

Brucki, S. M. D.; Nitrini, R.; Caramelli, P.; Bertolucci, P. H. F.; Okamoto, I. H. (2003). Sugestões para o estudo do Mini-Exame do Estado Mental no Brasil. Arquivos em Neuropsiquiatria, 61(3-B),777-781.

Paciente:

Data da Avaliação: Avaliador:

ORIENTAÇÃO:

- Dia da Semana (1 Ponto)

- Dia do mês (1 Ponto)

- Mês (1 Ponto).

- Ano (1 Ponto)

- Hora Aproximada (1 Ponto)

- Local Específico (aposento ou setor) (1 Ponto)

- Instituição (residência, hospital, clinica) (1 Ponto).

- Bairro ou Rua próxima (1 Ponto)

- Cidade (1 Ponto)

-Estado (1 Ponto).....

\section{MEMÓRIA IMEDIATA}

- Fale 3 palavras não correlacionadas. Posteriormente pergunte ao paciente sobe as 3 palavras. Dê um ponto para cada resposta correta.

Depois repita as palavras e certifique-se de que o paciente aprendeu, pois mais adiante você irá perguntá-las novamente.

\section{ATENÇÃO E CÁLCULO}

-(100-7) Sucessivos, 5 vezes sucessivamente

(1 ponto para cada cálculo correto)

(alternativamente soletrar mundo de trás pra frente)

\section{EVOCAÇÃO}

- Pergunte ao paciente pelas 3 palavras ditas anteriormente

(1 ponto por palavra).

\section{LINGUAGEM}

- Nomear um relógio e uma caneta (2 pontos).

- Repetir: "Nem aqui, nem ali, nem lá) (1 ponto)

- Comando:

Pegue este papel com a mão direita, dobre ao meio e coloque no chão (3 pontos).

- Ler e obedecer: "feche os olhos" (1 ponto).

- Escrever uma frase (1 ponto)

- Copiar um desenho (1 ponto) 


\title{
APÊNDICE A - Termo de Consentimento Livre e Esclarecido (TCLE)
}

\author{
Termo de Consentimento Livre e Esclarecido (TCLE)

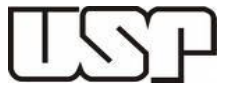 \\ UNIVERSIDADE DE SÃO PAULO \\ Faculdade de Filosofia, Ciência e Letras de Ribeirão Preto \\ Departamento de Psicologia - Centro de Pesquisas em Psicodiagnóstico (CPP)
}

\begin{abstract}
Gostaria de convidá-lo(a) a participar de uma pesquisa intitulada: "Características psicológicas de pacientes agudos e crônicos atendidos em contexto de Emergência”, que está sendo desenvolvida na Unidade de Emergência do Hospital das Clínicas da Faculdade de Medicina de Ribeirão Preto - Universidade de São Paulo (UE HC FMRP - USP)". Este trabalho será desenvolvido como meu Mestrado em Psicologia na Faculdade de Filosofia, Ciências e Letras de Ribeirão Preto (FFCLRP) da Universidade de São Paulo (USP), sob orientação da Profa. Dra. Sonia Regina Pasian, professora do Departamento de Psicologia dessa Faculdade.

Esse estudo tem por objetivo examinar e comparar características psicológicas de pacientes com doenças do coração atendidos em situação de emergência, por meio de instrumentos de avaliação psicológica. Os participantes da pesquisa serão voluntários com idade entre 55 e 75 anos, homens ou mulheres, internados na Unidade Coronariana (UCO) da Unidade de Emergência do HC-FMRP/USP, bem como pessoas não adoecidas (grupo de comparação) na mesma faixa de idade.

Caso o(a) senhor(a) aceite participar da pesquisa, será combinado um horário para a realização das atividades, previstas para durarem aproximadamente 90 minutos. Se o(a) senhor(a) for paciente da UCO, a coleta de dados será realizada nesse local. Caso o(a) senhor(a) seja participante não paciente, a coleta de dados poderá ser realizada no ambiente mais adequado para o(a) senhor(a), podendo ser em um cômodo reservado de sua casa ou numa sala da Unidade de Emergência do HC-FMRP/USP. Possíveis gastos com o deslocamento para participar da pesquisa serão ressarcidos por mim, caso necessário.
\end{abstract}

As atividades pedem que o(a) senhor(a) responda a um questionário com informações pessoais e de vida, e perguntas sobre sentimentos e afetos. Também será solicitado que o(a) senhor(a) fale de suas impressões sobre cartões com manchas de tinta e uma atividade final que envolve mexer em quadradinhos coloridos a partir de seu gosto pessoal.

O risco de participação nesta pesquisa pode ser considerado mínimo, envolvendo apenas a sensibilização eventual aos temas tratados nas atividades e na conversa a ser realizada. Será respeitada a sua disposição física e emocional, interrompendo-se a atividade de pesquisa caso relate algum desconforto emocional. $O$ benefício desta pesquisa está voltado ao conhecimento científico em Psicologia, portanto, o(a) senhor(a) não terá benefício direto. No entanto, caso o(a) senhor(a) se interesse poderá ser oferecida uma entrevista final devolutiva sobre os principais resultados individuais, considerando-se um ganho possível derivado da participação no estudo.

Os dados obtidos serão arquivados e codificados pelas pesquisadoras, formando um banco de dados de acesso restrito a elas. A sua participação neste estudo é voluntária e se o(a) senhor(a) não quiser mais fazer parte da pesquisa poderá desistir a qualquer momento. A sua recusa não trará prejuízos para o seu tratamento e assistência. Não 
serão oferecidos pagamentos ou recompensas para participar desta pesquisa, bem como não há custos nessa colaboração.

As informações relacionadas ao estudo serão conhecidas apenas pelos pesquisadores. No entanto, se qualquer informação for divulgada em relatório ou publicação, isto será feito sob forma codificada, para que a sua identidade seja preservada e seja mantida a confidencialidade. Serão assinadas duas vias desse termo, sendo que uma permanecerá com as pesquisadoras e a outra será entregue ao senhor(a).

Caso haja dúvidas e esclarecimento a serem realizados, o(a) senhor(a) poderá entrar em contato comigo pelos telefones (16) 3602-1144 ou (16) 98198-7000 ou pelo email aline antonechen@usp.br e com a Prof. Dra. Sonia Regina Pasian pelo email srpasian@ffclrp.usp.br.

Caso haja denúncias e/ou reclamações quanto aos aspectos éticos da pesquisa, o(a) senhor(a) poderá entrar em contato com Comitê de Ética em Pesquisa/FFCLRP/USP nos seguintes contatos: Avenida Bandeirantes, 3900 - Bloco 01 -Prédio da Administração - sala $07-$

14040-901 - Ribeirão Preto - SP - Brasil

Fone: (16) 3315-4811 - Atendimento de $2^{a}$ a $6^{a}$ das $13 \mathrm{~h} 30$ às $17 \mathrm{~h} 30$

E-mail: coetp@ffclrp.usp.br

Agradecemos desde já a colaboração e colocamo-nos à disposição para possíveis dúvidas e informações, a qualquer momento.

$\mathrm{Eu}$, $\mathrm{RG}$

li esse Termo de Consentimento Livre e Esclarecido e estou ciente de minha participação no estudo intitulado "Características Psicológicas de pacientes agudos e crônicos atendidos em contexto de Emergência", desenvolvido pela psicóloga Aline Cristina Antonechen, sob orientação da Profa. Dra. Sonia Regina Pasian. Compreendi a natureza e objetivo do estudo do qual estou concordando em participar. Recebi explicações sobre os benefícios e riscos envolvidos no estudo, bem como do sigilo proposto. Eu entendi que sou livre para interromper minha participação a qualquer momento sem justificar minha decisão e sem que esta decisão afete meu tratamento.

Ribeirão Preto, de de 201

(Assinatura do participante)

Aline Cristina Antonechen Psicóloga / Pesquisadora responsável CRP: 06/125304
Profa. Dra. Sonia Regina Pasian Orientadora CRP: 06/24018 


\section{APÊNDICE B - Questionário sócio demográfico e clínico}

Dados sobre nível econômico: ABEP (Associação Brasileira de Empresas de Pesquisa) (2015). Critérios de Classificação Econômica Brasil. Recuperado em maio, 2018, de www.abep.org/Servicos/Download.aspx?id=09

\section{QUESTIONÁRIO SÓCIO-DEMOGRÁFICO E CLÍNICO}

\section{Dados pessoais}

1.1. Nome: 1.2. Idade: anos
1.3. Sexo: ( ) Feminino ( ) Masculino
1.4. Data de nascimento:

1.5. Estado Civil:

1.6. Procedência: Cidade:

Estado: País:

1.7. Local de residência atual: Cidade:

Estado: País:

1.8. Anos de escolaridade (11 anos até o ensino médio): anos

1.9. Profissão: 1.10. Estado profissional:

1.11. Filhos? ( ) Sim ( ) Não Se sim, quantos?

1.12. Com quem reside?

\section{Dados socioeconômicos}

2.1. Assinale as alternativas com $\mathrm{X}$, de acordo com seu contexto atual:

\begin{tabular}{l|l|l|l|l|l} 
Itens Domésticos & Não & $\mathbf{1}$ & $\mathbf{2}$ & $\mathbf{3}$ & $\mathbf{4}$ ou \\
& Tem & & & & + \\
\hline Microcomputador/notebook & & & & & \\
\hline Televisão em cores & & & & & \\
\hline Empregada doméstica & & & & & \\
\hline Automóvel & & & & & \\
\hline Banheiro & & & & & \\
\hline Máquina de lavar & & & & & \\
\hline Geladeira & & & & & \\
\hline Microondas & & & & & \\
\hline Secadora de roupas & & & & & \\
\hline Freezer & & & & & \\
\hline Lava-louça & & & & \\
\hline Motocicleta & & & & \\
\hline
\end{tabular}

Escolaridade do chefe financeiro:

Analfabeto / Fundamental 1 ( ) incompleto

Fundamental 1 completo/ ()

Fundamental 2 incompleto

Fundamental 2 completo/ ()

Médio incompleto

Médio completo

Superior incompleto

Superior completo

\begin{tabular}{l|l|l}
\multicolumn{1}{c|}{ Serviços Públicos } & Sim & Não \\
\hline Água encanada & & \\
\hline Rua Pavimentada & & \\
& & \\
\hline Somatório Atual e Classe:
\end{tabular}




\section{Hábitos de vida}

3.1. Tabagista? ( ) Sim ( ) Não ( ) Fui, mas já parei

Se sim, há quanto anos? Média de maços/dia:

Se já foi, por quanto tempo fumou? anos

Não fuma há quanto tempo? anos

3.2. Etilista? ( ) Sim ( ) Não ( ) Fui, mas já parei

Se sim, há quanto anos?

Quantidade diária:

Se já foi, consumiu por quanto tempo? anos

Não consome há quanto tempo? anos

3.3. Pratica atividade física? ( ) Sim ( ) Não

Se sim, qual?

Quantas vezes por semana?

3.4. Assinale se tem diagnóstico de alguma das doenças abaixo: $\quad 3.5$. Assinale se faz uso de medicações para as doenças ao lado:

\begin{tabular}{l|l|l}
\cline { 2 - 3 } & Sim & Não \\
\hline Diabetes & & \\
\hline Hipertensão & & \\
\hline Doença Renal & & \\
\hline Doença Pulmonar & & \\
\hline Colesterol alto & & \\
\hline Angina & & \\
\hline AVC (Acidente Vascular Cerebral) & & \\
\hline Infarto & & \\
\hline Insuficiência Cardíaca & & \\
\hline Depressão & & \\
\hline Câncer & & \\
\hline Outros: & & \\
\hline
\end{tabular}

\begin{tabular}{l|l|l}
\hline Sim & Não & Qual? \\
\hline & & \\
\hline & & \\
\hline & & \\
\hline & & \\
\hline & & \\
\hline & & \\
\hline & & \\
\hline & & \\
\hline & & \\
\hline & & Outros: \\
\hline
\end{tabular}

\section{História familiar}

4.1. Mãe biológica é viva? ( ) Sim ( ) Não

Se sim, quantos anos tem? anos Se não, com quantos anos faleceu? anos

Causa de óbito da mãe (se pertinente):

Mãe tinha alguma das doenças relacionadas no quadro acima? ( ) Sim ( ) Não

Se sim, quais?

4.2. Pai biológico é vivo? ( ) Sim ( ) Não

Se sim, quantos anos tem? anos Se não, com quantos anos faleceu? anos

Causa de óbito do pai (se pertinente):

Pai tinha alguma das doenças relacionadas no quadro acima? ( ) Sim ( ) Não

Se sim, quais?

4.3. Há histórico de Morte Súbita na família? ( ) Sim （ ) Não Quem? 
5. Dados clínicos (exclusivo para participantes pacientes)

5.1. Data da internação:

5.2 .

Diagnóstico:

5.3. Sintomas antes da internação:

5.4. Tempo entre início dos sintomas e procura por auxílio:

5.5. Quem o levou ao serviço de saúde?

5.6. Primeira internação hospitalar? ( ) Sim ( ) Não

Se não, demais internações foram em Unidade de Emergência? ( ) Sim ( ) Não

5.7. Realiza tratamentos de saúde? ( ) Sim ( ) Não

Se sim, quais?

5.8. Uso de Marca-passo Definitivo? ( ) Sim ( ) Não

5.9. Uso de CDI? ( ) Sim ( ) Não

5.10. Cateterismo ou Angioplastia anterior? ( ) Sim ( ) Não Tempo:

5.11. Cirurgias anteriores?

5.12. Uso de dispositivo? ( ) SNE ( ) SVD ( ) TRAQUEO ( ) OSTOMIA ( ) OXIGENOTERAPIA

5.13. Uso de órteses? ( ) Sim ( ) Não Em quais membros? 


\section{APÊNDICE C - Codificações do Teste de Zulliger (Escola de Paris)}

Variáveis de produtividade e ritmo:

$\mathrm{R}=$ Resposta

$\mathrm{RA}=$ Respostas Adicionais

TLm $=$ Tempo de Latência médio

$\mathrm{TT}=$ Tempo Total

TRm $=$ Total de Reação médio

\section{Modos de Apreensão:}

$\mathrm{G}=$ Respostas Globais

$\mathrm{D}=$ Detalhe Grande

Dd = Detalhe Pequeno

$\mathrm{Dbl}=$ Detalhe Branco

\section{Determinantes:}

$\mathrm{F} \%=$ Respostas exclusivamente determinadas pelo aspecto formal em relação ao total das respostas.

$\mathrm{F}+\%=$ Respostas de Forma com qualidade formal positiva.

$\mathrm{F}+\mathrm{ext} \%=$ Respostas com qualidade formal positiva (independentemente de seu determinante).

$\mathrm{FC}=$ Resposta prioritariamente determinada pela forma e secundariamente pela cor.

$\mathrm{CF}=$ Resposta prioritariamente determinada pela cor e secundariamente pela forma.

$\mathrm{C}=$ Resposta unicamente determinada pela cor.

$\mathrm{FE}=$ Resposta prioritariamente determinada pela forma e secundariamente pelo sombreado.

$\mathrm{EF}=$ Resposta prioritariamente determinada pelo sombreado e secundariamente pela forma.

$\mathrm{E}=$ Resposta unicamente determinada pelo sombreado.

FClob $=$ Resposta prioritariamente determinada pela forma e secundariamente pelo sombreado disfórico.

ClobF $=$ Resposta prioritariamente determinada pelo sombreado disfórico e secundariamente pela forma.

Clob $=$ Resposta unicamente determinada pelo sombreado disfórico. 
$\sum \mathrm{Cp}=$ Soma ponderada das respostas determinadas pela cor.

$\sum \mathrm{Ep}=$ Soma ponderada das respostas determinadas pelo sombreado.

$\mathrm{K}=$ Resposta determinada pelo Movimento Humano.

$\sum$ pequenas cinestesias $=$ Soma das respostas determinadas por movimento animal (kan), humano parcial (kp) ou de objeto (kob).

Conteúdos:

$\mathrm{H}=$ Humano

$\mathrm{A}=$ Animal

Abs $=$ Abstração

Anat $=$ Anatomia

Arq $=$ Arquitetura

Art $=$ Arte

Bot $=$ Botânica

Elem $=$ Elemento

Frag $=$ Fragmento

Geo $=$ Geografia

Nat $=$ Natureza

Obj $=$ Objeto

Pais $=$ Paisagem

$\mathrm{Sg}=$ Sangue

Sex $=$ Sexo

Simb $=$ Símbolo 